\title{
The Rise of Exporting By U.S. Firms
}

Lincoln, William, F., and Andrew H. McCallum

Please cite paper as:
Lincoln, William, F., and Andrew H. McCallum (2016). The Rise
of Exporting By U.S. Firms. International Finance Discussion
Papers 1157.
http://dx.doi.org/10.17016/IFDP.2016.1157

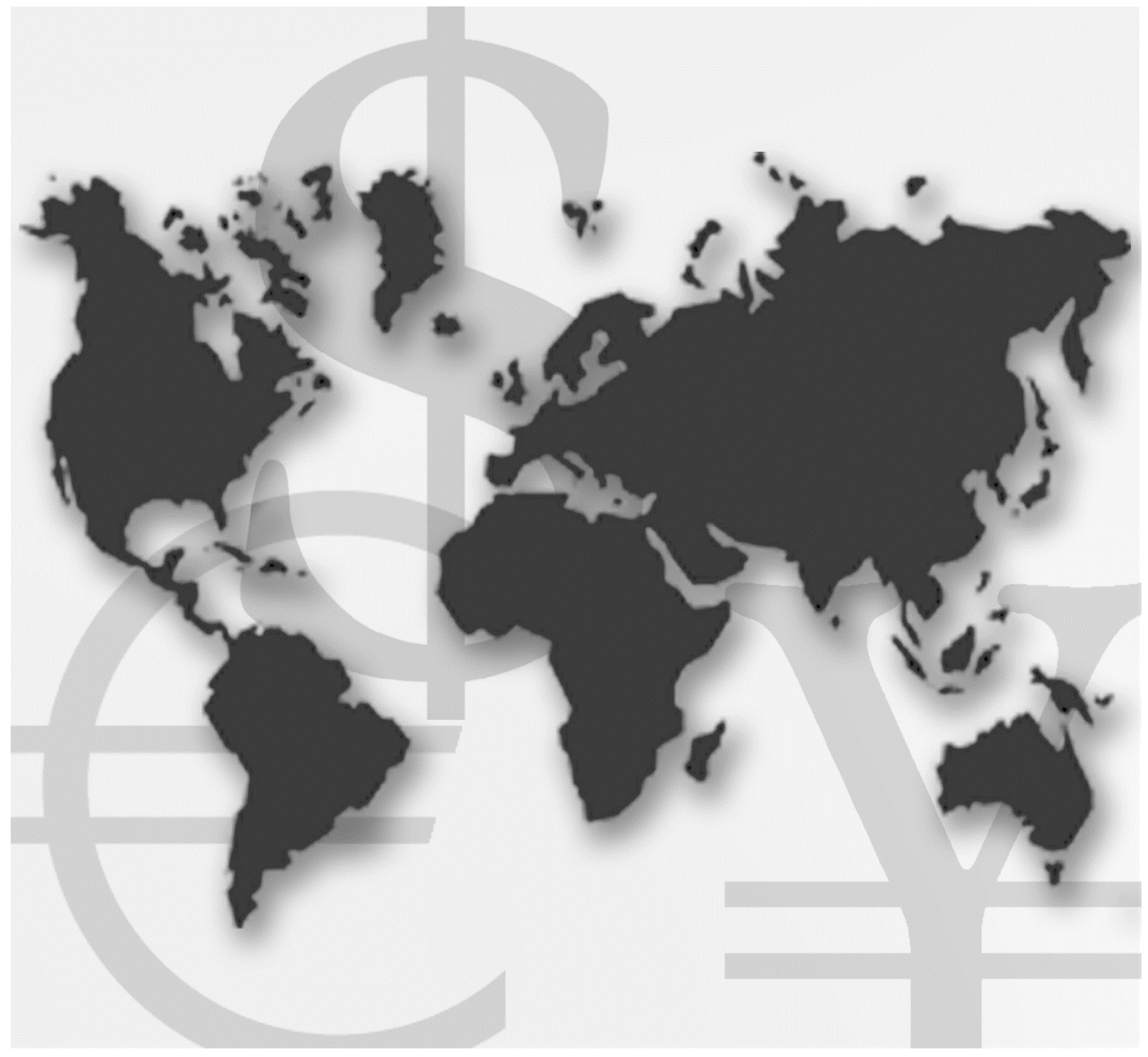

\section{International Finance Discussion Papers}

Board of Governors of the Federal Reserve System

Number 1157

January 2016 


\title{
Board of Governors of the Federal Reserve System \\ International Finance Discussion Papers
}

Number 1157

January 2016

\section{The Rise of Exporting By U.S. Firms}

\author{
William F. Lincoln and Andrew H. McCallum
}

NOTE: International Finance Discussion Papers are preliminary materials circulated to stimulate discussion and critical comment. References to International Finance Discussion Papers (other than an acknowledgment that the writer has had access to unpublished material) should be cleared with the author or authors. Recent IFDPs are available on the Web at www.federalreserve.gov/pubs/ifdp/. This paper can be downloaded without charge from the Social Science Research Network electronic library at www.ssrn.com. 


\title{
The Rise of Exporting By U.S. Firms*
}

\author{
William F. Lincoln \\ Claremont McKenna College \\ Andrew H. McCallum \\ Board of Governors of the Federal Reserve System
}

January 2016

\begin{abstract}
Although a great deal of ink has been spilled over the consequences of globalization, we do not yet fully understand the causes of increased worldwide trade. Using confidential microdata from the U.S. Census, we document widespread entry into countries abroad by U.S. firms from 1987 to 2006 . We show that this extensive margin growth is unlikely to have been due to significant declines in entry costs. We instead find evidence of large roles for the development of the internet, trade agreements, and foreign income growth in driving these trends.
\end{abstract}

JEL Classification: F10, F23, F60, L10, L86, M21.

Keywords: globalization, barriers to entry, international trade, internet.

*Any opinions and conclusions expressed herein are those of the authors and do not necessarily represent the views of the U.S. Census Bureau, the Board of Governors of the Federal Reserve System, or any other person associated with the Federal Reserve System. All results have been reviewed to ensure that no confidential information is disclosed. We especially thank our dissertation chairs Andrei Levchenko and Jim Levinsohn. Dan Ackerberg, Vanessa Alviarez, Wenjie Chen, Alan Deardorff, Ying Fan, Aaron Flaaen, Rob Feenstra, Jeremy Fox, Fariha Kamal, Bill Kerr, Brian Kovak, Pravin Krishna, C.J. Krizan, Pawel Krolikowski, Rosana Lincoln, Day Manoli, Prachi Mishra, Ryan Monarch, Dan Murphy, Justin Pierce, Mark Roberts, Mine Senses, Jagadeesh Sivadasan, Heiwai Tang, James Tybout, and Jing Zhang have all provided helpful comments. The staff at the U.S. Census Bureau has been exceptionally helpful, particularly Clint Carter, James Davis, Barbara Downs, Cheryl Grim, Shawn Klimek, Margaret Levenstein, Danielle Sandler, and William Wisniewski. We thank Alex Avramov, Hannah Kwon, Alejandro Perez-Segura, and Isaac Rabbani for superb research assistance. The authors can be reached at william.lincoln@claremontmckenna.edeu and andrew.h.mccallum@frb.gov. All errors are our own. 


\section{Introduction}

One of the most notable and controversial trends in the past few decades is that worldwide trade has expanded significantly, both in terms of the volume of trade as well as the number of varieties of goods traded across countries. While much has been written on the consequences of these changes, we still have yet to fully understand their causes. In this study we investigate the reasons for this growth by focusing on the experience of the United States. Along with the well known expansion of U.S. export volumes, we document a significant increase in the prevalence of selling abroad by American firms from 1987 to 2006. We find little evidence that this large scale entry into foreign markets was due to significant declines in upfront costs of entry. Using a novel approach to understanding changes in trade, we find that the development of the internet, trade agreements, and growth in foreign income were important drivers of these trends. As neither the evolution of barriers to entry over time nor a full accounting of the determinants of the rise of exporting by firms has been explored to date, we hope that our work contributes to a better understanding of the causes of the second era of globalization.

Increases in the number of firms exporting and the associated growth in the number of varieties of goods traded across countries likely had significant effects on welfare worldwide through several channels. As in the seminal work of Krugman (1979) and more recently Feenstra (2014), if consumers have a love of variety then access to a significantly larger set of goods is likely to have improved their standards of living. This has been argued to be one of the most important channels for the gains from trade at least since the work of Hicks: "The extension of trade does not primarily imply more goods ... the variety of goods available is (also) increased, with all the widening of life that that entails. There can be little doubt that the main advantage that will accrue to those with whom our merchants are trading is a gain of precisely this kind ..." (Hicks 1969, p. 56). Broda and Weinstein (2006), for example, have argued that the tripling of the number of varieties of goods imported into the United States from 1972 to 2001 had significant effects on consumer welfare.

On the production side, access to a wider range of intermediate inputs likely affected the productivity of importing firms abroad. Roughly 60 percent of international trade is in intermediate goods (Johnson 2014) and developing countries are often heavily dependent on imports of capital goods from industrialized nations that embody the latest technologies (Eaton and Kortum 2001). Indeed, 89 percent of U.S. manufacturing exports come from firms that hold patents (Lin and Lincoln 2015). Access to a wider range of imported intermediates also likely increased the incentives to develop new products domestically. For example, Goldberg, Khandelwal, Pavcnik, and Topalova (2010) find that the large declines in tariffs

in the early 1990s in India led to a significant increase in the development of new types of goods. To a large extent these effects were driven by access to new input varieties from 
abroad. Finally, the distributional impacts on firms of increased worldwide trade, such as reallocation effects, are likely to have been different than if they had been driven solely by larger foreign sales from existing exporters (Melitz 2003).

A growing body of evidence has further highlighted the importance of better understanding the determinants of the extensive margin of international trade. Hummels and Klenow (2005) and Bernard, Jensen, and Schott (2009), for example, show that it accounts for most of the cross-country variation in the volume of trade. Across a number of different countries for which we have firm level data, we have also seen significant increases in exporting by firms. These nations include Chile, Colombia, Costa Rica, India, Mexico, and Morocco (documented in Roberts and Tybout 1997a, Mukerji 2009, Bergoeing, Micco, and Repetto 2011, and Lederman, Rodríguez-Clare, and Xu 2011). Little in depth analysis of the sources of these trends has been undertaken, however.

Although evidence at the firm level is naturally restricted by data availability, we additionally see large scale increases in the number of varieties of goods sold across countries in disaggregated industry level data since the 1980s (Evenett and Venables 2002, Broda and Weinstein 2006, Harris, Kónya, and Mátyás 2012, and Kehoe and Ruhl 2013). These results are consistent with substantial foreign market entry by firms in different sectors for a range of countries. Dutt, Mihov, and Van Zandt (2013) have in particular documented that increases in worldwide trade since the 1970s have been driven by growth in the number of varieties of goods traded across countries. Growth in the number of nations newly trading with one another and expansions in the volume of goods that were already exported across markets played much smaller roles.

Our analysis begins by documenting a number of stylized facts that provide new insight into the U.S. experience. Focusing on the manufacturing sector, we find that there was an increase in both the prevalence of selling abroad by firms and in the average number of countries sold to by each exporter. Together this lead to a 52 percent increase in the probability that a firm sells to a given country in our sample. These changes were even more dramatic at the plant level, with the percentage of manufacturing establishments in our sample that exported rising from 21 percent in 1987 to 39 percent in 2006. At both the firm and plant level, we see increases in foreign market participation when considering absolute numbers of exporters as well as percentages. This entry into foreign markets was also broad-based; it was experienced across a wide range of firm size categories, industries, and geographic regions of the United States. While Mexico and China accounted for disproportionate shares, the rise in exporting was seen widely across countries as well.

A natural explanation for this large scale entry into foreign markets is that barriers to entry declined over time. Despite the considerable literature to date on changes in variable trade costs such as tariffs, an analysis of how sunk entry costs have evolved over time has not been done. Coupled with the fact that declines in these costs have been suggested pre- 
viously as a potential cause of the extensive margin growth in exporting to other countries (Melitz 2003), we begin by looking at how much of a role they played. Simple fixed effects as well as simulated maximum likelihood estimations that consider the manufacturing sector as a whole find little change in these costs over time. Computationally intensive structural estimations for three particular industries using Bayesian Monte Carlo Markov Chain methods also suggest that large scale declines in barriers to entry were unlikely. Taken together, the results from these different approaches suggest that reductions in the costs of entering foreign markets are unlikely to have been the driving force behind greater foreign market participation.

We then turn to an analysis of other potential explanations for these trends. Using decomposition methods from labor economics that have been used to study topics such as the causes of the rise in female labor force participation, we introduce a new methodology into the literature on understanding changes in international trade. Combining data from a wide range of sources, we find evidence that the development of the internet, trade agreements, and foreign economic growth were significant drivers of the rise in exporting. In particular, we find that the North American Free Trade Agreement (NAFTA) played a substantial role. Changes in overall tariff levels, the number of countries with a common currency with the United States, and exchange rates had only modest effects. The fall of the Soviet Union also played a small role.

Our results have a number of implications. First, they are consistent with arguments made in the public debate that improvements in communication technologies have played an important role in facilitating the international exchange of goods or making the world more "flat" (Cairncross 1997, Friedman 2005, Leamer 2007). The academic literature has also similarly provided evidence that reductions in communication costs can spur trade (Steinwender 2015, Freund and Weinhold 2004). We further document that the importance of the internet in facilitating trade increased over time, consistent with the literature on network externalities.

At the same time, however, we find that the effect of distance on firms' decisions of where to export did not decline significantly over time. These extensive margin results are consistent with the meta-analysis in Disdier and Head (2008) on the volume of trade as well as the broader literature on changes in the importance of proximity in market transactions (Moretti 2012). Given that the improvements in communications technologies and foreign GDP growth of the past few decades are unlikely to be reversed, it is reasonable to think that the changes that we have seen in exporting behavior will persist without considerable adjustments in the current global trading system.

The estimates further support the idea that free trade agreements affect the number of firms that export and the number of varieties of goods that are traded internationally. While the patterns that we document for exporting to Mexico after the passage of NAFTA are the 
starkest evidence of this, it is clear from our estimations that the other U.S. trade agreements enacted during this period also played a significant role. This finding has implications for whether the trade agreements currently being negotiated by the U.S. Trade Representative can be expected to ease U.S. firms' entry into foreign markets.

Finally, our findings have a number of implications concerning barriers to entry in international trade. Efforts to liberalize trade in the past few decades have focused on lowering variable costs such as tariffs. Our results suggest that reducing entry costs is one way in which trade policy could potentially facilitate international exchange. Indeed, we discuss later how many countries that have their hands tied with respect to tariffs due to international agreements have turned to other measures to protect favored industries. Many of these policies likely increased barriers to entry.

In the next section, we discuss our primary sources of data and document a number of stylized facts about U.S. firms' exporting behavior from 1987 to 2006. In Section 3, we explore the evolution of barriers to entry in foreign markets over time. Section 4 analyzes the factors that accounted for the rise of exporting by U.S. firms and Section 5 concludes.

\section{Data and Stylized Facts}

\subsection{Data}

Our data come from two main sources, each with its own advantages. The first is the Longitudinal Firm Trade Transactions Database (LFTTD), which was originally constructed by Bernard, Jensen, and Schott (2009). This data set contains records from U.S. Customs and Border Protection and has information on the shipment value, firm identification number, and country of destination associated with all U.S. export transactions. We link these records to the Longitudinal Business Database (LBD), which includes information on the annual employment, payroll, industry, and location of each establishment for all firms in the United States. To allow for a comparison with our second primary source of data, we limit the sample to firms that have the majority of their employment in the manufacturing sector. This merged database has the advantage of allowing us to follow small firms over time and to perform analyses by destination. Given its limited information on firm characteristics, however, it does not allow for the type of structural estimations that are possible with our other sources of data. It also only affords an analysis beginning in 1992.

Information on exports to Canada in the LFTTD is collected differently by U.S. Customs and Border Protection and this difference poses issues of measurement error in the data that are not present for other countries (Bernard, Jensen, and Schott 2009). Where appropriate, we drop the years 1992 and 1998 due to evidence of especially large measurement error for exports to Canada in these years. In addition, we limit the sample to firms with 20 or more employees throughout our analysis to focus on better measured data. These firms 
account for the overwhelming majority of foreign sales. Export patterns in the data are little changed with this restriction. One exception is that the fraction of producers that export is systematically higher in each year, as firms with less than 20 employees typically only sell domestically.

To focus the analysis on the countries for which we have sufficient information on the factors that affected the rise in exporting in Section 4, we also limit our sample using the LFTTD to the top 50 U.S. export destinations. These countries are similarly responsible for roughly 95 percent of the value of U.S. manufacturing exports. They also account for the vast majority of the rise of exporting, both in terms of changes in the number of exporting firms and in terms of shifts in the volume of exports. In all of our analyses, we use 2006 as our last sample year.

Our second primary source of data is the Annual Survey of Manufactures (ASM), which contains information on the annual operations of a sample of U.S. manufacturing plants. While the ASM does not contain information on the countries from which export revenues came, it does have detailed plant characteristics that are valuable for performing a number of our estimations. The time span of the data on exports is also longer than that in the LFTTD, extending for 20 years from 1987 to 2006. The sampling frames in the ASM are redone in years ending in 4 and 9 (e.g. 1994) and establishments are followed over time for five years until the next set of plants is chosen. The survey includes large plants in every year with certainty but samples smaller plants according to their contribution to total output.

This design imposes some structure on our panel estimations that use the ASM. Due to the loss of non-certainty cases across different sampling frames, we limit our analysis to plants with 250 or more employees. This avoids the problem of following smaller plants over time across different sampling frames and allows for a comparability with previous studies that have used the same type of approach. Despite this restriction, the sample covers a significant portion of economic activity and a majority of total exports. Bernard and Jensen (2004a) use a similar sample in 1987 and note that it accounts for 41 percent of employment, 52 percent of shipments, and 70 percent of exports. We also find that the export patterns over time for this subset of plants are comparable to those for the manufacturing sector as a whole.

\subsection{Stylized Facts}

With these data we document a number of new stylized facts regarding the pace and character of the rise of exporting by U.S. firms. We begin by discussing the changes seen in the LFTTD and then look at the plant level patterns in the ASM that cover an even longer time frame. As mentioned earlier, we find that the probability that a firm exports to a given country in our sample increases by 52 percent from 1993 to 2006. These changes can be broken down into different components. First, we find that the percentage of firms that export to 
any destination in our sample grew by 20 percent, from 40 percent to 48 percent. When considering firms that were in operation in both 1993 and 2006, we conclude that these changes were even larger. ${ }^{1}$

At the same time that the fraction of exporting firms was growing, the number of countries to which they sold was also increasing. The average number of destinations for exporting firms grew from 4.94 to 6.22 and the median similarly increased from 2 to 3 . This growth led to a 36 percent increase in the total number of unique firm-country pairs that had positive exports. Accounting for shifts in the total number of businesses, we find that the fraction of firms that sell to a given country in our sample rose from 3.96 percent in 1993 to 6 percent in 2006.

To get a better sense of these trends, we look at how the composition of the destinations to which firms exported changed over time. We find that participation increased for every country in our sample. Figure 1 plots the percentage of firms selling to each of these countries, with the fraction in 1993 on the x-axis and the fraction in 2006 on the y-axis. Since each data point lies above the 45 degree line, we find an increase for every single country. Although not shown in the figure, the fraction of firms that export to Canada rose from 31 percent in 1993 to 33 percent in 2006. A similar picture emerges when looking at the raw number of firms exporting to each country in 1993 and 2006.

At the same time, participation increased to some countries more than others. Indeed, many of the markets that saw the largest increases in firm participation were already popular destinations in 1993. In Table 1 we list the top 10 countries in terms of their contributions to the overall rise in the total number of unique firm-country pairs with exports. These markets account for nearly half of the overall increase in participation.

A few conclusions come out of these initial figures. First, given that NAFTA was passed in 1994, it is perhaps not surprising that increases in exporting to Mexico played a significant role. Second, the set of the most important contributors includes a variety of countries, from industrialized nations like Germany and the United Kingdom to fast growing developing markets such as China and India. As in Kehoe and Ruhl (2013), countries that had significant shifts in trade policy and those that underwent structural transformations are well represented on the list. Contrary to the findings of this study, however, several markets that experienced neither, such as Germany and the United Kingdom, also experienced substantial entry. We think that this points to a role for factors that affected all countries, such as the development of the internet.

\footnotetext{
${ }^{1}$ Bernard and Jensen (2004b) have previously documented a significant increase in the fraction of manufacturing plants that export over the period from 1987 to 1992. Bernard, Jensen, and Schott (2009) additionally report significant extensive margin entry for U.S. firms in goods (agriculture, manufacturing, and mining) sectors across the two years 1993 and 2000. Taking the 40 percent figure from 1993 as a baseline, we find that firms that were no longer in the sample in 2006 were only modestly less likely to be exporters. Firms that entered the sample were similarly only slightly more likely to sell abroad.
} 
Third, the growth in exporting was experienced broadly across countries; while the distribution of contributions is skewed, no individual market accounts for more than 12 percent of the increase. As a result, the overall destination profile of exporting by U.S. firms did not change dramatically over time. Indeed, the rank correlation across countries between the beginning and end of the sample is 89 percent. These results point to the importance of factors that were experienced by a range of countries. Finally, with a share of only 1.6 percent, it is also clear that growth in exporting to Russia after the fall of the Soviet Union was not an important driving factor underlying these trends.

We next looked at these trends broken down by industry as well as region of the United States. In Figure 2 we plot the probability of exporting to a given country in our sample across two digit 1987 Standard Industrial Classification (SIC) sectors in 1993 and 2006. We find that the rise of exporting was experienced across all but one sector. Given that the classification of industries in the LBD changes from the SIC to the North American Industry Classification System (NAICS) after 1997, we develop a concordance from NAICS to SIC so that our industry definitions remain consistent over time. In columns (1)-(3) of Table 2, we similarly document that the rise in exporting was experienced across geographic regions of the United States. The results thus suggest that these trends were not primarily driven by idiosyncratic factors such as the growth of high-tech industries but rather by changes that affected different types of firms broadly.

In a similar vein, we looked at how the rise of exporting varied across firms of different sizes. The intuition developed from a number of the recent models of firm heterogeneity and international trade suggests that these trends may have been driven by smaller firms (e.g. Melitz 2003, Helpman, Melitz, and Yeaple 2004, and Chaney 2008). We find that this was in fact not the case. In columns (4)-(6) of Table 2 we look at the change in the probability that a firm exports to a given country in our sample across different firm size categories. While there is some variation in the increase across different types of companies, the rise of exporting was experienced by each group. Given the relationship between size and other firm characteristics that has been established in the prior literature, this finding suggests that even the most productive, lowest cost, and innovative businesses likely began exporting as well. This in turn implies that the welfare effects in countries abroad from these changes were likely larger than they would have been if they were driven solely by smaller firms.

While our focus is on understanding changes in the extensive margin of trade, considering the intensive margin is also informative about the sources of these trends. We find that average real foreign sales per exporter across countries increased by 57 percent from 1993 to 2006, where nominal sales are deflated using the National Bureau of Economic Research Productivity Database price index for the firm's primary sectors. Forty two out of the top fifty countries experienced increases. These results are suggestive of what happened to the upfront costs of entering foreign markets over time. 
In their influential work, Eaton, Kortum, and Kramarz (2011) show that a primary determinant of foreign sales per exporter are barriers to entry. In their model, if entry costs are high in a particular country, then only the most efficient firms will sell there, leading to high levels of exports per firm. Changes in factors such as tariffs and market size, in contrast, have no effect on average foreign sales per exporter since the effects on total exports and the mass of exporters cancel out. While this prediction of the model is stark, the data suggest at least that any declines in barriers to entry were of insufficient magnitude to outweigh the other factors that worked to increase average foreign sales.

Turning to our plant level data in the ASM, which has an earlier start date of 1987, we see even greater entry into foreign markets over time. In Figure 3, we plot the fraction of plants with 20 or more employees that export in each year. The share rises from 21 percent in 1987 to 39 percent in 2006. As in the LFTTD, these changes were driven both by increases in the raw number of plants selling abroad and by declines in the total number of establishments. The magnitudes of these changes are similar, however, when we look at plants that were present at both the beginning and end of the sample. A significant portion of this growth also occurred between 1987 and 1992, highlighting the benefits of looking at these trends with both the ASM and LFTTD data. In Table 3, we see an analogous picture to the LFTTD when we look at the rise of exporting across industries, regions, and plant size categories from 1987 to 2006. We come to similar conclusions both overall as well as across industries and regions when limiting the sample to plants with 10 or more employees or 250 or more employees.

The trends depicted in Figure 3 are also essentially the same when we consider plants with 10 or more or 250 or more employees, with the exception that the percentages are systematically shifted down or up in each year. This reflects the fact that smaller plants are significantly more likely to only sell domestically. These results are especially important for our estimation approach in the next section in which we are limited to plants with at least 250 employees, in that the same basic patterns in the data are similar for smaller plants. Indeed, we find the same basic trends in export participation when looking separately across categories of the employment size distribution. We additionally find significant increases in exporting at the level of the firm in Census of Manufactures years (1987 and 2002), for which we can aggregate the operations of plants.

As in the LFTTD, average real foreign sales per exporting plant expanded significantly over time. Average sales among establishments with at least 10 employees are nearly indistinguishable from average sales among plants with at least 20 employees. The changes for plants with 250 or more employees similarly increased. In the appendix we document additional stylized facts about these trends using both the LFTTD and ASM that further support our conclusions. 


\section{$3 \quad$ Barriers to Entry}

A natural starting point for better understanding the large scale entry into countries abroad documented earlier is to examine how the upfront costs of entering foreign markets have changed over time. As these costs cannot be directly observed, we use models of firm behavior to estimate changes in their magnitude. We consider multiple approaches to ensure that our results are not being driven by the specifics of a particular model. We begin by considering regression evidence and then in the next subsection move on to Monte Carlo Markov Chain estimations that will allow us to directly estimate the magnitude of changes in these costs.

\subsection{Regression Evidence}

Drawing upon the seminal work of Dixit (1989) and Baldwin and Krugman (1989), several prior studies have used a dynamic discrete choice model of whether or not to export to study the existence of barriers to entry in foreign markets. ${ }^{2}$ The basic premise of the theory is that a firm will sell abroad if the benefits from exporting exceed the additional costs of doing so. The benefits include the extra gross profits that the firm could make in the current period as well as any option value associated with being an exporter in the future. Firms that did not export previously, however, have to pay upfront costs to enter. This has a fundamental effect on who sells abroad as well as the dynamics of exporting behavior over time. Specifically, a firm that has not exported for more than two years must pay a sunk cost $F_{0}$ to enter the foreign market and a re-entry cost $F_{R}$ if it last exported two years ago. Dispensing with an extended discussion of the set up of the theory, it leads to the following decision rule:

$$
y_{i t}= \begin{cases}1 & \text { if } p_{i t}^{*}-\left(1-y_{i t-1}\right) \cdot F_{0}+\left(F_{0}-F_{R}\right) \cdot \tilde{y}_{i t-2} \geq 0 \\ 0 & \text { otherwise }\end{cases}
$$

Here $y_{i t}$ is firm $i$ 's export status in year $t$ and $\tilde{y}_{i t-2}=y_{i t-2}\left(1-y_{i t-1}\right)$ is an indicator function for whether the firm last exported two years ago. The extra benefits that a firm will gain from exporting $p_{i t}^{*}$ can be written as

$$
p_{i t}^{*}=p_{i t}+\delta\left(E_{t}\left[V_{i t+1} \mid y_{i t}=1\right]-E_{t}\left[V_{i t+1} \mid y_{i t}=0\right]\right)
$$

It is determined by the extra gross profit that the firm could make by exporting this year $p_{i t}$ plus the option value associated with being an exporter next period. This option value, in

\footnotetext{
${ }^{2}$ See Roberts and Tybout (1997b), Bernard and Wagner (2001), and Bernard and Jensen (2004a). For related work, see also Alessandria and Choi (2007), Arkolakis (2010), Moxnes (2010), Hanson and Xiang (2011), Aw, Roberts, and Xu (2011), Dutt, Santacreu, and Traca (2015), McCallum (2015), Dickstein and Morales (2015), and Morales, Sheu, and Zahler (2015).
} 
turn, is given by the difference in the discounted future expected value of being an exporter today relative to only selling domestically. If there are no costs to entering the foreign market in the model, the condition for exporting in equation (1) collapses to $p_{i t} \geq 0$. In this case, the firm decides whether or not to export based solely on what is most profitable today and ignores dynamic considerations. Thus, once controlling for factors that account for changes in $p_{i t}$, if there are no upfront costs to entering foreign markets we should see a lack of state dependence in exporting status.

To obtain an estimating equation that will allow us to look at changes in $F_{0}$ and $F_{R}$, we parameterize the term $p_{i t}^{*}-F_{0}$. We use the functional form $p_{i t}^{*}-F_{0} \approx \mu_{i}+X_{i t}^{\prime} \beta+\phi_{t}+\varepsilon_{i t}$ to develop the specification:

$$
y_{i t}=\mu_{i}+X_{i t}^{\prime} \beta+\alpha_{1} \cdot y_{i t-1}+\alpha_{2} \cdot \tilde{y}_{i t-2}+\phi_{t}+\varepsilon_{i t} .
$$

This equation provides the basis for our estimations. The vector $X_{i t}$ contains a number of covariates that affect $p_{i t}^{*}$ and thus predict export market participation. Unobserved firm characteristics that influence $p_{i t}^{*}$ are captured in $\mu_{i}$. Business cycle effects and other time varying factors are absorbed into the year effects $\phi_{t}$. The coefficients $\alpha_{1}=F_{0}$ and $\alpha_{2}=\left(F_{0}-F_{R}\right)$ parameterize the importance of barriers to entry in foreign markets. Larger estimates of state dependence associated with the parameter $\alpha_{1}$, for example, suggest higher sunk costs $F_{0}$. We can thus associate higher or lower levels of state dependence in exporting with corresponding changes in barriers to entry. ${ }^{3}$

As our ASM data give us the longest time horizon and allow us to control for a greater amount of heterogeneity in time varying producer characteristics, we begin by estimating equation (3) at the plant level. As a first step, in Table 4 we estimate the specification with a simple fixed effects regression. Since information on exports in the ASM is only available beginning in 1987 and our approach includes a covariate based on twice lagged export status, we begin the analysis in 1989 and use 1987 and 1988 as pre-sample years. Standard errors in parentheses are clustered at the plant level and plant specific characteristics in $X_{i t}$ are lagged by one period in order to avoid issues of simultaneity. These controls include the logarithms of employment, total factor productivity, and average wages as well as the ratio of nonproduction worker employment to total employment. Across all of our results, productivity is estimated with the semiparametric approach of Levinsohn and Petrin (2003). We also include an industry level, trade weighted exchange rate series estimated using the approach

\footnotetext{
${ }^{3}$ Prior studies have found little difference between the costs of entering foreign markets anew and those of entering after two years of not exporting. They have also found a small difference between $F_{0}$ and $F_{R}$ above. We find similar results. The model can be extended to include a cost of leaving the foreign market $L$, which makes the coefficient $\alpha_{1}$ in equation (3) a function of $F_{0}+L$. It can also be changed to allow for the upfront costs of learning about the foreign market, where $p_{i t}^{*}-F_{0}$ is a function of prior export status $y_{i t-1}$. This change similarly makes the coefficient on $y_{i t-1}$ in equation (3) a function of both the costs of learning and the costs $F_{0}$.
} 
employed by the Federal Reserve to produce official published exchange rate indexes and detailed in Loretan (2005).

In column (1) we present our findings from estimating equation (3) as presented earlier. Controlling for other factors, exporting last year raises a plant's probability of exporting this year by 44 percent. These results are consistent with the prior literature on testing for the existence of barriers to entry. In column (2) we include interaction terms of the variables

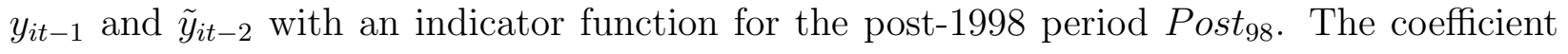
estimates on these interaction terms are given by how the costs $F_{0}$ and $F_{R}$ compare in the second half of the period with those in the first. We find little change in the coefficient $\alpha_{1}$ in the second part of the panel and a somewhat larger decrease in $\alpha_{2}$. This suggests relatively small changes in the costs $F_{0}$ and an increase in the sunk costs of re-entering foreign markets $F_{R}$. In column (3) we additionally include interactions of the variables in $X_{i t}$ with Post P8 $_{9}$ and the results do not change significantly.

We come to similar conclusions when considering alternative approaches. These include using different years for the post-period (e.g. Post ${ }_{99}$ ), only considering plants with 350 or more employees, using different covariates in $X_{i t}$, estimating productivity with alternative approaches, and adding the variable "Last exported three years ago" and its interaction

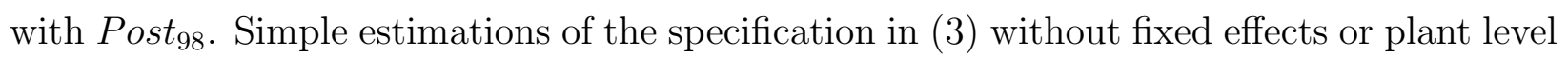
controls also suggest little change in export status persistence.

In these baseline estimations, we make no restrictions on entry into or exit out of the sample. We also do not find large declines in entry costs when using a balanced panel and these results are robust to the alternative approaches described earlier. The same is true when we allow for entry but drop plants that exit the sample. This is reassuring not only for the validity of our results here but also for our subsequent estimations in which we are constrained to use a balanced panel. In a similar vein, we performed estimations like those described in Table 4 but restricted the sample to the industries that we considered for our structural estimations in the next section. We come to similar conclusions here as well, suggesting that the industries that we chose to focus on are broadly representative of overall trends.

The estimations in Table 4 have the advantage that they make few parametric restrictions. However, they potentially suffer from three particular concerns. The first two are initial conditions bias and Nickell (1981) bias, although the length of the panel $(T=18)$ is likely to significantly attenuate these concerns. To address these issues we estimate the specification in equation (3) with a dynamic random effects probit estimator. This approach uses the Gaussian-Hermite quadrature methods of Butler and Moffitt (1982) and bounds the predicted probabilities between zero and one. It has the limitations, however, that it specifies a parametric distribution for the firm effect $\mu_{i}$ and only includes one lag of the dependent variable. It also requires using a balanced panel, although the robustness to dif- 
ferent restrictions on entry and exit in our fixed effects estimations earlier is reassuring on this score.

Instead of considering the whole panel at once, given the structure of the estimator we choose to estimate the model in an earlier period and a later period and compare the levels of state dependence. To do so, we create two balanced panels covering the period from 1987 to 1997 and from 1995 to 2006. We deal with the problem of initial conditions in each of these panels by using the approach of Heckman (1981). In the initial conditions equation we include the logarithms of employment, average real wages, total factor productivity, and the industry exchange rate two years prior to the start of the sample. We also include the ratio of non-production worker employment to total employment two years prior to the start of the sample as well as a set of two digit SIC industry dummies.

In columns (1) and (2) of Table 5 we estimate the specification without any plant specific controls. Since accounting for firm heterogeneity is important in this context, following Mundlak (1978) in columns (3) and (4) we specify $\mu_{i}=\bar{X}_{i}^{\prime} \psi+\zeta_{i}$. Here $\zeta_{i} \stackrel{i i d}{\sim} N\left(0, \sigma_{\zeta}^{2}\right)$ and is independent of $X_{i t}$ and $\varepsilon_{i t}$ for all $i$ and $t$. The independence assumption is a strong one in this context but it will allow us to better account for firm characteristics. In $\bar{X}_{i}$ we include the time means of the plant specific variables included in the initial conditions equation. The term $\zeta_{i}$ is integrated out using Gaussian-Hermite quadrature. The effects increase across the early and later panels with each approach, suggesting a higher level state dependence and a corresponding change in barriers to entry. We also estimated these specifications on a sample limited to plants in the industries that we consider for the structural analysis in the next section and come to similar conclusions.

An additional concern with the estimators considered so far is that they assume that the error term $\varepsilon_{i t}$ is serially uncorrelated. If there are persistent unobserved shocks, this would bias our estimates of the level of state dependence. In order to address this concern we turn to a simulated maximum likelihood estimator based on the GHK algorithm (see Hyslop 1999 and Stewart 2007) developed and analyzed in work by Geweke (1991), Hajivassiliou, McFadden, and Ruud (1992), and Keane (1994). This dynamic random effects approach makes parametric assumptions on the form of the serial correlation in the error term, which in turn determines the likelihood function. It then uses the property that the likelihood of a sequence of outcomes can be written as the product of recursively defined conditional probabilities. We deal with the problem of initial conditions as in earlier sections. The results are presented in the appendix. We find little change in state dependence here as well, suggesting little change in barriers to entry. More broadly, with the GHK approach and that of Butler and Moffitt (1982) presented in Table 5, we obtain similar sets of results when considering the non-overlapping panels 1987-1995 and 1996-2006.

While our approach using the ASM importantly allows us to estimate equation (3) controlling for a number of different producer characteristics, it does not consider the foreign 
markets to which plants were exporting. We next turn to a similar analysis using the LFTTD. To begin, for each country we create a set of balanced panels for 1992-1999 and 2000-2006. We then consider the dynamic probit model of Butler and Moffitt (1982) with no additional firm level controls and estimate a modified version of the specification in (3) for each country. The logarithms of firm employment and the average wage in the firm lagged by two years are used in the initial conditions equation along with a set of two digit SIC industry dummies.

In Figure 4 we take the estimates of the coefficient on $y_{i t-1}$ in the two different panels and plot them for each country. The coefficient in the earlier period is indicated on the $\mathrm{x}$-axis and the coefficient in the later period is plotted on the y-axis. We include a 45 degree line in the figure to indicate how the coefficients relate to one another across the two different panels. We find that the results cluster around this line, suggesting that barriers to entry have not declined significantly. We focus the graph on the relevant parameter space for the purposes of presentation but it should be noted that the percentage change for each coefficient across the two different panels is typically quite small, with an average increase of 1.4 percent. Notably, for the ten countries that accounted for roughly half of the rise in exporting listed in Table 1, eight show increases in state dependence and the declines for the other two are relatively small. A similar picture emerges when we include time means of the logarithms of firm employment and wages using the approach of Mundlak (1978). Simple persistence levels estimated by regressing the firm's current export status on its lagged export status with a linear probability model are also similar across the two different panels. ${ }^{4}$

\subsection{Monte Carlo Markov Chain Estimations}

\subsubsection{Model and Estimation Approach}

In this section we turn to a different approach to addressing how the costs of entering foreign markets have evolved over time. We use the methodology developed by Das, Roberts, and Tybout (2007) to look at the average level of costs facing plants over the earlier and later parts of our sample. The extra structure afforded by the model allows us to provide dollar value estimates of barriers to entry in the different time periods. Comparing the results across the two different panels will then give us a sense of how they have changed.

As variation over time in exporting behavior provides important information for our estimations, we consider relatively long time periods. We create a sample covering 11 years from 1987 to 1997 and another one covering 12 years from 1995 to 2006. We then separately estimate the sunk costs using each panel. The model uses information on both costs and

\footnotetext{
${ }^{4}$ We additionally considered estimating the specification at the country level using the simulated maximum likelihood approach discussed earlier. These estimations were computationally infeasible to do for all countries. Trial estimations for the countries that accounted for the largest increases in exporting in Table 1 had poor convergence properties, unlike our estimations with the ASM. The fact that we come to similar overall conclusions about the change in barriers to entry using both simulated maximum likelihood and the approach of Butler and Moffitt with the ASM is reassuring on this score.
} 
revenues to identify demand parameters and we thus focus on estimating it using our plant level data when such information is available. In addition to addressing the question of the determinants of the rise in exporting, our results contribute to the emerging literature on understanding the magnitude of these barriers. Indeed, this is the first set of estimates of these costs for the United States.

Here we lay out the basics of the theory underlying the estimation approach. At the heart of the model is a binary choice decision of whether or not to export. The net potential profits from selling abroad in the current period are given by

$$
u(\cdot)= \begin{cases}\pi_{i t}^{*}\left(e_{t}, x_{i t}, z_{i}\right)+\varepsilon_{1 i t} & \text { if } y_{i t}=1 \text { and } y_{i t-1}=1 \\ \pi_{i t}^{*}\left(e_{t}, x_{i t}, z_{i}\right)-\gamma_{s}\left(z_{i}\right)+\varepsilon_{2 i t} & \text { if } y_{i t}=1 \text { and } y_{i t-1}=0 \\ 0 & \text { if } y_{i t}=0\end{cases}
$$

The variable $y_{i t}$ is an indicator for whether plant $i$ exported in year $t . \pi_{i t}^{*}$ represents the gross potential profits from the foreign market that the plant could earn and is a function of the exchange rate $e_{t}$, a set of serially correlated shocks $x_{i t}$, and time invariant plant characteristics $z_{i}$. The shocks $x_{i t}$ are identified from information on domestic revenues, foreign revenues, and total costs. The error terms $\varepsilon_{j i t}$ are normally distributed with mean zero and variance $\sigma_{\varepsilon j}^{2}$, are serially uncorrelated, and are uncorrelated with $x_{i t}$ and $e_{t}$ for each $j=1,2$. The plant's potential net export profits depend on its prior status in the foreign market, since we assume that the sunk costs $\gamma_{s}\left(z_{i}\right)$ have to be paid if the plant did not export in the previous year and wants to do so this year. The parameter $\gamma_{s}$ is allowed to vary across the different types of plants in our sample, although computational constraints limit us to simply considering the costs for larger plants relative to those for smaller plants. It is the term $\gamma_{s}$ in which we are most interested.

In each period $t$, the plant observes the values of $e_{t}, x_{i t}$ and $\varepsilon_{j i t}$ and forms its expectations about the future using the fact that it knows the processes by which these factors evolve over time. The plant then decides whether or not to export based on maximizing its net discounted expected profit stream over a 30 year horizon. Formally, we have the Bellman equation:

$$
V_{i t}=\max _{y_{i t} \in\{0,1\}}\left\{u\left(e_{t}, x_{i t}, z_{i}, \varepsilon_{j i t}, y_{i t-1}, y_{i t} \mid \theta\right)+\delta E_{t} V_{i t+1}\right\}
$$

where

$$
E_{t} V_{i t+1}=\int_{e^{\prime}} \int_{x^{\prime}} \int_{\varepsilon^{\prime}} V_{i t+1} \cdot f_{e}\left(e^{\prime} \mid e_{t}, \theta\right) \cdot f_{x}\left(x^{\prime} \mid x_{t}, \theta\right) \cdot f_{\varepsilon}\left(\varepsilon^{\prime} \mid \varepsilon_{t}, \theta\right) d \varepsilon^{\prime} d x^{\prime} d e^{\prime}
$$

and $\theta$ is the full vector of parameters.

The decision rule of whether or not to export can be written as a binary choice problem where $y_{i t}=I\left(y_{i t}^{*}>0\right)$. Here $I(\cdot)$ is an indicator function and $y_{i t}^{*}$ is a comparison of the 
benefits from exporting and not exporting:

$$
y_{i t}^{*}=u\left(e_{t}, x_{i t}, z_{i}, \varepsilon_{i t}, 1, y_{i t-1} \mid \theta\right)+\delta \Delta E_{t} V_{i t+1}\left(e_{t}, x_{i t}, z_{i} \mid \theta\right) \text {, }
$$

where

$$
\Delta E_{t} V_{i t+1}\left(e_{t}, x_{i t}, z_{i} \mid \theta\right)=E_{t}\left[V_{i t+1} \mid y_{i t}=1\right]-E_{t}\left[V_{i t+1} \mid y_{i t}=0\right]
$$

The first term in equation (7) reflects the direct benefits from exporting today, whereas the second term reflects the option value of being an exporter tomorrow.

There are two central problems with estimating the likelihood function $L(D \mid \theta)$ that results from the model with classical methods. The first is that in order to account for producer heterogeneity, each plant is allowed to have a different foreign demand elasticity

$\eta=\left\{\eta_{i}\right\}_{i=1}^{n}$. These elasticities are used in calculating the shocks $x_{i t}$ to gross potential export profits $\pi_{i t}^{*}$. This creates an incidental parameters problem, since the number of elasticity parameters $\eta_{i}$ increases with the number of plants in the sample. Second, the likelihood function that results from the model is highly non-standard and may not be globally concave in $\theta$. To circumvent these issues, we use a Bayesian approach and consider the posterior distribution $P(\theta \mid D) \propto q(\theta) L(D \mid \theta)$, where $q(\theta)$ gives our prior beliefs about the parameters. To characterize $P(\theta \mid D)$ we then use the random walk MetropolisHastings algorithm. This approach essentially allows us to estimate $E(\theta \mid D)$ by performing Monte Carlo integration using a Markov chain. Given that we have multiple state variables, the Rust (1997) random grid algorithm is used in implementing the dynamic programming estimations.

With a few exceptions, we choose the prior distributions of the parameters to be highly diffuse to let the data speak for itself. We list the priors for the most important parameters in the model in Table 6 and these are held fixed across each of our estimations. To ensure that they are stationary, we restrict the priors on the root of the $A R(1)$ processes in the model so that they are distributed uniformly on $(-1,1)$. To impose non-negativity on the variance parameters, our priors are that they are distributed log normally. For each plant, the prior for the elasticity of demand in the foreign market is given by $\ln \left(\eta_{i}-1\right) \sim N(2,1)$. This is consistent with evidence from the prior literature (see, for example, Goldberg and Knetter 1999) and ensures that $\eta_{i}>1$, which is a necessary condition for the model. We describe further details about our estimation approach in the appendix.

\subsubsection{Results}

The assumptions of the model make it appropriate to consider different industries separately. At the same time, one of the primary limitations of the estimation approach is that it is highly computationally intensive. In choosing which industries to focus on, we used several 
criteria to narrow down our choices: (i) there were enough plants in each panel to allow for identification, (ii) the industry was sufficiently export oriented, (iii) like the manufacturing sector as a whole, the overall destination composition of industry exports was relatively stable from 1987 to 2006, and (iv) in order to get a broad view, the industries were in different two digit SIC sectors. These criteria led us to consider three particular three digit SIC industries: Preserved Fruits and Vegetables (SIC 203), Aircraft and Parts (SIC 372), and Measuring and Controlling Devices (SIC 382). The threshold for defining large plants, $z_{i}=1$, is set equal to the median level of real sales for each industry in 1987, such that half of the plants in the first panel are considered to be large. We keep this threshold for the second panel, capturing changes in plant size.

Table 7 presents the results for our main sunk cost parameters by industry across each of the two different time periods. The appendix presents the full estimation results. For each parameter we report the estimated mean and standard deviation and all figures are in 1987 dollars. Following the recommended strategy for posterior simulation suggested by Gelman, Carlin, Stern, Dunson, Vehtari, and Rubin (2003), to construct our estimates we consider 100,000 post-burn in draws from the posterior distribution from three separate chains. Thus, our estimates are each based on a total of 300,000 draws. For each chain, we discard the first 50,000 draws and check for convergence using the diagnostic tests reviewed in Brooks and Roberts (1998). Despite generally using highly diffuse priors, the posterior distributions for most of our parameters are significantly concentrated. This suggests that the estimates are primarily informed by the data rather than our choice of priors.

Consistent with the results from the previous section, we find generally comparable results for the sunk cost parameters $\gamma_{s}$ across the two different time periods. For Preserved Fruits and Vegetables we find modest declines across both plant size categories, for Aircraft and Parts we find increases across both categories, and for Measuring and Controlling Devices we find a decline for smaller plants and an increase for larger plants. The sunk cost parameters for each industry are generally between 2 and 3 million dollars and the standard deviations of the posterior distributions range from 360 thousand dollars to 1.21 million dollars. Calculations using the elasticity estimates for each plant suggest that the magnitude of the sunk costs is typically roughly equal to a few years of the average level of exporting profits. Elasticity estimates are also consistent with the values suggested by the literature.

To get a sense of how the entry cost estimates compare across the two different time periods, we calculate the percentage of draws from the sunk cost posterior distribution for the 1995-2006 panel that lie above the expected value of the sunk cost posterior in the 1987-1997 panel. The results range from having 75 percent of the draws for small plants in Aircraft and Parts above the mean for 1987-1997 to having 19 percent of the draws above for small plants in Preserved Fruits and Vegetables. Thus, while these posterior distributions are not concentrated enough to make stark claims on the precise change in barriers to entry, 
in concert with our estimates of these parameters from Section 3.1 they do suggest that large scale declines are unlikely.

In interpreting these results more broadly, a number of factors likely worked to increase as well as decrease these costs. For example, trade agreements could have lowered them. At the same time, in what little survey evidence we have firms list market research and redesigning their products for foreign markets as two of the primary costs that they face in beginning to sell abroad. With the increasing integration of the world economy, market research costs may have increased substantially due to the need to identify and study competition from a greatly expanded number of source countries. Additionally, there is evidence that technical barriers to trade have increased over time, particularly among countries that have had their hands tied with respect to tariffs due to international agreements. Many of these policy changes likely raised the costs of entry. ${ }^{5}$ We consider the effects of these factors to be an open area for future research.

\section{Accounting for the Rise in Exporting}

While looking for declines in barriers to entry is a natural place to begin to understand increasing firm participation in foreign markets, there are a number of other potential explanations for these trends. As upfront costs have not fallen significantly over time, here we consider the contribution of alternative factors. Although the determinants of large changes in firm export participation have not yet been studied in a comprehensive way, there is a small but influential literature that looks at the factors that have driven the large increase in the volume of worldwide trade over time. Many of these studies have employed a gravity equation to understand the main determinants of greater trade flows. We combine this type of approach with econometric decomposition methods developed in the labor economics literature. By considering a more recent time period than that of much of the existing literature, we can also explore the role of factors that have not yet been studied in the literature on export volumes and consider changes in exporting to a larger set of countries.

We draw on a number of additional data sources for this analysis. Foreign GDP are sourced from the World Bank's World Development Indicators (WDI) data set. Measures of the number of internet users are also from the WDI. "Gravity" variables on country distance, time zone difference, and indicators for common currency, common language, common legal origins, contiguity, regional trade agreements, and colonial relationships with the United States are obtained from the Centre d'Études Prospectives et d'Informations Internationales (CEPII). We treat countries that share a common language with the United States as those

\footnotetext{
${ }^{5}$ For evidence on changes in technical barriers to trade, see Baldwin, McLaren, and Panagariya (2000), Maskus, Wilson, Otsuki (2000), U.S. Department of Commerce (2004), United Nations Conference on Trade and Development (2005), and U.S. Trade Representative (2011). For survey evidence on the nature of barriers to entry, see the study conducted for the World Bank found in First Washington Associates (1991).
} 
where the official language is English. Britain, Spain, France, and the Philippines are all considered as having had a colonial relationship with the United States. Panama and, beginning in 2001, El Salvador use the dollar as legal tender and as such are the only countries in our sample that ever share a common currency with the United States. Information on sectoral tariffs is from the World Bank's TRAINS database. We describe our development of these data in further detail in the appendix.

Before undertaking a formal analysis, it is instructive to begin by simply considering how much some of the potential drivers of these trends changed over the course of our sample period. In Table 8, we look at the mean of several of these factors in 1993 and 2006. The average number of internet users across countries grew dramatically from 80 thousand per country to 16 million. The United States also enacted seven new trade agreements among the 50 countries in our sample between 1993 and 2006. These partners are Australia, Chile, El Salvador, Guatemala, Honduras, Mexico, and Singapore and the agreements complemented the already existing ones with Canada and Israel. Average foreign market size grew from 409 billion to 558 billion in 2000 U.S. dollars. Tariffs measured using a value added equivalent fell from an average of 13.69 percent to 7.37 percent and the real exchange rate experienced relatively small shifts. Finally, El Salvador joined Panama in 2001 in adopting the U.S. dollar as an official currency. While these figures are simple averages by country, we come to similar conclusions when weighting these changes across foreign markets by their popularity as export destinations at the beginning of our sample in 1993.

As discussed in Section 2, given that NAFTA was signed and passed during these years it is perhaps not surprising that increases in exporting to Mexico played a significant role in these trends. In Figure 5 we plot the number of firms exporting to Mexico in our sample year by year. In order to focus on percentage changes we normalize the measure in 1994, when NAFTA entered into force, to one hundred percent. The figures for all other years are presented in relation to this base year. The response to NAFTA was not immediate and was likely restrained by the ongoing "Tequila Crisis" as well as the corresponding devaluation of the peso. Large scale entry took hold soon after 1994, however, such that the number of firms exporting there had more than doubled by 2000. While other developments were going on at the same time, given the timing of these trends we interpret these results as evidence that NAFTA had a significant effect on exporting to Mexico.

Another notable feature of Figure 1 and Table 1 discussed in Section 2 is that many of the countries that contributed the most to the rise in exporting also experienced rapid economic growth. While China and India are perhaps the most notable examples, Mexico, Brazil, and South Korea also experienced significant growth over this time period. Figure 6 looks at the unconditional relationship between changes in exporting behavior and changes in market size across countries. The log of the ratio of the probability of exporting to a given country in 2006 relative to 1993 is plotted on the y-axis. The log of the ratio of real GDP in U.S. 
dollars in 2006 relative to 1993 is similarly measured on the x-axis. Without controlling for other factors, the figure shows a strong and positive relationship between changes in market size and changes in export participation.

Figure 7 similarly highlights an additional potential driver of greater export participation. Similar to Figure 6, we consider whether changes in the number of internet users in each country are associated with shifts in exporting there. The development of the internet likely affected trade through a number of channels, such as reducing communication costs. For each country in our sample we include the log of the ratio of the probability of exporting in 2006 relative to 1993 on the y-axis. This is then plotted against the log of the ratio of the number of internet users in 2006 relative to 1993. The unconditional relationship is strong and positive here as well.

In order to decompose the sources of the rise in exporting in a comprehensive way, we draw on the canonical methodology developed by Oaxaca (1973) and Blinder (1973). This approach and related methods have been used to understand issues such as the reasons for the rise of female labor force participation and declining rates of membership in labor unions. ${ }^{6}$ Analogous to these applications, this methodology is particularly well suited to looking at changes in the decision of a particular firm to export to a given country. To our knowledge, however, it has not been used to evaluate the sources of changes in the pattern of international trade over time. The methodology is straightforward to apply with many covariates, valid in unbalanced samples, and allows for easy computation of standard errors. Since it has little precedent for analyzing changes in trade, here we give a brief overview of the decomposition.

We begin by discussing the approach that uses our baseline methodology. Denoting $y_{i c}^{t}$ as an indicator for whether firm $i$ exported to country $c$ in year $t$, we can model export participation in a given year with the following specification:

$$
y_{i c}^{t}=\alpha^{t}+\phi_{i}^{t}+X_{i c}^{t} \beta^{t}+\varepsilon_{i c}^{t} .
$$

Here $\alpha^{t}$ is a constant, $\phi_{i}^{t}$ are firm fixed effects, the vector $X_{i c}^{t}$ contains a set of firm-country specific explanatory variables, and $\varepsilon_{i c}^{t}$ is the error term. By the law of iterated expectations, the change in the probability that a firm exports to a given country can be written as

$$
\begin{aligned}
P\left(y_{i c}^{06}=1\right)-P\left(y_{i c}^{93}=1\right) & =E\left(y_{i c}^{06}\right)-E\left(y_{i c}^{93}\right) \\
& =E\left(E\left(y_{i c}^{06} \mid X_{i c}^{06}, \phi_{i}^{06}\right)\right)-E\left(E\left(y_{i c}^{93} \mid X_{i c}^{93}, \phi_{i}^{93}\right)\right) .
\end{aligned}
$$

\footnotetext{
${ }^{6}$ See, for example, Gomulka and Stern (1990), Even and Macpherson (1990), and Antonczyk, Fitzenberger, and Sommerfeld (2010). Kline (2011) shows that the Oaxaca-Blinder estimator has robust statistical properties to commend its use in other contexts and Fortin, Lemieux, and Firpo (2011) review decomposition methods in detail.
} 
Considering our estimates, by adding and subtracting $\bar{X}^{06} \hat{\beta}^{93}$ and then rearranging terms, the change in the predicted probability of exporting between 1993 and 2006 can be decomposed as

$$
\begin{aligned}
& P \widehat{\left(y_{i c}^{06}=1\right)}-P \widehat{\left(y_{i c}^{93}=1\right)}=\left(\hat{\alpha}^{06}+\overline{\hat{\phi}}_{i}^{06}+\bar{X}^{06} \hat{\beta}^{06}\right)-\left(\hat{\alpha}^{93}+\overline{\hat{\phi}}_{i}^{93}+\bar{X}^{93} \hat{\beta}^{93}\right) \\
& =\left(\hat{\alpha}^{06}+\overline{\hat{\phi}}_{i}^{06}+\bar{X}^{06} \hat{\beta}^{06}\right)-\left(\hat{\alpha}^{93}+\overline{\hat{\phi}}_{i}^{93}+\bar{X}^{93} \hat{\beta}^{93}\right) \\
& +\left(\bar{X}^{06} \hat{\beta}^{93}-\bar{X}^{06} \hat{\beta}^{93}\right) \\
& =\underbrace{\left(\bar{X}^{06}-\bar{X}^{93}\right) \hat{\beta}^{93}}_{\text {explained by observable covariates }} \\
& +\underbrace{\left(\hat{\alpha}^{06}-\hat{\alpha}^{93}\right)+\left(\overline{\hat{\phi}}_{i}^{06}-\overline{\hat{\phi}}_{i}^{93}\right)+\bar{X}^{06}\left(\hat{\beta}^{06}-\hat{\beta}^{93}\right)}_{\text {unexplained by observable covariates }} .
\end{aligned}
$$

The first term in the last expression gives the change in the outcome due to shifts in the average value of the observable covariates. It measures the contribution of these changes by keeping the estimated effects $\hat{\beta}^{93}$ fixed at their counterfactual 1993 value. The second term is determined by changes in factors that are unexplained by the observables. Considering the decomposition in this way, where we hold the coefficients fixed at those estimated for 1993, ensures that the estimates by which we weight the changes in the determinants of exporting are not affected by subsequent within-sample developments. It should be noted, however, that other approaches are possible. For example, if we were to add and subtract $\bar{X}^{93} \hat{\beta}^{06}$ instead of $\bar{X}^{06} \hat{\beta}^{93}$ in the expression above, we would end up multiplying the changes in the observable factors by the effects estimated for 2006.

We now turn to our particular application of this methodology. Motivated by the considerable literature on estimating gravity equations for the volume of trade, the probability that a firm exports to a given country is given by

$$
\begin{aligned}
\operatorname{Pr}\left(y_{i c}^{t}=1 \mid X_{i c}^{t}, \phi_{i}^{t}\right) & =E\left(y_{i c}^{t} \mid X_{i c}^{t}, \phi_{i}^{t}\right) \\
& =\alpha^{t}+\phi_{i}^{t}+\beta_{1}^{t} \ln \left(\text { InternetUsers }_{c}^{t}\right)+\beta_{2}^{t} \mathrm{FTA}_{c}^{t} \\
& +\beta_{3}^{t} \ln \left(\text { MarketSize }_{c}^{t}\right)+\beta_{4}^{t} \ln \left(\operatorname{Tariffs}_{c}^{t}\right)+\beta_{5}^{t} \text { Common Currency }_{c}^{t} \\
& +\beta_{6}^{t} \ln \left(\mathrm{RER}_{c}^{t}\right)+\beta_{7}^{t} \ln \left(\text { Distance }_{c}\right)+\beta_{8}^{t} \text { Contiguous }_{c} \\
& +\beta_{9}^{t} \text { Language }_{c}+\beta_{10}^{t} \operatorname{Legal}_{c}+\beta_{11}^{t} \operatorname{Landlocked}_{c} \\
& +\beta_{12}^{t} \text { Colony }_{c}+\beta_{13}^{t} \operatorname{TimeDiff}_{c}
\end{aligned}
$$

where $\phi_{i}^{t}$ are a set of firm characteristics. We estimate this specification separately for 
1993 and 2006. Since each regression uses a cross section in each year, the effects of these characteristics are allowed to differ between 1993 and 2006 .

We consider two variants of this approach, both of which lead to similar conclusions. The first departs from the firm fixed effects approach laid out above and takes advantage of the limited firm characteristics that we can observe, such as employment, real wages, and industry and U.S. region fixed effects. The second instead simply follows the approach in (12). Including firm fixed effects allows us to control for a greater number of firm level characteristics and for this reason we take these estimations as our baseline results. At the same time, including firm fixed effects precludes us from considering changes in specific firm characteristics. In particular, while they control non-parametrically for the changes in firm productivity that happened during the sample period, we are unable to disentangle these effects from any other shifts in firm characteristics. Given these considerations, with both of these approaches we focus on the contribution of developments in foreign markets.

In using a gravity equation approach, our work follows the influential literature on the determinants of rising worldwide trade volumes (e.g. Baier and Bergstrand 2001, Estevadeordal, Frantz, and Taylor 2003, Whalley and Xian 2015). Our work has advantages over the type of approach used in these studies but also shares some of its limitations. In particular, while our specification in (12) accounts for the standard set of factors that have been shown to influence trade flows, as with any gravity equation estimation there may be some factors for which we cannot control. As such, these estimations should be considered descriptive. By combining the gravity equation approach with decomposition methods, however, we weight the changes in the covariates by the marginal effects estimated at the beginning of our sample. Our coefficient estimates will thus not be affected by within-sample developments.

In Table 9 we present the results from separately estimating the specification in (12) in 1993 and 2006. The dependent variable is scaled to 100 if a firm exports to a country and equals 0 otherwise. As such, each of the coefficients on the variables in logarithms has the interpretation of a semi-elasticity in percentage points. In columns (1) and (2) we exclude the firm fixed effects and simply control for the log of firm employment, the log of the average annual payroll in the firm, and industry and U.S. region fixed effects. In our baseline results in columns (3) and (4) we instead include firm fixed effects and come to similar conclusions. Reflecting the fact that we have a great deal of identifying variation, the estimated marginal effects are highly significant across each of the specifications.

Comparing the results for our baseline estimations in the two years speaks to the shifting structure of the global economy. While many of the coefficients are similar in magnitude across the two years, the changes in two are of particular interest. First, as in the comprehensive analysis of the gravity equation literature on the volume of trade by Disdier and Head (2008), the effect of distance does not decline significantly over time. This finding is true both with and without the control for time zone difference. In fact, the marginal effect 
in our baseline results increases in magnitude by 54 percent. Thus, we find that the effect of distance has not declined over time not only for trade volumes but also for the extensive margin of where firms export.

Second, between 1993 and 2006 the importance of the availability of the internet in a country in affecting firms' decisions of whether or not to export there also increased. A long and influential literature has documented and analyzed the effects of network externalities, in which the use of a particular good or service affects the value of that product to other people (e.g. Katz and Shapiro 1985). The classic example is the telephone, the focus of much of the early literature on this topic. Our results are consistent with the idea that these forces were at play with respect to one of the latest communications technologies, the internet. While the effect of the internet on the volume of trade has been analyzed previously (Freund and Weinhold 2004), to our knowledge these are the first set of results to consider how network effects changed the role of the internet in facilitating trade over time. We see this as a promising area for future research.

In looking at the decomposition results for our baseline specification in Table 10, we focus on how much each covariate contributed to the overall change predicted by the factors that we observe. The first column for each specification contains the estimated change in the probability of exporting to a given country due to the shifts in each covariate. It is measured as $\left(\bar{X}_{j}^{06}-\bar{X}_{j}^{93}\right) \hat{\beta}_{j}^{93}$ for each factor $j$. While serving as important controls in our estimations, the gravity variables such as distance play no role in these changes since they are held fixed across time. The second column contains the share for each factor of the overall change in the predicted probability of exporting due to shifts in observable characteristics. It is calculated for each factor $j$ as Fraction $_{j}=\left(\bar{X}_{j}^{06}-\bar{X}_{j}^{93}\right) \hat{\beta}_{j}^{93} / \sum_{j}\left(\bar{X}_{j}^{06}-\bar{X}_{j}^{93}\right) \hat{\beta}_{j}^{93}$.

From the most to the least important, the factors that lead to greater participation in our baseline estimations are growth in the number of internet users, which explains 51 percent of the predicted increase, followed by trade agreements with 28 percent, foreign income with 18 percent, tariffs with 2 percent, and changes in the number of countries that use the U.S. dollar as an official currency with 1 percent. Shifts in real exchange rates explain little of the change in participation. If we were to pursue the composition differently by multiplying the changes in the observables by the estimated coefficients in 2006, the estimated impact of the development of the internet increases, while trade agreements and foreign economic growth are still of significant importance. The contribution of changes in overall tariffs, using the U.S. dollar as a currency, and the real exchange rate continue to be small.

In our baseline estimations, we simply consider direct trade agreements with foreign countries that went into effect during our sample period that are identified by the Office of U.S. Trade Representative. One major event that occurred during our sample period that precipitated significant changes in export volumes was that the U.S. normalized trade relations with China in 2001. Given that we weight the changes in our covariates by the coefficient 
estimated for the 1993 cross section, treating this as an additional trade agreement does not affect the estimated contribution of trade agreements significantly in our decomposition. Interestingly, it also only modestly alters the coefficient on the trade agreements covariate in 2006 either.

To get a sense of how these developments affected different types of firms, we separately estimate the decomposition with the specification in (12) across the firm size categories considered in Table 2. The relative importance of the factors that lead to greater participation in these estimations generally retains the ordering presented earlier with one exception. For firms with 20 to 50 employees trade agreements account for the largest share of the explained increase in participation, followed by the increase in the number of internet users. The ordering for the other determinants remains the same.

While the relative importance of each factor is fairly stable by firm size, the absolute magnitudes of the effects do differ. The number of internet users accounts for more of the change in participation for larger firms, while trade agreements account for more of the change among smaller firms. Income growth has a similar effect on all firms regardless of their size and tariffs account for more of the change for larger firms than for smaller ones. One potential explanation for these results is that larger firms are more sensitive to variable trade costs, whereas smaller firms are more responsive to the declines in non-tariff barriers and reductions in uncertainty that often come with trade agreements (Handley 2014, Handley and Limão 2015, Limão and Maggi, forthcoming).

We also estimated the decomposition separately based on firms' main two digit 1987 SIC industry. Here we again use our baseline specification in (12). Among the twenty different sectors, eight retain the same ordering as in the baseline results for manufacturing as a whole. Twelve of the sectors find that trade agreements were more important than the development of the internet. Market size, tariffs, the number of countries with a common currency with the United States, and the real exchange rate always follow these top two factors in order of importance. While there is some variation in the ranking of the importance of these determinants across the sectors, if we take the average magnitude of the importance of each factor across industries we come to similar conclusions as in the baseline results.

More broadly, the large roles for the internet and trade agreements that we find are consistent with work by Alessandria and Choi (2014), who show that falling iceberg trade costs in a calibrated model in the spirit of Melitz (2003) can explain the rise of U.S. manufacturing export volumes. The results are also consistent with the emerging literature on how information frictions affect economic activity and international exchange in particular. In related work, Steinwender (2015) finds that the establishment of the transatlantic telegraph connection in 1886 increased average trade flows and made them more responsive to foreign demand shocks. Freund and Weinhold (2004) similarly look at worldwide export volumes and find evidence that the internet stimulates trade flows. A number of studies have also 
found reductions in price dispersion across markets in response to greater access to the internet or mobile phones (e.g. Allen 2014). These findings suggest that the number of firms trading with one another is an additional consequence of reductions in information frictions.

\section{Conclusion}

In this study we document a significant rise in exporting among U.S. firms over the 20 year period from 1987 to 2006. In looking at the reasons for these trends, we initially consider a natural explanation that has been suggested as a primary cause for similar developments in other countries: declines in the upfront costs of entering foreign markets. Across different approaches to understanding this issue, however, we show that reductions in these barriers were unlikely to have played a significant role in these trends. We then turn to methods from the labor economics literature to decompose the sources of the rise in exporting. We find significant roles for the development of the internet, trade agreements, and foreign income growth in driving these changes.

We close with a discussion of a few areas of research that are likely to be fruitful for future work. First, qualitative evidence on the determinants of export market entry costs would be valuable. Despite the evidence presented here and how common they have become as a part of models of international trade, there is surprisingly little direct survey evidence about the nature of these costs. Second, as firm level data become increasingly available, further analyses of the experiences of firms in other countries would add greatly to our understanding of the growth of exporting worldwide. While a number of the factors explored here like the development of the internet and rising incomes likely affected firms in other countries, some factors such as the trade agreements that were signed during this period are quite specific

to the U.S. experience. Finally, we believe that the decomposition methods that we have used in our estimations have significant potential for better understanding other questions in international trade. 


\section{References}

1. Alessandria, George, and Horag Choi. 2007. "Do Sunk Costs of Exporting Matter for Net Export Dynamics?" Quarterly Journal of Economics 122 (1): 289-336.

2. 一, and -. 2014. "Do Falling Iceberg Costs Explain Recent US Export Growth?." Journal of International Economics 94 (2): 311-25.

3. Allen, Treb. 2014. "Information Frictions in Trade." Econometrica 82 (6): 2041-83.

4. Antonczyk, Dirk, Bernd Fitzenberger, and Katrin Sommerfeld. 2010. "Rising Wage Inequality, the Decline of Collective Bargaining, and the Gender Wage Gap." Labour Economics 17 (5): 835-47.

5. Arkolakis, Costas. 2010. "Market Penetration Costs and the New Consumers Margin in International Trade." Journal of Political Economy 118 (6): 1151-99.

6. Aw, Bee Yan, Mark J. Roberts, and Daniel Yi Xu. 2011. "R\&D Investment, Exporting, and Productivity Dynamics." American Economic Review 101 (4): 131244.

7. Baier, Scott L., and Jeffrey H. Bergstrand. 2001. "The Growth of World Trade: Tariffs, Transport Costs, and Income Similarity." Journal of International Economics $53(1): 1-27$.

8. Baldwin, Richard, John McLaren, and Arvind Panagariya. 2000. "Regulatory Protectionism, Developing Nations and a Two-Tier World Trading System [With Comments and Discussion]." In Brookings Trade Forum, edited by S. Collins and D. Rodrik: 237-93. Washington: Brookings Institution.

9. - - and Paul Krugman. 1989. "Persistent Trade Effects of Large Exchange Rate Shocks." Quarterly Journal of Economics 104 (4): 635-54.

10. Bergoeing, Raphael, Alejandro Micco, and Andrea Repetto. 2011. "Dissecting the Chilean Export Boom." University of Chile Working Paper 339.

11. Bernard, Andrew, and J. Bradford Jensen. 2004a. "Why Some Plants Export." Review of Economics and Statistics 86: 561-69.

12. —. 2004b. "Entry, Expansion, and Intensity in the U.S. Export Boom, 1987-1992." Review of International Economics 12 (4): 662-75. 
13. - , J. Bradford Jensen, and Peter K. Schott. 2009. "Importers, Exporters and Multinationals: A Portrait of Firms in the U.S. that Trade Goods." In Producer Dynamics: New Evidence from Micro Data, edited by T. Dunne, J.B. Jensen, and M.J. Roberts, 513-56. Chicago: University of Chicago Press.

14. - , and Joachim Wagner. 2001. "Export Entry and Exit by German Firms." Review of World Economics (Weltwirtschaftliches Archiv) 137: 105-23.

15. Blinder, Alan S. 1973. "Wage Discrimination: Reduced Form and Structural Estimates." Journal of Human Resources 8 (4): 436-55.

16. Broda, Christian, and David E. Weinstein. 2006. "Globalization and the Gains from Variety." Quarterly Journal of Economics 121 (2): 541-85.

17. Brooks, Stephen, and Gareth Roberts. 1998. "Convergence Assessment Techniques for Markov Chain Monte Carlo." Statistics and Computing 8: 319-35.

18. Butler, J.S., and Robert Moffitt. 1982. "A Computationally Efficient Quadrature Procedure for the One-Factor Multinomial Probit Model." Econometrica 50 (3): 76164.

19. Cairncross, Frances. 1997. The Death of Distance: How the Communications Revolution Is Changing our Lives. Cambridge, MA: Harvard Business School Press.

20. Chaney, Thomas. 2008. "Distorted Gravity: The Intensive and Extensive Margins of International Trade." American Economic Review 98 (4): 1707-21.

21. Das, Sanghamitra, Mark J. Roberts, and James R. Tybout. 2007. "Market Entry Costs, Producer Heterogeneity, and Export Dynamics." Econometrica 75 (3): 837-73.

22. Dickstein, Michael, and Eduardo Morales. 2015. "What Do Exporters Know?" Princeton University, mimeo.

23. Disdier, Anne-Célia, and Keith Head. 2008. "The Puzzling Persistence of the Distance Effect on Bilateral Trade." The Review of Economics and Statistics 90 (1): $37-48$.

24. Dixit, Avinash. 1989. "Entry and Exit Decisions Under Uncertainty." Journal of Political Economy 97 (3): 620-38.

25. Dutt, Pushan, Ilian Mihov, and Timothy Van Zandt. 2013. "The Effect of WTO on the Extensive and the Intensive Margins of Trade." Journal of International Economics 91 (2): 204-19. 
26. — Ana Maria Santacreu, and Daniel Traca. 2015. "The Gravity of Experience." INSEAD, mimeo.

27. Eaton, Jonathan, and Samuel Kortum. 2001. "Trade in Capital Goods." European Economic Review 45 (7): 1195-1235.

28. - - - , and Francis Kramarz. 2011. "An Anatomy of International Trade: Evidence from French Firms." Econometrica 79 (5): 1453-98.

29. Estevadeordal, Antoni, Brian Frantz, and Alan M. Taylor. 2003. "The Rise and Fall of World Trade, 1870-1939." Quarterly Journal of Economics 118 (2): 359407.

30. Even, William E., and David A. Macpherson. 1990. "Plant Size and the Decline of Unionism." Economics Letters 32 (4): 393-98.

31. Evenett, Simon J., and Anthony J. Venables. 2002. "Export Growth in Developing Countries: Market Entry and Bilateral Trade Flows." London School of Economics, mimeo.

32. Feenstra, Robert C. 2014. "Restoring the Product Variety and Pro-competitive Gains from Trade with Heterogeneous Firms and Bounded Productivity." NBER Working Paper 19833.

33. First Washington Associates. 1991. "Export Finance and Promotion Study: PROEXPO/Colombia." Arlington, VA.

34. Fortin, Nicole, Thomas Lemieux, and Sergio Firpo. 2011. "Decomposition Methods in Economics." In Handbook of Labor Economics, edited by O. Ashenfelter and D. Card, vol. 4, chapter 1, 1-102. San Diego, CA: North Holland.

35. Freund, Caroline L., and Diana Weinhold. 2004. "The Effect of the Internet on International Trade." Journal of International Economics 62 (1): 171-89.

36. Friedman, Thomas L. 2005. The World Is Flat: A Brief History of the Twenty-first Century. New York: Farrar, Straus and Giroux.

37. Gelman, Andrew, John Carlin, Hal Stern, David Dunson, Aki Vehtari, and Donald Rubin. 2003. Bayesian Data Analysis (2nd ed.). Boca Raton, FL: CRC Press.

38. Geweke, John. 1991. "Efficient Simulation from the Multivariate Normal and Student-t Distributions Subject to Linear Constraints and the Evaluation of Constraint 
Probabilities." In Computing Science and Statistics: Proceedings of the 23rd Symposium on the Interface, 571-78. Fairfax, VA: Interface Foundation of North America, Inc.

39. Goldberg, Pinelopi K., Amit K. Khandelwal, Nina Pavcnik, and Petia Topalova. 2010. "Multiproduct Firms and Product Turnover in the Developing World: Evidence from India." Review of Economics and Statistics 92 (4): 1042-49.

40. —, and Michael M. Knetter. 1999. "Measuring the Intensity of Competition in Export Markets." Journal of International Economics 47 (1): 27-60.

41. Gomulka, Joanna, and Nicholas Stern. 1990. "The Employment of Married Women in the United Kingdom, 1970-1983." Economica 57 (226): 171-99.

42. Hajivassiliou, Vassilis, Daniel McFadden, and Paul Ruud. 1992. "Simulation of Multivariate Normal Orthant Probabilities: Methods and Programs." Cowles Foundation, mimeo.

43. Handley, Kyle. 2014. "Exporting Under Trade Policy Uncertainty: Theory and Evidence." Journal of International Economics 94 (1): 50-66.

44. — - and Nuno Limão. 2015. "Trade and Investment under Policy Uncertainty: Theory and Firm Evidence." American Economic Journal: Economic Policy. Forthcoming.

45. Hanson, Gordon, and Chong Xiang. 2011. "Trade Barriers and Trade Flows with Product Heterogeneity: An Application to U.S. Motion Picture Exports." Journal of International Economics 83 (1): 14-26.

46. Harris, Mark, László Kónya, and László Mátyás. 2012. "Some Stylized Facts about International Trade Flows." Review of International Economics 20 (4): 781-92.

47. Head, Keith, and Thierry Mayer. 2002. "Illusory Border Effects: Distance Mismeasurement Inflates Estimates of Home Bias in Trade." CEPII Working Paper 200201.

48. - - - - and John Ries. 2010. "The Erosion of Colonial Trade Linkages after Independence." Journal of International Economics 81 (1): 1-14.

49. Heckman, James. 1981. "The Incidental Parameters Problem and the Problem of Initial Conditions in Estimating a Discrete Time - Discrete Data Stochastic Process and Some Monte Carlo Evidence." In Structural Analysis of Discrete Data and Econometric Applications, edited by C. Manski and D. McFadden, 179-95. Cambridge, MA: MIT Press. 
50. Helpman, Elhanan, Marc J. Melitz, and Stephen R. Yeaple. 2004. "Export versus FDI with Heterogeneous Firms." American Economic Review 94 (1): 300-16.

51. Hicks, John. 1969. A Theory of Economic History. London: Oxford University Press.

52. Hummels, David, and Peter J. Klenow. 2005. "The Variety and Quality of a Nation's Exports." American Economic Review 95 (3): 704-23.

53. Hyslop, Dean. 1999. "State Dependence, Serial Correlation and Heterogeneity in Intertemporal Labor Force Participation of Married Women." Econometrica 67 (6): 1255-94.

54. Johnson, Robert C. 2014. "Five Facts about Value-Added Exports and Implications for Macroeconomics and Trade Research." Journal of Economic Perspectives 28 (2): 119-42.

55. Katz, Michael L., and Carl Shapiro. 1985. "Network Externalities, Competition, and Compatibility." American Economic Review 75 (3): 424-40.

56. Keane, Michael. 1994. "A Computationally Practical Simulation Estimator for Panel Data." Econometrica 62 (1): 95-116.

57. Kehoe, Timothy J., and Kim J. Ruhl. 2013. "How Important Is the New Goods Margin in International Trade?" Journal of Political Economy 121 (2): 358-92.

58. Kline, Patrick. 2011. "Oaxaca-Blinder as a Reweighting Estimator." American Economic Review: Papers and Proceedings 101 (3): 532-37.

59. Krugman, Paul. 1979. "Increasing Returns, Monopolistic Competition, and International Trade." Journal of International Economics 9 (4): 469-79.

60. Leamer, Edward E. 2007. "A Flat World, a Level Playing Field, a Small World After All, or None of the Above? A Review of Thomas L. Friedman's The World Is Flat." Journal of Economic Literature 45 (1): 83-126.

61. Lederman, Daniel, Andrés Rodríguez-Clare, and Daniel Xu. 2011. "Entrepreneurship and the Extensive Margin in Export Growth: A Microeconomic Accounting of Costa Rica's Export Growth during 1997-2007." World Bank Economic Review 25(3): 543-61.

62. Levinsohn, James, and Amil Petrin. 2003. "Estimating Production Functions Using Inputs to Control for Unobservables." Review of Economic Studies 70 (2): 31741. 
63. Limão, Nuno, and Giovanni Maggi. "Uncertainty and Trade Agreements." American Economic Journal: Microeconomics. Forthcoming.

64. Lin, Jenny, and William Lincoln. 2015. "U.S. Firm Exports and Intellectual Property Rights." Claremont McKenna College, mimeo.

65. Loretan, Mico. 2005. "Indexes of the Foreign Exchange Value of the Dollar." Federal Reserve Bulletin, vol. 91 (Winter): 1-8.

66. Maskus, Keith, John Wilson, and Tsunehiro Otsuki. 2000. "Quantifying the Impact of Technical Barriers to Trade." World Bank Policy Research Working Paper 2512.

67. McCallum, Andrew H. 2015. "The Structure of Export Entry Costs." Federal Reserve Board, mimeo.

68. Melitz, Marc J. 2003. "The Impact of Trade on Intra-Industry Reallocations and Aggregate Industry Productivity." Econometrica 71 (6): 1695-725.

69. Morales, Eduardo, Gloria Sheu, and Andrés Zahler. 2015. "Extended Gravity." Princeton University, mimeo.

70. Moretti, Enrico. 2012. The New Geography of Jobs. New York: Houghton Mifflin Harcourt.

71. Moxnes, Andreas. 2010. "Are Sunk Costs in Exporting Country Specific?" Canadian Journal of Economics 43 (2): 467-93.

72. Mukerji, Purba. 2009. "Trade Liberalization and the Extensive Margin." Scottish Journal of Political Economy 56 (2): 141-66.

73. Mundlak, Yair. 1978. "On the Pooling of Time Series and Cross Section Data." Econometrica 46 (1): 69-85.

74. Nickell, Stephen. 1981. "Biases in Dynamic Models with Fixed Effects." Econometrica 49 (6): 1417-26.

75. Oaxaca, Ronald. 1973. "Male-Female Wage Differentials in Urban Labor Markets." International Economic Review 14 (3): 693-709.

76. Roberts, Mark, and James R. Tybout. 1997a. "Directions in Development: What Makes Exports Boom?" Washington, D.C.: World Bank.

77. —. 1997b. "The Decision to Export in Colombia: An Empirical Model of Entry with Sunk Costs." American Economic Review 87 (4): 545-64. 
78. Rust, John. 1997. "Using Randomization to Break the Curse of Dimensionality." Econometrica 65 (3): 487-516.

79. Steinwender, Claudia. 2015. "Information Frictions and the Law of One Price: 'When the States and the Kingdom Became United.'" Princeton University, mimeo.

80. Stewart, Mark. 2007. "The Interrelated Dynamics of Unemployment and Low-Wage Employment." Journal of Applied Econometrics 22 (3): 511-31.

81. United Nations Conference on Trade and Development. 2005. "Methodologies, Classifications, Quantification and Development Impacts of Non-Tariff Barriers." United Nations Conference on Trade and Development Commission Report.

82. U.S. Department of Commerce. 2004. "Measuring Economic Effects of Technical Barriers to Trade on U.S. Exporters." Planning Report 04-3. Washington: U.S. Government Printing Office.

83. U.S. Trade Representative. 2011. "2011 Report on Technical Barriers to Trade." Washington: United States Government Publishing Office.

84. Whalley, John, and Xin Xian. 2015. "Regionalization, Changes in Home Bias, and the Growth of World Trade." Journal of Policy Modeling, forthcoming. 
Table 1: Top Ten Countries That Contributed to the Rise in Exporting

\begin{tabular}{clr}
\hline \hline Rank & Country & Percentage \\
\hline 1 & Mexico & 12.1 \\
2 & China & 11.0 \\
3 & India & 4.9 \\
4 & Brazil & 3.7 \\
5 & South Korea & 3.3 \\
6 & United Kingdom & 3.1 \\
7 & United Arab Emirates & 2.9 \\
8 & Germany & 2.8 \\
9 & Malaysia & 2.8 \\
10 & Australia & 2.7 \\
\hline
\end{tabular}

Notes: The table lists the top ten countries in terms of their contribution to the change in the total number of firm-country pairs with exports from 1993 to 2006. Estimations are for manufacturing firms with 20 or more employees using the Longitudinal Firm Trade Transactions Database (LFTTD).

Table 2: LFTTD Regional and Firm Size Decomposition

\begin{tabular}{lrr|lrr}
\hline \hline Region & 1993 & 2006 & Employees & 1993 & 2006 \\
\hline New England & 5.6 & 8.4 & $20-49$ & 1.4 & 2.6 \\
Middle Atlantic & 4.1 & 7.1 & $50-149$ & 3.6 & 5.9 \\
East North Central & 4.1 & 6.4 & $150-249$ & 7.5 & 10.7 \\
West North Central & 3.9 & 5.8 & $250-499$ & 10.3 & 14.8 \\
South Atlantic & 3.2 & 4.9 & $500-999$ & 15.6 & 22.9 \\
East South Central & 2.7 & 4.3 & $1000+$ & 36.1 & 41.9 \\
West South Central & 3.2 & 4.6 & & & \\
Mountain & 3.5 & 4.7 & & & \\
Pacific & 4.5 & 6.4 & & & \\
\hline
\end{tabular}

Notes: The table reports the probability that a given firm sells goods to one of the top 50 export destinations in 1993 and 2006, broken down by the region of the United States in which the firm is located and by firm size category. The states corresponding to each region are listed in the appendix. Results broken down by industry are contained in Figure 2. Estimations are for manufacturing firms with 20 or more employees and draw on the LFTTD. Increases in exporting are found across industries, regions, and firm size categories. 
Table 3: ASM Industry, Regional, and Firm Size Decomposition

\begin{tabular}{lrr|lrr}
\hline \hline Industry & 1987 & 2006 & Region & 1987 & 2006 \\
\hline Food & 15 & 30 & New England & 25 & 46 \\
Beverage \& Tobacco & 45 & 30 & Middle Atlantic & 19 & 39 \\
Textile Mill Products & 16 & & East North Central & 25 & 45 \\
$\quad$ (Textile Mills) & & 47 & West North Central & 23 & 41 \\
$\quad$ (Textile Product Mills) & & 35 & South Atlantic & 18 & 36 \\
Apparel & 5 & 19 & East South Central & 18 & 36 \\
Wood products & 12 & 19 & West South Central & 19 & 33 \\
Furniture & 10 & 20 & Mountain & 18 & 30 \\
Paper & 19 & 43 & Pacific & 21 & 36 \\
Printing \& Publishing & 5 & 15 & & & \\
Chemicals & 40 & 63 & & & \\
\cline { 4 - 6 } Petroleum \& Coal & 22 & 37 & Employment & 1987 & 2006 \\
\cline { 4 - 6 } Plastics \& Rubber & 26 & 51 & $20-49$ & 11 & 23 \\
Leather & 19 & 47 & $50-149$ & 22 & 41 \\
Non-metallic Minerals & 14 & 17 & $150-249$ & 33 & 54 \\
Primary Metals & 27 & 56 & $250-499$ & 42 & 61 \\
Fabricated Metals & 21 & 32 & $500-999$ & 54 & 69 \\
Machinery & 33 & 62 & $1000+$ & 70 & 78 \\
Electrical Equipment & 37 & 65 & & & \\
Instruments/Computer \& & 48 & 68 & & & \\
$\quad$ Electronic Products & & & & & \\
Transportation Equipment & 29 & 56 & & & \\
Misc. Manufacturing & 20 & 42 & & & \\
\hline
\end{tabular}

Notes: The table lists the percentage of manufacturing plants that export to at least one country abroad using the Census of Manufactures in 1987 and the Annual Survey of Manufactures in 2006. Results are broken down by industry, region, and firm size. The states corresponding to each region are listed in the appendix. Due to concerns about disclosure, the industry figures for 1987 are from Bernard and Jensen (2004b) and we report the results for 1987 in two digit 1987 SIC codes and the results for 2006 in three digit 2002 NAICS codes. These industry codes match well at this level of aggregation. Estimations are for plants with 20 or more employees. Increases in exporting are found across industries, regions, and plant size categories. 
Table 4: Fixed Effects Estimations

\begin{tabular}{|c|c|c|c|}
\hline \multirow[b]{2}{*}{ Variable } & \multicolumn{3}{|c|}{ Specification } \\
\hline & $\begin{array}{l}\text { Without } \\
\text { Interactions } \\
(1)\end{array}$ & $\begin{array}{l}\text { Baseline } \\
\text { (2) }\end{array}$ & $\begin{array}{l}\text { Additional } \\
\text { Interactions } \\
(3)\end{array}$ \\
\hline Exported last year & $\begin{array}{l}0.439^{* *} \\
(0.005)\end{array}$ & $\begin{array}{l}0.436^{* *} \\
(0.006)\end{array}$ & $\begin{array}{l}0.431^{* *} \\
(0.006)\end{array}$ \\
\hline Exported last year $*$ Post $_{98}$ & & $\begin{array}{l}0.005 \\
(0.005)\end{array}$ & $\begin{array}{l}0.012^{* *} \\
(0.006)\end{array}$ \\
\hline Last exported two years ago & $\begin{array}{l}0.103^{* *} \\
(0.007)\end{array}$ & $\begin{array}{l}0.140^{* *} \\
(0.009)\end{array}$ & $\begin{array}{l}0.138^{* *} \\
(0.009)\end{array}$ \\
\hline Last exported two years ago $*$ Post $_{98}$ & & $\begin{array}{l}-0.091^{* *} \\
(0.013)\end{array}$ & $\begin{array}{l}-0.087^{* *} \\
(0.013)\end{array}$ \\
\hline $\ln$ (Employment) & $\begin{array}{l}0.031^{* *} \\
(0.005)\end{array}$ & $\begin{array}{l}0.031^{* *} \\
(0.005)\end{array}$ & $\begin{array}{l}0.030^{* *} \\
(0.006)\end{array}$ \\
\hline $\ln$ (Wages) & $\begin{array}{l}0.026^{* *} \\
(0.008)\end{array}$ & $\begin{array}{l}0.026^{* *} \\
(0.008)\end{array}$ & $\begin{array}{l}0.039^{* *} \\
(0.010)\end{array}$ \\
\hline Non-production/Total Employment & $\begin{array}{l}-0.021 \\
(0.016)\end{array}$ & $\begin{array}{l}-0.021 \\
(0.016)\end{array}$ & $\begin{array}{l}-0.003 \\
(0.018)\end{array}$ \\
\hline $\ln$ (Productivity) & $\begin{array}{l}0.005^{* *} \\
(0.002)\end{array}$ & $\begin{array}{l}0.005^{* *} \\
(0.002)\end{array}$ & $\begin{array}{l}0.007^{* *} \\
(0.002)\end{array}$ \\
\hline ln (Exchange Rate) & $\begin{array}{l}0.060 \\
(0.031)\end{array}$ & $\begin{array}{l}0.057 \\
(0.032)\end{array}$ & $\begin{array}{l}0.031 \\
(0.044)\end{array}$ \\
\hline Plant Fixed Effects & Yes & Yes & Yes \\
\hline Year Fixed Effects & Yes & Yes & Yes \\
\hline Interactions between $X_{i t}$ and Post $_{98}$ & No & No & Yes \\
\hline$R^{2}$ & 0.552 & 0.553 & 0.552 \\
\hline
\end{tabular}

Notes: The table presents the results from estimating equation (3) in the text. The baseline estimations in column (2) suggest no decline in initial entry costs and an increase in the re-entry cost. The coefficient on "Exported last year" is an increasing function of the costs of entering foreign markets anew, $F_{0}$. The coefficient on "Last exported two years ago" is similarly an increasing function of the difference $F_{0}-F_{R}$, where $F_{R}$ is the cost of re-entering foreign markets after leaving in the previous year. Post ${ }_{98}$ is an indicator function for the post1998 part of the sample. The dependent variable is a $0 / 1$ indicator for a given plant's export status in the current year. Column (1) presents the results from estimating equation (3) with no interactions and column (2) contains our baseline results. Column (3) reports results from additionally including interactions between the variables in $X_{i t}$ and Post $t_{98}$. Plant specific characteristics in $X_{i t}$ are lagged by one period in all specifications. All estimations include 106,000 observations (this figure is rounded to the nearest 100 observations for the purposes of disclosure). Standard errors in parentheses are clustered at the plant level. The results with ${ }^{* *}$ denote significance at the 5 percent level. 
Table 5: Butler-Moffitt Estimations

\begin{tabular}{|c|c|c|c|c|}
\hline \multirow[b]{2}{*}{ Variable } & \multicolumn{4}{|c|}{ Specification } \\
\hline & $\begin{array}{l}\text { Earlier } \\
(1)\end{array}$ & $\begin{array}{l}\text { Later } \\
(2)\end{array}$ & $\begin{array}{l}\text { Earlier } \\
(3)\end{array}$ & $\begin{array}{l}\text { Later } \\
(4)\end{array}$ \\
\hline Exported last year & $\begin{array}{l}1.476^{* *} \\
(0.022)\end{array}$ & $\begin{array}{l}1.792^{* *} \\
(0.026)\end{array}$ & $\begin{array}{l}1.424^{* *} \\
(0.021)\end{array}$ & $\begin{array}{l}1.771^{* *} \\
(0.026)\end{array}$ \\
\hline $\ln$ (Employment) & & & $\begin{array}{l}0.152^{* *} \\
(0.023)\end{array}$ & $\begin{array}{l}0.139^{* *} \\
(0.028)\end{array}$ \\
\hline $\ln$ (Wages) & & & $\begin{array}{l}0.963^{* *} \\
(0.049)\end{array}$ & $\begin{array}{l}0.704^{* *} \\
(0.059)\end{array}$ \\
\hline $\begin{array}{l}\text { Non-production/ } \\
\text { Total Employment }\end{array}$ & & & $\begin{array}{l}-0.033 \\
(0.088)\end{array}$ & $\begin{array}{l}-0.250^{* *} \\
(0.107)\end{array}$ \\
\hline $\ln$ (Productivity) & & & $\begin{array}{l}0.023^{* *} \\
(0.007)\end{array}$ & $\begin{array}{l}0.006 \\
(0.009)\end{array}$ \\
\hline $\ln$ (Exchange Rate) & & & $\begin{array}{l}-0.738 \\
(0.444)\end{array}$ & $\begin{array}{l}-1.116^{* *} \\
(0.291)\end{array}$ \\
\hline$\rho=\sigma_{\zeta}^{2} /\left(\sigma_{\zeta}^{2}+\sigma_{\varepsilon}^{2}\right)$ & $\begin{array}{c}0.381^{* *} \\
(0.011)\end{array}$ & $\begin{array}{l}0.379^{* *} \\
(0.014)\end{array}$ & $\begin{array}{c}0.363^{* *} \\
(0.011)\end{array}$ & $\begin{array}{l}0.373^{* *} \\
(0.014)\end{array}$ \\
\hline Average Partial Effect & 0.418 & 0.463 & 0.394 & 0.453 \\
\hline
\end{tabular}

Notes: The table presents the results from estimating equation (3) in the text with the dynamic random effects estimator of Butler and Moffitt (1982). The results suggest a modest increase in initial entry costs. The coefficient on "Exported last year" is an increasing function of the costs of entering foreign markets anew, $F_{0}$. The dependent variable is a $0 / 1$ indicator for a given plant's export status in the current year. Year effects are included in each specification. The average partial effect refers to the effect of exporting last year on the probability of exporting this year. The earlier period considers 1987-1997 and the later period considers 1995-2006 where both are balanced panels of plants. All estimations include 54,300 observations in the first panel and 43,100 observations in the second (both of these figures are rounded to the nearest 100 observations for the purposes of disclosure). Standard errors are in parentheses. The results with ${ }^{* *}$ denote significance at 5 percent level. 
Table 6: Prior Distributions

\begin{tabular}{ll}
\hline \hline Parameters & Priors \\
\hline$\gamma_{s 1}$ (sunk cost, small plants) & $\gamma_{s 1} \sim N(0,20)$ \\
$\gamma_{s 2}$ (sunk cost, large plants) & $\gamma_{s 2} \sim N(0,20)$ \\
$\kappa$ (mean, $\left.\varepsilon_{1} \& \varepsilon_{2}\right)$ & $\kappa \sim N(0,20)$ \\
$\sigma_{\varepsilon 1}$ (st. dev., $\left.\varepsilon_{1}\right)$ & $\ln \left(\sigma_{\varepsilon 1}\right) \sim N(0,2)$ \\
$\sigma_{\varepsilon 2}$ (st. dev., $\left.\varepsilon_{2}\right)$ & $\ln \left(\sigma_{\varepsilon 2}\right) \sim N(0,2)$ \\
$\eta_{i}$ (demand elasticity) & $\ln \left(\eta_{i}-1\right) \sim N(2,1)$ \\
\hline
\end{tabular}

Notes: The table presents the priors used for the main parameters in our structural estimations. The same priors are used for each of our estimations. We generally choose diffuse priors to allow the data to speak for themselves. Variance parameters have log normal distributions to impose non-negativity. The prior on the elasticity parameters is consistent with evidence from the prior literature. 
Table 7: Monte Carlo Markov Chain Estimations

\begin{tabular}{lrr}
\hline \hline & \multicolumn{2}{c}{ Panel } \\
Parameters for Each Industry & $1987-1997$ & $1995-2006$ \\
\hline Preserved Fruits \& Vegetables (SIC 203) & & \\
$\gamma_{s 1}$ (sunk cost, small plants) & $2.85(0.80)$ & $2.49(0.41)$ \\
$\gamma_{s 2}$ (sunk cost, large plants) & $2.65(0.74)$ & $2.26(0.36)$ \\
$\kappa$ (mean of profit shock $\varepsilon$ ) & $-0.14(0.04)$ & $-0.17(0.03)$ \\
$\sigma_{\varepsilon_{1}}$ (std. error, $\varepsilon_{1}$ ) & $1.55(0.48)$ & $1.17(0.32)$ \\
$\sigma_{\varepsilon_{2}}$ (std. error, $\varepsilon_{2}$ ) & $0.90(0.38)$ & $0.62(0.38)$ \\
$\eta_{\mu}$ (demand elas., $\mu$ across plants) & $13.71(8.81)$ & $12.93(6.16)$ \\
$\eta_{\sigma}$ (demand elas., $\sigma$ across plants) & $11.61(7.35)$ & $12.59(6.67)$ \\
& & \\
Aircraft \& Parts (SIC 372) & & \\
$\gamma_{s 1}$ (sunk cost, small plants) & $2.39(0.62)$ & $2.90(0.65)$ \\
$\gamma_{s 2}$ (sunk cost, large plants) & $2.45(0.65)$ & $2.54(0.59)$ \\
$\kappa$ (mean of profit shock $\varepsilon$ ) & $-0.24(0.07)$ & $-0.26(0.07)$ \\
$\sigma_{\varepsilon_{1}}$ (std. error, $\varepsilon_{1}$ ) & $1.09(0.40)$ & $1.11(0.29)$ \\
$\sigma_{\varepsilon_{2}}$ (std. error, $\varepsilon_{2}$ ) & $0.85(0.38)$ & $1.06(0.40)$ \\
$\eta_{\mu}$ (demand elas., $\mu$ across plants) & $12.20(4.82)$ & $11.86(4.17)$ \\
$\eta_{\sigma}$ (demand elas., $\sigma$ across plants) & $12.80(5.56)$ & $12.16(4.55)$ \\
& & \\
Measuring \& Controlling Devices (SIC 382$)$ & & \\
$\gamma_{s 1}$ (sunk cost, small plants) & $2.89(0.98)$ & $2.62(0.93)$ \\
$\gamma_{s 2}$ (sunk cost, large plants) & $2.66(0.89)$ & $3.29(1.21)$ \\
$\kappa$ (mean of profit shock $\varepsilon$ ) & $-0.56(0.32)$ & $-0.95(0.74)$ \\
$\sigma_{\varepsilon_{1}}$ (std. error, $\varepsilon_{1}$ ) & $1.60(0.55)$ & $1.35(0.64)$ \\
$\sigma_{\varepsilon_{2}}$ (std. error, $\varepsilon_{2}$ ) & $1.12(0.84)$ & $2.75(2.17)$ \\
$\eta_{\mu}$ (demand elas., $\mu$ across plants) & $10.95(6.39)$ & $10.58(5.49)$ \\
$\eta_{\sigma}$ (demand elas., $\sigma$ across plants) & $7.76(4.81)$ & $7.85(4.46)$ \\
\hline
\end{tabular}

Notes: The table presents the estimates for the main parameters in our model for each industry over the time periods 1987-1997 and 1995-2006. Means are presented along with the standard deviations of the posterior distribution in parentheses. Median values and estimates based on thinning each chain give similar results. Figures are in 1987 dollars. To get a sense of how the results compare, we considered the probability mass in the sunk cost parameter distribution (the percentage of draws) for the 1995-2006 panel that lies above the expected value in the 1987-1997 panel. The results are intuitive. For Preserved Fruits and Vegetables the figures are 19 percent and 40 percent for small and large plants, respectively; for Aircraft and Parts they are 75 percent and 59 percent; and, for Measuring and Controlling Devices they are 41 percent and 65 percent. The full results for each industry are found in the appendix. 
Table 8: Factors Affecting Export Participation

\begin{tabular}{lrr}
\hline \hline & Mean & Mean \\
Variable & 1993 & 2006 \\
\hline Internet Users (m) & 0.08 & 16.18 \\
Trade Agreement (pct) & 4.00 & 18.00 \\
Market Size (bn 2000 USD) & 408.51 & 557.90 \\
Tariffs (VAE) & 13.69 & 7.37 \\
Real Exchange Rate (NCU/USD) & 93.02 & 93.05 \\
Distance (thousands of km) & 8.71 & 8.71 \\
Contiguous (pct) & 4.00 & 4.00 \\
Common Language (pct) & 22.00 & 22.00 \\
Common Legal Origin (pct) & 28.00 & 28.00 \\
Common Currency (pct) & 2.00 & 4.00 \\
Landlocked (pct) & 4.00 & 4.00 \\
Colonial Relationship (pct) & 8.00 & 8.00 \\
Time Difference (hours) & 6.93 & 6.93 \\
\hline
\end{tabular}

Notes: The table gives summary statistics on the variables in our regressions that affected the rise in export participation between 1993 and 2006. Units are indicated in parentheses. The real exchange rate reported here is an index for each country with base year 2000 set equal to 100 and calculated with respect to U.S. dollars in the same year. The regression uses exchange rates without a common base year in order to allow for consistent interpretation with the market size variable. These exchange rates have mean 182.41 and 204.72 in 1993 and 2006 respectively. For variables that are binary indicators, we list the percentage of the 50 countries in our sample for which they equal one. For example, two out of the 50 countries had a trade agreement with the United States in 1993 and nine had one in 2006. 
Table 9: Oaxaca-Blinder Estimations

\begin{tabular}{|c|c|c|c|c|}
\hline \multirow[b]{3}{*}{ Year } & \multicolumn{4}{|c|}{ Specification } \\
\hline & \multicolumn{2}{|c|}{$(1)$} & \multicolumn{2}{|c|}{$(2)$} \\
\hline & 1993 & 2006 & 1993 & 2006 \\
\hline \multirow[t]{2}{*}{$\ln$ (Internet Users) } & $0.28^{* *}$ & $1.06^{* *}$ & $0.28^{* *}$ & $1.06^{* *}$ \\
\hline & $(0.005)$ & $(0.022)$ & $(0.005)$ & $(0.022)$ \\
\hline \multirow[t]{2}{*}{ Trade Agreement } & $6.96^{* *}$ & $1.27^{* *}$ & $6.96^{* *}$ & $1.27^{* *}$ \\
\hline & $(0.065)$ & $(0.031)$ & $(0.065)$ & $(0.031)$ \\
\hline \multirow[t]{2}{*}{ ln (Market Size) } & $1.23^{* *}$ & $1.25^{* *}$ & $1.23^{* *}$ & $1.25^{* *}$ \\
\hline & $(0.012)$ & $(0.025)$ & $(0.012)$ & $(0.025)$ \\
\hline \multirow[t]{2}{*}{$\ln$ (Tariffs) } & $-1.25 * *$ & $-2.37 * *$ & $-1.25^{* *}$ & $-2.37^{* *}$ \\
\hline & $(0.075)$ & $(0.158)$ & $(0.075)$ & $(0.158)$ \\
\hline \multirow[t]{2}{*}{ Common Currency } & $1.83^{* *}$ & $1.41^{* *}$ & $1.83^{* *}$ & $1.41^{* *}$ \\
\hline & $(0.038)$ & $(0.039)$ & $(0.038)$ & $(0.039)$ \\
\hline \multirow[t]{2}{*}{ ln (Real Exchange Rate) } & $-0.05^{* *}$ & $-0.05^{* *}$ & $-0.05^{* *}$ & $-0.05^{* *}$ \\
\hline & $(0.003)$ & $(0.005)$ & $(0.003)$ & $(0.005)$ \\
\hline \multirow[t]{2}{*}{$\ln ($ Distance $)$} & $-1.46^{* *}$ & $-2.26^{* *}$ & $-1.46^{* *}$ & $-2.26^{* *}$ \\
\hline & $(0.034)$ & $(0.046)$ & $(0.034)$ & $(0.046)$ \\
\hline \multirow[t]{2}{*}{ Contiguity } & $5.52^{* *}$ & $10.42^{* *}$ & $5.52^{* *}$ & $10.42^{* *}$ \\
\hline & $(0.075)$ & $(0.109)$ & $(0.075)$ & $(0.109)$ \\
\hline \multirow[t]{2}{*}{ Common Language } & $0.72^{* *}$ & $2.38^{* *}$ & $0.72^{* *}$ & $2.38^{* *}$ \\
\hline & $(0.028)$ & $(0.039)$ & $(0.028)$ & $(0.039)$ \\
\hline \multirow[t]{2}{*}{ Common Legal Origin } & $2.19^{* *}$ & $2.41^{* *}$ & $2.19^{* *}$ & $2.41^{* *}$ \\
\hline & $(0.027)$ & $(0.035)$ & $(0.027)$ & $(0.035)$ \\
\hline \multirow[t]{2}{*}{ Landlocked } & $-0.58 * *$ & $-0.30 * *$ & $-0.58^{* *}$ & $-0.30 * *$ \\
\hline & $(0.036)$ & $(0.044)$ & $(0.036)$ & $(0.044)$ \\
\hline \multirow[t]{2}{*}{ Colonial Relationship } & $0.99^{* *}$ & -0.02 & $0.99^{* *}$ & -0.02 \\
\hline & $(0.034)$ & $(0.042)$ & $(0.034)$ & $(0.042)$ \\
\hline \multirow[t]{2}{*}{ Time Difference } & $-0.21^{* *}$ & $-0.09 * *$ & $-0.21^{* *}$ & $-0.09 * *$ \\
\hline & $(0.005)$ & $(0.008)$ & $(0.005)$ & $(0.008)$ \\
\hline \multirow[t]{2}{*}{$\ln ($ Employment $)$} & $3.45^{* *}$ & $2.89^{* *}$ & & \\
\hline & $(0.084)$ & $(0.106)$ & & \\
\hline \multirow[t]{2}{*}{$\ln$ (Wages) } & $1.57^{* *}$ & $3.11^{* *}$ & & \\
\hline & $(0.044)$ & $(0.072)$ & & \\
\hline SIC Four Digit Industry Fixed Effects & Yes & Yes & No & No \\
\hline Census Division Region Fixed Effects & Yes & Yes & No & No \\
\hline Firm Fixed Effects & No & No & Yes & Yes \\
\hline$R^{2}$ & 0.170 & 0.173 & 0.336 & 0.352 \\
\hline
\end{tabular}

Notes: The table presents the results from estimating equation (12) in the text. The sample includes 4,085,000 observations and 81,700 firms in 1993 and 3,665,000 observations and 73,300 firms in 2006 (both of these figures are rounded to the nearest 100 observations for the purposes of disclosure). The dependent variable is a $0 / 1$ indicator for a firm's export status to a given country in the specified year $y_{i c}^{t}$. Standard errors clustered at the firm level are in parentheses. The results with ${ }^{* *}$ denote significance at the 5 percent level. 
Table 10: Oaxaca-Blinder Decomposition

\begin{tabular}{|c|c|c|c|c|}
\hline & \multicolumn{4}{|c|}{ Specification } \\
\hline & (1) & & $(2)$ & \\
\hline & Percentage & & Percentage & \\
\hline & Points & Percent & Points & Percent \\
\hline Internet Users & $\begin{array}{l}1.79^{* *} \\
(0.03)\end{array}$ & 47.61 & $\begin{array}{l}1.79^{* *} \\
(0.03)\end{array}$ & 50.85 \\
\hline Trade Agreement & $\begin{array}{l}0.97^{* *} \\
(0.01)\end{array}$ & 25.80 & $\begin{array}{l}0.97^{* *} \\
(0.01)\end{array}$ & 27.56 \\
\hline Market Size & $\begin{array}{l}0.65^{* *} \\
(0.01)\end{array}$ & 17.29 & $\begin{array}{l}0.65 * * \\
(0.01)\end{array}$ & 18.47 \\
\hline Tariffs & $\begin{array}{l}0.07^{* *} \\
(0.00)\end{array}$ & 1.86 & $\begin{array}{l}0.07^{* *} \\
(0.00)\end{array}$ & 1.99 \\
\hline Common Currency & $\begin{array}{l}0.04^{* *} \\
(0.00)\end{array}$ & 1.06 & $\begin{array}{l}0.04^{* *} \\
(0.00)\end{array}$ & 1.14 \\
\hline Real Exchange Rate & $\begin{array}{l}-0.00 \\
(0.00)\end{array}$ & 0.00 & $\begin{array}{l}-0.00 \\
(0.00)\end{array}$ & 0.00 \\
\hline Employment & $\begin{array}{l}0.04^{* *} \\
(0.00)\end{array}$ & 1.06 & & \\
\hline Wages & $\begin{array}{l}0.20^{* *} \\
(0.01)\end{array}$ & 5.32 & & \\
\hline Total & 3.76 & 100.00 & 3.52 & 100.00 \\
\hline
\end{tabular}

Notes: The increase in the number of internet users, free trade agreements, and income growth account for most of the explained rise in export participation. The table reports the results from the Oaxaca-Blinder decomposition using the estimates of each specification in Table 9. We focus on the contribution of observable factors to the rise in exporting. Variables that do not vary over time do not play a role in these changes and so we limit our attention here to time varying factors. The first and third columns contain the estimated change in the predicted probability of exporting to a given country due to shifts in each covariate. The second and fourth columns contain the share of each factor on the overall change in the predicted probability of exporting due to shifts in observable characteristics. Standard errors clustered at the firm level are in parentheses. The results with ${ }^{* *}$ denote significance at the 5 percent level. 
Fig. 1: Export Participation Across Countries

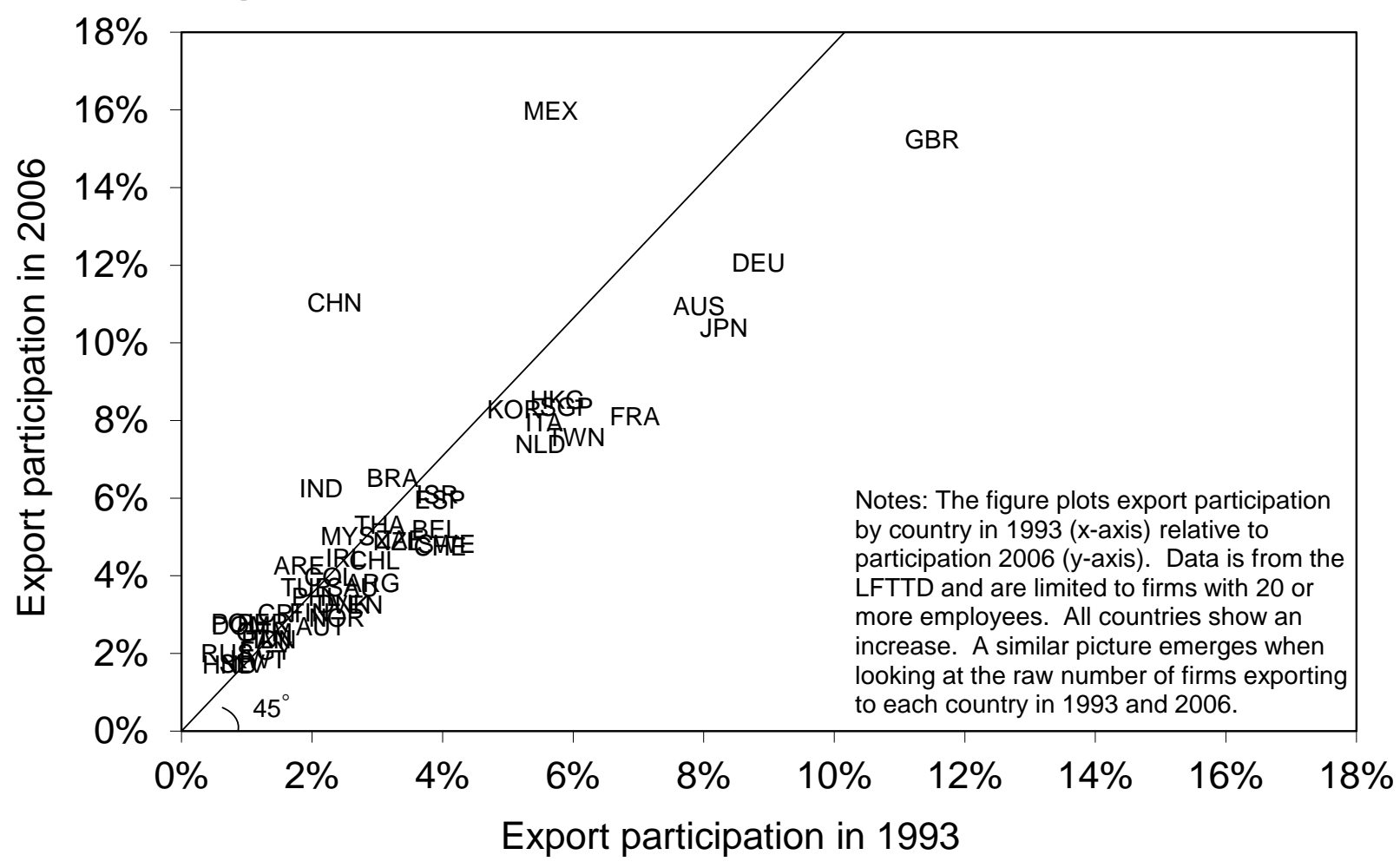

Fig. 2: Industry Decomposition

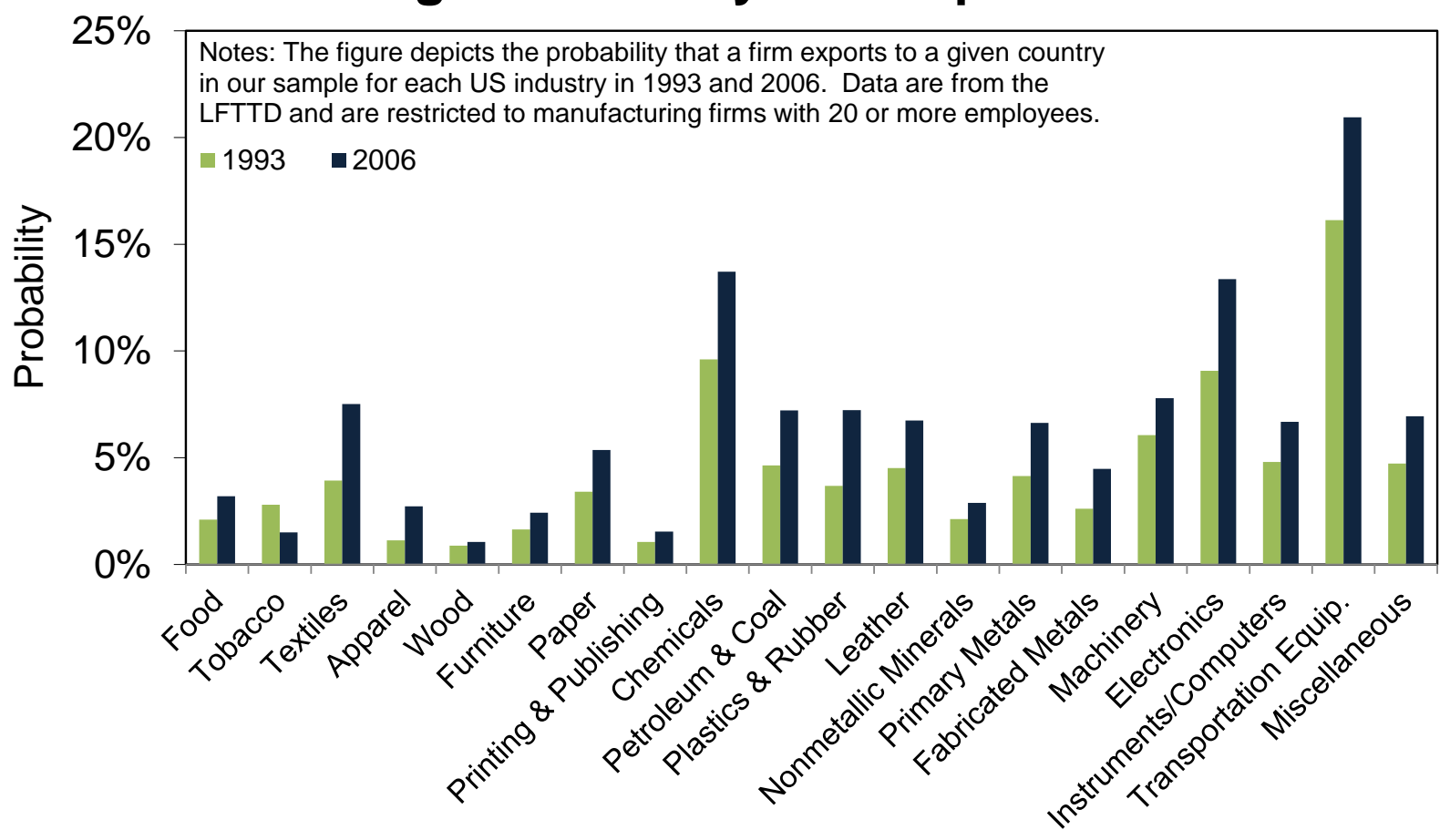

Industry 


\section{Fig. 3: Percentage of U.S. Manufacturing Plants That Export}

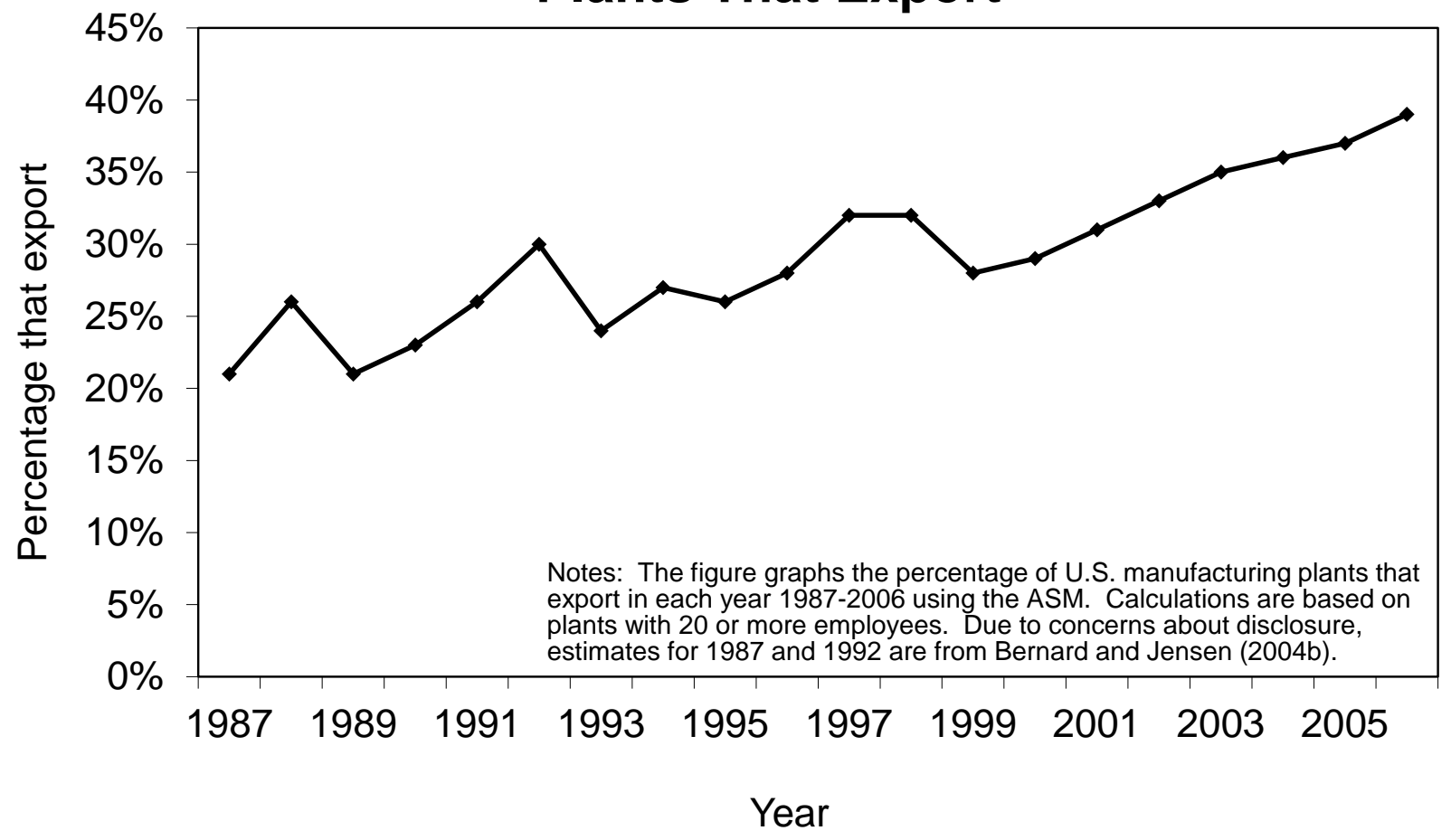

Fig. 4: Changes in Barriers to Entry

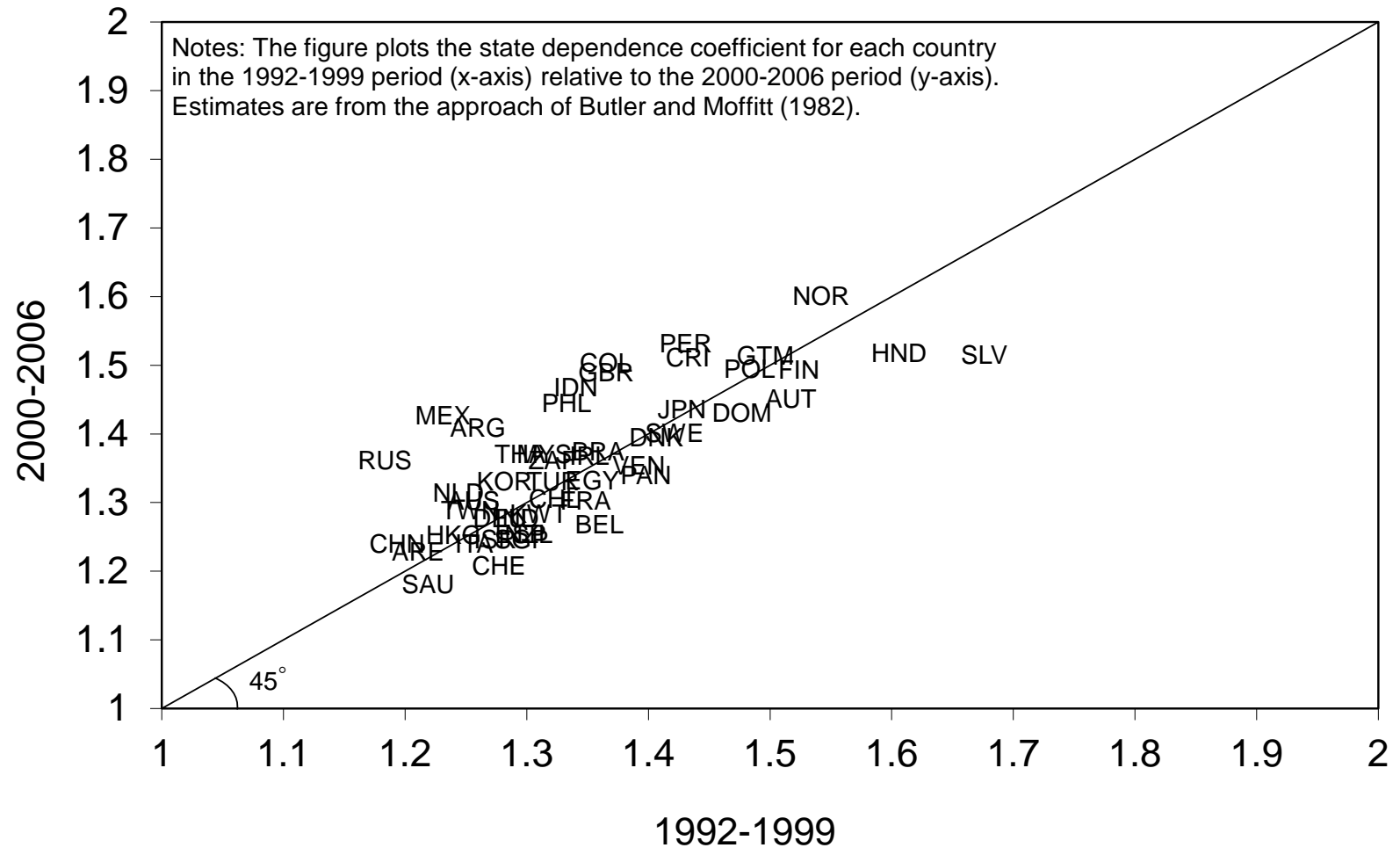


Fig. 5: Number of Firms Exporting To Mexico

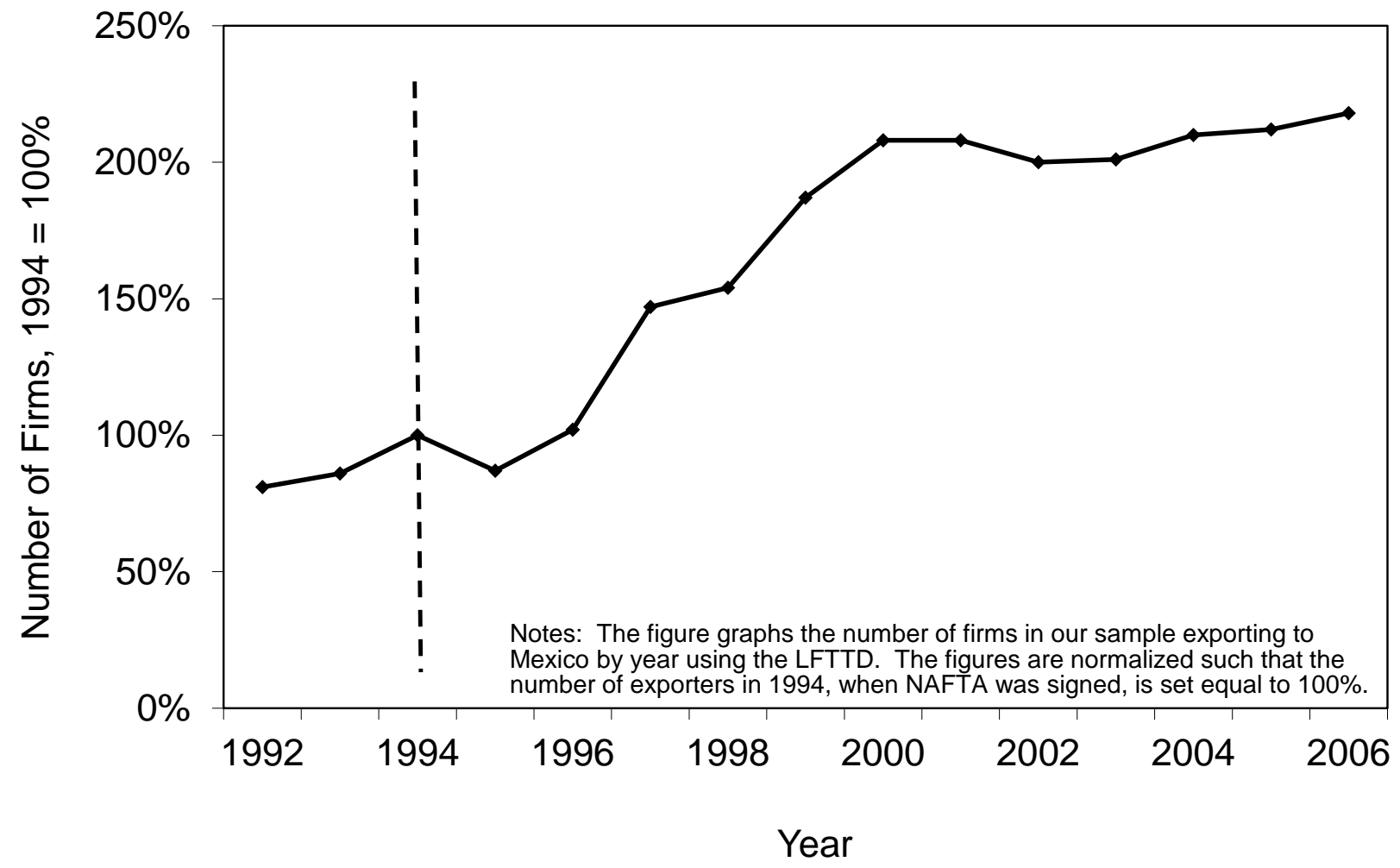

Fig. 6: Market Size and the Rise of Exporting

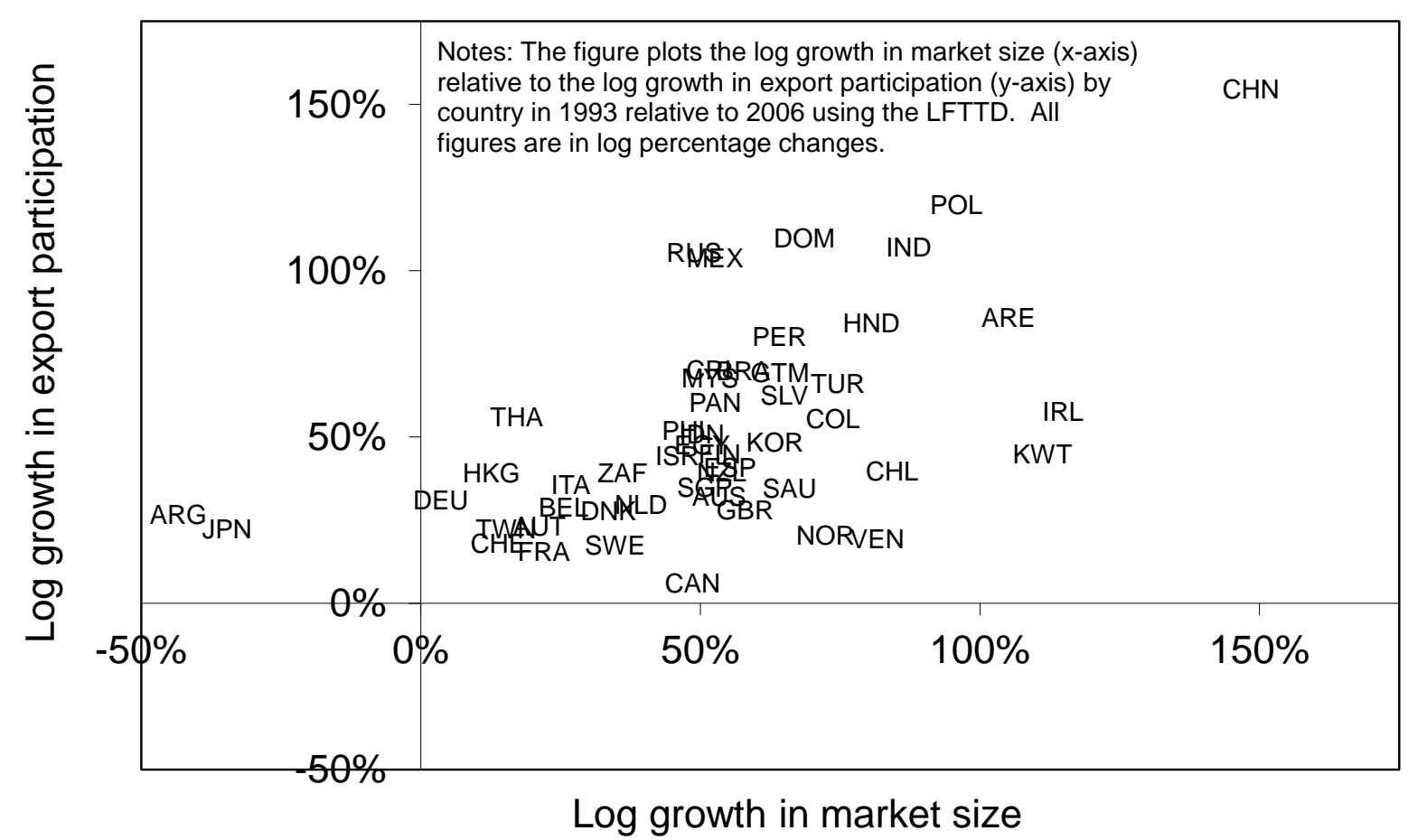




\section{Fig. 7: Internet Use and the Rise of Exporting}

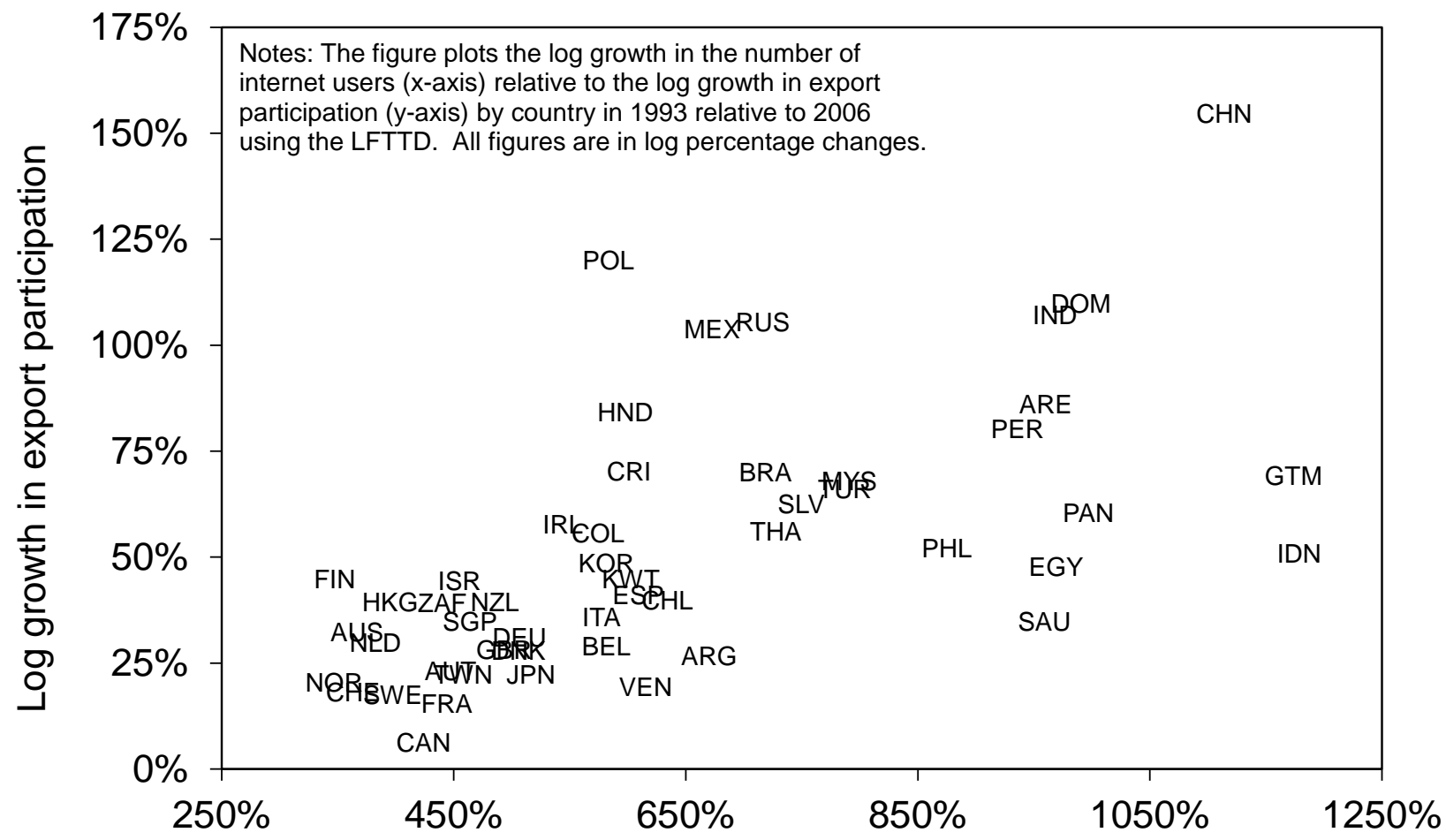

Log growth in number of internet users 


\title{
Appendix to \\ "The Rise of Exporting By U.S. Firms"
}

\author{
William F. Lincoln \\ Claremont McKenna College \\ Andrew H. McCallum \\ Board of Governors of the Federal Reserve \\ January 2016
}




\section{Introduction}

In this appendix we begin by describing additional details about the Annual Survey of Manufactures (ASM) and the Longitudinal Firm Trade Transactions Database (LFTTD). We then discuss several new stylized facts that we have documented, including those mentioned in the main text as well as additional analyses. The next section discusses our estimations on how barriers to entry in foreign markets have changed over time at further length. We close by describing more about the data that we use in Section 4 of the main text to understand the sources of the rise of exporting by U.S. firms.

\section{$2 \quad$ Data and Stylized Facts}

\subsection{Data}

In all of our analyses using both the ASM and LFTTD we drop administrative records, which are essentially imputed data for small employers and new businesses. All establishment level estimations are done using the identifier lbdnum and all firm level estimations are done using the identifier firmid. With the LFTTD we drop observations with no country identifier and only keep shipments of U.S. origin. Data are collected for every export transaction greater than $\$ 2,500$, and we replace all values of shipments below $\$ 2,500$ with 0 for the sake of consistency. Appendix Table 1 reports the countries in our sample that uses the LFTTD. Due to data disclosure concerns, estimates in Figure 3 of the main text for 1987 and 1992 as well as the percentages in Table 3 of the main text for 1987 are from Bernard and Jensen (2004b). As this study also focuses on plants with 20 or more employees, we adopt a similar approach both for the purposes of the disclosure of the results from the U.S. Census Bureau as well as for comparability. In Appendix Figure 1 we present the shipper's export declaration form from U.S. Customs and Border Protection that is the basis for the collection of the LFTTD data.

Due to changes in the sampling frame for the ASM, we needed to make some minor adjustments to the sample. Over the period 1987-1998 plants with 250 or more employees were sampled with certainty. In 1999-2003 this threshold was increased to 500 employees and was further raised to 1,000 in the 2004-2008 ASM. In our estimations that span these years, we reweight the plants accordingly. As the sampling probability is inversely related to a plant's contribution to output, however, plants between 250 and 1,000 employees are still sampled with a high degree of certainty after 1998. These reweighting adjustments consequently did not end up affecting the sample significantly. In order to estimate plant productivity with the ASM, we also needed to construct the capital stock for each plant. We did so using the perpetual inventory method and book values are used as initial measures. Productivity is measured with the semiparametric approach of Levinsohn and Petrin (2003).

In addition to the data described in the main text, we use information from a number of additional sources. Information on price deflators is obtained from the NBER manufacturing productivity database (Bartelsman and Gray 1996). Exchange rate series are sourced from the International Monetary Fund and the Federal Reserve Bank of New York. In order to construct a plant specific exchange rate series in our estimations using the ASM, we use a 
geometric export weighted average of bilateral real exchange rates. This aggregation method is used by the U.S. Federal Reserve to construct official published exchange rate indexes, as detailed in Loretan (2005). The weights are constructed using three digit SIC export data. We use the same industry level exchange rate series for our estimations using the ASM in both Sections 3 and 4 of the main text.

\subsection{Stylized Facts}

In Appendix Figures 2-3 we depict the change in exporting across regions and firm size categories in the LFTTD presented in the main text. In Appendix Figures 4-6 we depict the results in Table 3 of the main text graphically. The states corresponding to each region are listed in Appendix Table 7. In Appendix Tables 2 and 3 we report the time path of plant export participation across the years 1987, 1992, and 1997 using the Census of Manufactures (CMF) as well as for 2003 and 2006 using the ASM. We do this both across industries and regions. The ultimate conclusions are the same as those in the text but these tables show that there was significant heterogeneity across industries in the time path of the rise of exporting. The patterns of participation rates in each region, in contrast, roughly match the overall trend across these years.

While the results presented in the main text focused on the percentage of firms or plants exporting, they do not consider absolute numbers. In Appendix Tables 4-6 we report each country, industry, and region's contribution to the change in the total number of firm-country pairs with exports between the two years 1993 and 2006. As in our prior results, in looking at the raw number of exporters we find that these trends were experienced across all three categories.

\section{Barriers to Entry}

\subsection{Introduction}

In Section 3 of the main text we considered the evolution of barriers to entry in foreign markets. Here we provide additional results for these analyses. The findings support our main conclusions. We begin by discussing how we calculated the average partial effects for our dynamic random effects estimators. We then present the results from our simulated maximum likelihood estimations and provide additional details on our Monte Carlo Markov Chain (MCMC) estimations.

\subsection{Average Partial Effects}

In our Butler and Moffit estimations as well as our simulated maximum likelihood estimations, we report the average partial effect (APE) of exporting last year $y_{i t-1}$ on the probability of exporting this year $P\left(y_{i t}=1\right)$. To do this, we calculate $a p e_{1}=\frac{1}{n} \sum_{i=1}^{n} \Phi\left\{\left(\hat{\alpha}_{1}+\bar{X}_{i}^{\prime} \hat{\beta}\right)(1-\right.$ $\left.\hat{\rho})^{1 / 2}\right\}$ and $a p e_{0}=\frac{1}{n} \sum_{i=1}^{n} \Phi\left\{\left(\bar{X}_{i}^{\prime} \hat{\beta}\right)(1-\hat{\rho})^{1 / 2}\right\}$, where $\hat{\rho}=\hat{\sigma}_{\zeta}^{2} /\left(\hat{\sigma}_{\zeta}^{2}+\hat{\sigma}_{\varepsilon}^{2}\right)$ and $\Phi(\cdot)$ is the cumulative distribution function of the standard normal distribution. The APE is then given by ape $_{1}-$ ape $_{0}$. The estimates of $\rho$ and the APE are presented in the tables. Throughout, 
APEs are calculated with respect to the last year in each panel and the effects tend to be similar across the different years.

\subsection{Simulated Maximum Likelihood Estimations}

In estimating the parameters in equation (3), one concern was that if the unobservable factors in the error term $\varepsilon_{i t}$ are serially correlated, then our results could be biased. In the main text we discussed estimations that used a simulated maximum likelihood approach that allows the error term to be serially correlated. In Appendix Tables 8 and 9 we present the results assuming that the error term follows an $A R(1)$ or $M A(1)$ process. All results consider at least 20 simulations and use antithetic sampling. We find little change in state dependence across the different panels; both sets of results thus suggest that barriers to entry have not declined significantly.

\subsection{Monte Carlo Markov Chain Estimations}

Here we provide additional details about our MCMC estimations. Appendix Table 10 lists the four digit SIC subindustries that are a part of the three digit SIC industries that we consider in our analysis. The number of $A R(1)$ processes $x_{j i t}$ additively included in the profit function disturbance term is set to two, intuitively reflecting separate cost and demand shock processes. We set the discount rate $\delta$ to 0.9 . We do not estimate the parameters for the exchange rate process simultaneously with the rest of the model. Instead, we estimate them separately using the export weighted industry real exchange rates that were constructed with the approach of Loretan (2005). We fit each of these series with an $A R(1)$ process from 1972 until the last year of each panel. Appendix Table 11 presents the results.

In Appendix Table 12 we describe the full set of priors that we use in our estimations. We generally use diffuse distributions in order to let the data speak for themselves. The priors on the variance parameters are log normal in order to impose non-negativity and those on the roots of $A R(1)$ processes are uniform on $(-1,1)$ to impose stationarity. Our prior for each of the elasticity terms $\eta_{i}$ is given by $\ln \left(\eta_{i}-1\right) \sim N(2,1)$, which implies a mean and standard deviation of 12.2 and 16 respectively. This approach is consistent with evidence from the literature (Goldberg and Knetter 1999) and ensures that $\eta_{i}>1$. The prior for the parameter that determines the ratio of foreign and domestic demand elasticities $v$ is uniformly distributed on $[-5,5]$. This bounds how different the demand structures are in the home and foreign markets. Our estimates for this parameter are all well within this range. For a full explanation of the model and parameters see Das, Roberts, and Tybout (2007). We keep the same notation here as in the original paper for the sake of comparison.

In estimation, acceptance rates are kept within the range suggested by the literature and we use a burn-in period of 50,000 iterations for each chain. Starting values are set at 500 thousand dollars for each panel. We looked at a number of the diagnostic statistics reviewed in Brooks and Roberts (1998) to check for the convergence of each chain to the true posterior distribution. For each of these chains, we also looked at the results from several different levels of thinning. We alternately constructed our estimates by keeping every 2nd, 5th, 10th, 50 th, or 100th draw. This standard robustness check for MCMC methods is often used to diagnose a lack of convergence of the chain to the posterior distribution $P(\theta \mid D)$ or slow 
movement of the chain across the parameter space ("slow mixing"). These different levels of thinning all give similar results to our baseline estimates.

Appendix Tables 13-15 list the full set of estimates for each parameter in the model for each of our industries. We report the expected values along with the standard deviation of the posterior distribution in parentheses. To get a sense of how the entry cost estimates compare across the two different time periods, we calculate the percentage of draws from the sunk cost posterior distribution for the 1995-2006 panel that lie above the expected value of the sunk cost posterior in the 1987-1997 panel. The results range from having 75 percent of the draws for small plants in Aircraft and Parts above the mean for 1987-1997 to having 19 percent of the draws above for small plants in Preserved Fruits and Vegetables. We discuss this in the notes to Table 7 in the main text.

\section{Accounting for the Rise in Exporting}

\subsection{Introduction}

For our estimations in Section 4 of the main text, we compile a rich data set of information on the top 50 U.S. export destinations. Our data cover the years 1993-2006 and all 459 of the four digit SIC 1987 manufacturing industries. We draw annual macroeconomic indicators, geographic data, and tariff variables for each country from various sources. These include data from the Centre d'Études Prospectives et d'Informations Internationales (CEPII), Federal Reserve Bank of New York, International Monetary Fund, and World Bank. Each of the following sections explains in greater detail the sources and definitions of the measures that are used in our estimations. We then discuss additional details of our analysis.

\subsection{Data}

\subsubsection{Tariffs}

TRAINS contains data on tariffs and trade flows by importer-exporter pairs. We restrict the sample to the top 50 U.S. export destinations, manufactured goods sectors (which correspond to those four digit 1987 SIC codes that begin with 2 or 3), and the years 1993-2006. Since some observations are missing, we imputed the values to get a consistent set of data. European Union (EU) countries are assigned the common EU post-accession tariff so that we retain a balanced set of countries. If a country-year-SIC4 combination is missing a four digit sector tariff observation within a particular year, we instead use the average of the tariff rates for that country-year one SIC digit level higher. If the observations are also missing one level above, we go two levels higher. After this step, if a country is missing tariff observations in a given year, we use the prior year's value. If the prior value is missing, we use the subsequent year's value. We keep these measures in percentage points, such that a 20 percent tariff is recorded as the number 20 . 


\subsubsection{Gravity Variables}

Several of the country characteristics that determine export status come from the CEPII gravity and distance data sets. Head, Mayer, and Ries (2010) compile a "square" gravity data set for all pairs of countries in our sample for the period from 1948 to 2006, and the CEPII makes this information available on its website. All variables are described in the data appendix of their paper, to which one should turn for further details.

We use the following CEPII gravity variables: country area (in square kilometers); population weighted distance and time zone difference between country pairs; and indicators for country pairs that have common currencies, common languages, common legal origins, contiguity, regional trade agreements and colonial relationships. For details on how these are calculated, see Head and Mayer (2002) and Head, Mayer, and Ries (2010).

\subsubsection{Gross Domestic Product}

Country level information on real GDP in U.S. dollars, population, and the GDP deflator are sourced from the World Bank's World Development Indicators (WDI) data set. A few countries are missing data in the WDI. In particular, Ireland is missing its GDP deflator from 1990 to 1999 and so we use Ireland's consumer price index (CPI) for all years instead. Kuwait is also missing the GDP deflator from 1990 to 1991 and we use the same solution. Furthermore, the Kuwaiti population data are missing from 1990 to 1994. As such, we fill in those years' populations using the population measure from the CEPII data set described earlier. Taiwan is not included in the WDI but is a major U.S. trading partner. Therefore, the Taiwanese National Statistical Agency is the source for Taiwan's GDP, population, and GDP deflator.

\subsubsection{Exchange Rates}

For our country level estimations, we use nominal exchange rates (NER) and consumer prices indexes from the Federal Reserve Bank of New York (FRBNY) and the International Monetary Fund's International Financial Statistics (IFS) to construct real exchange rates (RER). All euro zone countries have synthetic NER defined by their official conversion rate after their accession to the euro zone. All exchange rate and CPI measures were collected at the quarterly level and then averaged to form the estimate within each year. We choose the base for CPIs for each country such that the average of the four quarters in the year 2000 equals one. We use data from the FRBNY to construct RER for countries whenever possible and turn to the IFS if the FRBNY data are incomplete for the countries and time periods that we need. In particular, inflation during the 1990s left Brazil's CPI and NER at zero in the FRBNY data set during the early part of our sample. This causes a problem when we take logarithms. Greater numerical precision was available from the IFS for both the NER and CPI, so we use these numbers instead. Finally, since the IFS lacks CPI and GDP deflator data for the United Arab Emirates, we approximate a price index for the country using the period-wise average of the CPIs of Kuwait and Saudi Arabia in each quarter. Russia is missing observations for the first quarter of 1992, so we use the available three quarters to form the 1992 observation. 
Table 1: Countries in Our Sample

\begin{tabular}{l|l}
\hline \hline Argentina & Japan \\
Australia & Kuwait \\
Austria & Malaysia \\
Belgium & Mexico \\
Brazil & Netherlands \\
Canada & New Zealand \\
Chile & Norway \\
China & Panama \\
Colombia & Peru \\
Costa Rica & Philippines \\
Denmark & Poland \\
Dominican Republic & Russia \\
Egypt & Saudi Arabia \\
El Salvador & Singapore \\
Finland & South Africa \\
France & South Korea \\
Germany & Spain \\
Guatemala & Sweden \\
Honduras & Switzerland \\
Hong Kong & Taiwan \\
India & Thailand \\
Indonesia & Turkey \\
Ireland & United Arab Emirates \\
Israel & United Kingdom \\
Italy & Venezuela \\
\hline
\end{tabular}

Notes: The table lists the countries in our sample for the estimations using the Longitudinal Firm Trade Transactions Database (LFTTD). These countries represent the top 50 U.S. export destinations and account for 95 percent of U.S. manufacturing exports. 
Table 2: Plant Export Participation by Industry

\begin{tabular}{lrrrrr}
\hline \hline & \multicolumn{5}{c}{ Percent of Plants That Export } \\
\cline { 2 - 7 } Industry & 1987 & 1992 & 1997 & 2003 & 2006 \\
\hline Food & 15 & 23 & 25 & 27 & 30 \\
Tobacco & 45 & 51 & 47 & & \\
$\quad$ Beverage \& Tobacco) & & & & 28 & 30 \\
Textile Mill Products & 16 & 25 & 28 & & \\
$\quad$ Textile Mills) & & & & 40 & 47 \\
$\quad$ Textile Product Mills) & 5 & 9 & 13 & 13 & 35 \\
Apparel & 12 & 18 & 16 & 16 & 19 \\
Wood Products & 10 & 25 & 24 & 18 & 20 \\
Furniture & 19 & 31 & 32 & 35 & 43 \\
Paper & 5 & 10 & 11 & 14 & 15 \\
Printing \& Publishing & 40 & 49 & 49 & 55 & 63 \\
Chemicals & 22 & 30 & 30 & 31 & 37 \\
Petroleum \& Coal & 26 & 36 & 39 & 40 & 51 \\
Plastics \& Rubber & 19 & 28 & 35 & 38 & 47 \\
Leather & 14 & 21 & 20 & 17 & 17 \\
Non-metallic Minerals & 27 & 39 & 39 & 43 & 56 \\
Primary Metals & 21 & 31 & 32 & 30 & 32 \\
Fabricated Metals & 33 & 43 & 41 & 56 & 62 \\
Machinery & 37 & 46 & 47 & & \\
Electronic \& Other Electric Equipment & & & & 54 & 65 \\
$\quad$ Electrical Equipment, etc.) & 48 & 55 & 56 & & \\
Instruments & & & & 58 & 68 \\
$\quad$ Computer \& Electronic Products) & 29 & 40 & 41 & 49 & 56 \\
Transportation Equipment & 20 & 34 & 36 & 37 & 42 \\
Miscellaneous Manufacturing & 21 & 30 & 32 & 35 & 39 \\
Total & & & & & \\
\hline
\end{tabular}

Notes: The table lists the percentage of manufacturing plants that export in each industry using the Census of Manufactures in 1987, 1992, and 1997 as well as the Annual Survey of Manufacturers in 2003 and 2006. Due to concerns about disclosure, the results reported for 1987 and 1992 are from Bernard and Jensen (2004b) and we report the results for 1987 in two digit 1987 SIC codes and the results for 2003 and 2006 in three digit 2002 NAICS codes. These codes match well at this level of aggregation. As in Bernard and Jensen (2004b), estimates for all years are for plants with 20 or more employees. The figures suggest that there was significant heterogeneity across industries in the time path of the rise of exporting. 
Table 3: Plant Export Participation by Region

\begin{tabular}{lrrrrr}
\hline \hline \multirow{2}{*}{ Region } & \multicolumn{5}{c}{ Percent of Plants That Export } \\
\cline { 2 - 6 } & 1987 & 1992 & 1997 & 2003 & 2006 \\
\hline New England & 25 & 37 & 37 & 42 & 46 \\
Middle Atlantic & 19 & 29 & 30 & 34 & 39 \\
East North Central & 25 & 34 & 35 & 39 & 45 \\
West North Central & 23 & 32 & 33 & 37 & 41 \\
South Atlantic & 18 & 27 & 29 & 32 & 36 \\
East South Central & 18 & 27 & 27 & 30 & 36 \\
West South Central & 19 & 28 & 28 & 31 & 33 \\
Mountain & 18 & 26 & 27 & 32 & 30 \\
Pacific & 21 & 31 & 31 & 33 & 36 \\
Total & 21 & 30 & 32 & 35 & 39 \\
\hline
\end{tabular}

Notes: The table lists the percentage of manufacturing plants that export in each U.S. Census division using the Census of Manufactures in 1987, 1992, and 1997 as well as the Annual Survey of Manufactures in 2003 and 2006. We report the states corresponding to these divisions in Appendix Table 7. Estimates for all years are for plants with 20 or more employees. These results suggest that the time path of participation rates of each region roughly matches the overall trend across these years. 
Table 4: Country Contribution to the Rise in Export Participation

\begin{tabular}{llr|llr}
\hline \hline Rank & Country & $\begin{array}{r}\text { Contribution } \\
\text { (Percent) }\end{array}$ & Rank & Country & $\begin{array}{r}\text { Contribution } \\
\text { (Percent) }\end{array}$ \\
\hline 1 & Mexico & 12.0 & 26 & South Africa & 1.6 \\
2 & China & 11.0 & 27 & New Zealand & 1.5 \\
3 & India & 28 & Philippines & 1.5 \\
4 & Brazil & 3.7 & 29 & Japan & 1.4 \\
5 & South Korea & 3.3 & 30 & Guatemala & 1.4 \\
6 & United Kingdom & 3.1 & 31 & Chile & 1.4 \\
7 & United Arab Emirates & 2.9 & 32 & Panama & 1.2 \\
8 & Germany & 2.8 & 33 & Honduras & 1.1 \\
9 & Malaysia & 2.8 & 34 & Finland & 1.1 \\
10 & Australia & 2.7 & 35 & Belgium & 1.1 \\
11 & Hong Kong & 2.7 & 36 & Taiwan & 1.0 \\
12 & Thailand & 2.5 & 37 & Saudi Arabia & 1.0 \\
13 & Poland & 2.3 & 38 & Indonesia & 1.0 \\
14 & Singapore & 2.3 & 39 & El Salvador & 0.9 \\
15 & Italy & 2.2 & 40 & Egypt & 0.8 \\
16 & Israel & 2.2 & 41 & Argentina & 0.7 \\
17 & Dominican Republic & 2.2 & 42 & Kuwait & 0.7 \\
18 & Ireland & 2.1 & 43 & Denmark & 0.7 \\
19 & Turkey & 2.0 & 44 & France & 0.5 \\
20 & Spain & 2.0 & 45 & Switzerland & 0.4 \\
21 & Colombia & 1.8 & 46 & Austria & 0.4 \\
22 & Peru & 1.8 & 47 & Sweden & 0.4 \\
23 & Costa Rica & 1.7 & 48 & Venezuela & 0.3 \\
24 & Netherlands & 1.6 & 49 & Norway & 0.3 \\
25 & Russia & 1.6 & 50 & Canada & -1.9 \\
\hline
\end{tabular}

Notes: The table reports each country's contribution to the change in the total number of firm-country pairs with exports between the two years 1993 and 2006. 
Table 5: Industry Contribution to the Rise in Export Participation

\begin{tabular}{lr}
\hline \hline Industry & $\begin{array}{r}\text { Contribution } \\
\text { (Percent) }\end{array}$ \\
\hline Food & 4.9 \\
Tobacco & -0.2 \\
Textile Mill Products & 1.1 \\
Apparel & 1.2 \\
Wood Products & 1.4 \\
Furniture & 0.9 \\
Paper & 2.2 \\
Printing \& Publishing & 1.3 \\
Chemicals & 11.1 \\
Petroleum \& Coal & 0.5 \\
Plastics \& Rubber & 12.0 \\
Leather & -0.4 \\
Non-metallic Minerals & 2.2 \\
Primary Metals & 3.9 \\
Fabricated Metals & 14.8 \\
Machinery & 16.5 \\
Electronic \& Other Electric Equipment & 10.0 \\
Transportation Equipment & 6.0 \\
Instruments & 7.7 \\
Miscellaneous Manufacturing & 3.1 \\
& \\
Total & 100 \\
\hline
\end{tabular}

Notes: The table reports the contribution of each two digit SIC industry to the change in the total number of firm-country exporting pairs between the two years 1993 and 2006. 
Table 6: Regional Contribution to the Rise in Export Participation

\begin{tabular}{lr}
\hline \hline Region & $\begin{array}{r}\text { Contribution } \\
\text { (Percent) }\end{array}$ \\
\hline New England & 5.7 \\
Middle Atlantic & 15.2 \\
East North Central & 25.4 \\
West North Central & 9.2 \\
South Atlantic & 10.3 \\
East South Central & 4.6 \\
West South Central & 7.4 \\
Mountain & 4.6 \\
Pacific & 17.6 \\
& \\
Total & 100 \\
\hline
\end{tabular}

Notes: The table reports the contribution of each region to the change in the total number of firm-country pairs with exports between the two years 1993 and 2006. Appendix Table 7 lists the states that correspond to each of these areas of the country. 
Table 7: Census Divisions of the States

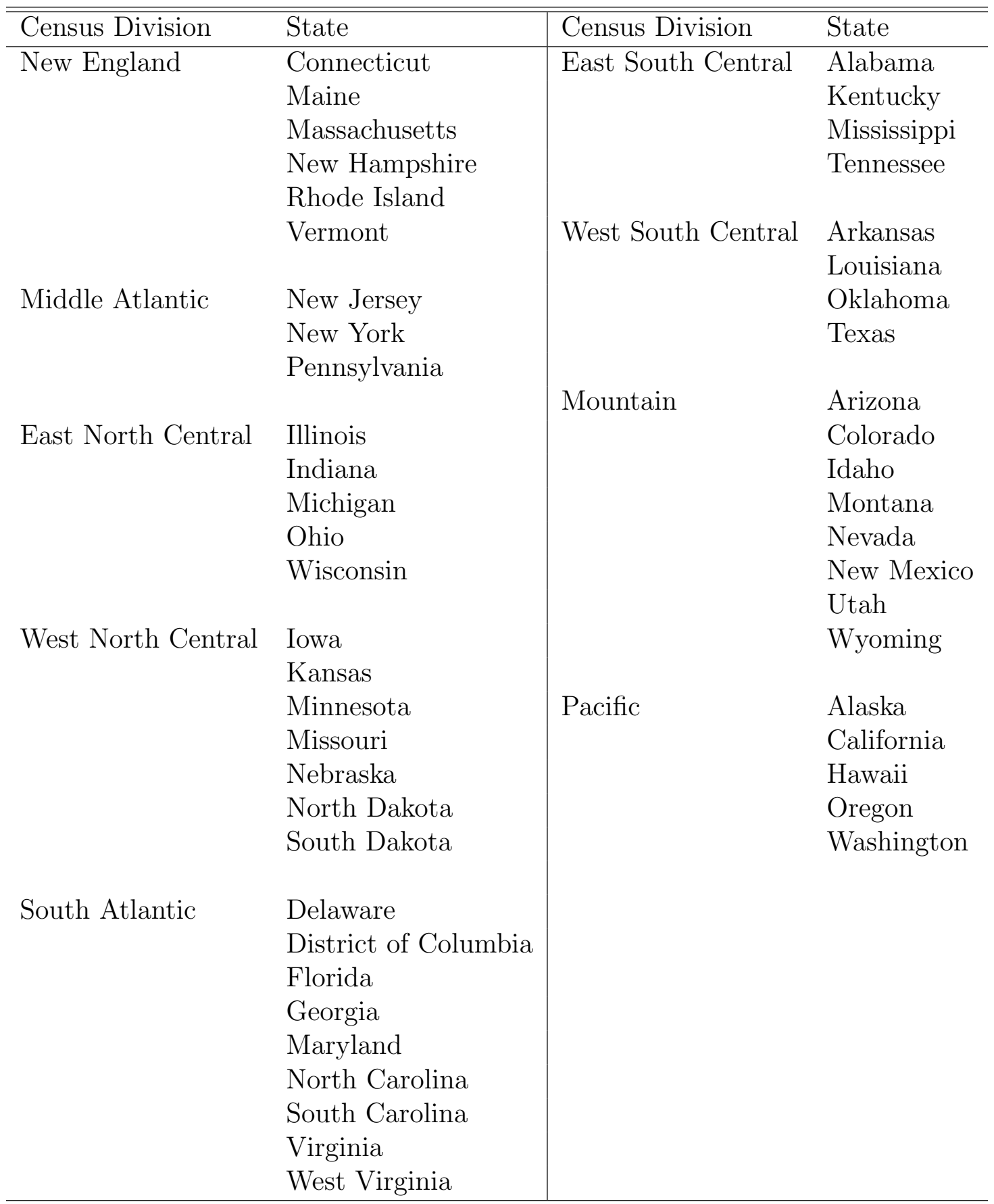

Notes: The table lists the states corresponding to the census divisions used for our analyses of U.S. regions. 
Table 8: Simulated Maximum Likelihood Estimations, AR(1) Errors

\begin{tabular}{lllll}
\hline \hline & & \multicolumn{2}{c}{ Specification } \\
& $\begin{array}{l}\text { Earlier } \\
\text { Variable }\end{array}$ & $\begin{array}{l}\text { Later } \\
(1)\end{array}$ & $\begin{array}{l}\text { Earlier } \\
(2)\end{array}$ & $\begin{array}{l}\text { Later } \\
(4)\end{array}$ \\
\hline Exported last year & $2.020^{* *}$ & $2.129^{* *}$ & $1.912^{* *}$ & $2.111^{* *}$ \\
& $(0.028)$ & $(0.034)$ & $(0.027)$ & $(0.035)$ \\
$\ln$ (Employment) & & & $0.110^{* *}$ & $0.110^{* *}$ \\
& & & $(0.017)$ & $(0.024)$ \\
$\ln$ (Wages) & & & $0.663^{* *}$ & $0.544^{* *}$ \\
& & & $(0.038)$ & $(0.049)$ \\
Non-production/ & & & -0.093 & $-0.182^{* *}$ \\
Total Employment & & & $0.067)$ & $(0.090)$ \\
$\ln$ (Productivity) & & & $(0.006)$ & 0.003 \\
& & & -0.543 & $-0.007)$ \\
$\ln ($ Exchange Rate) & & & $(0.327)$ & $(0.250)$ \\
& & & & \\
AR $(1)$ Coefficient & $-0.337^{* *}$ & $-0.229^{* *}$ & $-0.316^{* *}$ & $-0.226^{* *}$ \\
& $(0.011)$ & $(0.015)$ & $(0.012)$ & $(0.016)$ \\
$\rho=\sigma_{\zeta}^{2} /\left(\sigma_{\zeta}^{2}+\sigma_{\varepsilon}^{2}\right)$ & $0.190^{* *}$ & $0.277^{* *}$ & $0.210^{* *}$ & $0.266^{* *}$ \\
& $(0.016)$ & $(0.020)$ & $(0.015)$ & $(0.019)$ \\
Average Partial Effect & 0.619 & 0.586 & 0.574 & 0.578 \\
\hline
\end{tabular}

Notes: The table presents the results from estimating equation (3) in the main text with a simulated maximum likelihood estimator using the GHK algorithm with $A R(1)$ errors. We find slight increases in state dependence across the two different panels and interpret this as evidence of no decline in initial entry costs. The coefficient on "Exported last year" is an increasing function of the costs of entering foreign markets anew, $F_{0}$. The dependent variable is a $0 / 1$ indicator for a given plant's export status in the current year. Year effects are included in each specification. The average partial effect refers to the effect of exporting last year on the probability of exporting this year. The earlier period considers 1987-1997 and the later period considers 1995-2006 where both are balanced panels of plants. All estimations include 54,300 observations in the first panel and 43,100 observations in the second (both of these figures are rounded to the nearest 100 observations for the purposes of disclosure). Antithetic sampling is used in all estimations. Standard errors are in parentheses. The results with ${ }^{* *}$ denote significance at the 5 percent level. 
Table 9: Simulated Maximum Likelihood Estimations, MA(1) Errors

\begin{tabular}{|c|c|c|c|c|}
\hline \multirow[b]{2}{*}{ Variable } & \multicolumn{4}{|c|}{ Specification } \\
\hline & $\begin{array}{l}\text { Earlier } \\
(1)\end{array}$ & $\begin{array}{l}\text { Later } \\
(2)\end{array}$ & $\begin{array}{l}\text { Earlier } \\
(3)\end{array}$ & $\begin{array}{l}\text { Later } \\
\text { (4) }\end{array}$ \\
\hline Exported last year & $\begin{array}{l}2.392^{* *} \\
(0.022)\end{array}$ & $\begin{array}{l}2.462^{* *} \\
(0.041)\end{array}$ & $\begin{array}{l}2.184^{* *} \\
(0.031)\end{array}$ & $\begin{array}{l}2.368^{* *} \\
(0.042)\end{array}$ \\
\hline Total Employment & & & $\begin{array}{l}0.085^{* *} \\
(0.014)\end{array}$ & $\begin{array}{l}0.084^{* *} \\
(0.020)\end{array}$ \\
\hline Wages & & & $\begin{array}{l}0.496^{* *} \\
(0.034)\end{array}$ & $\begin{array}{l}0.416^{* *} \\
(0.043)\end{array}$ \\
\hline $\begin{array}{l}\text { Non-production/ } \\
\text { Total Employment }\end{array}$ & & & $\begin{array}{l}-0.088 \\
(0.054)\end{array}$ & $\begin{array}{l}-0.139 \\
(0.074)\end{array}$ \\
\hline Productivity & & & $\begin{array}{l}0.010^{* *} \\
(0.005)\end{array}$ & $\begin{array}{l}0.002 \\
(0.006)\end{array}$ \\
\hline Industry Exchange Rate & & & $\begin{array}{l}-0.431 \\
(0.266)\end{array}$ & $\begin{array}{l}-0.677^{* *} \\
(0.206)\end{array}$ \\
\hline$M A(1)$ Coefficient & $\begin{array}{l}0.712^{* *} \\
(0.035)\end{array}$ & $\begin{array}{l}0.474^{* *} \\
(0.033)\end{array}$ & $\begin{array}{l}0.536^{* *} \\
(0.028)\end{array}$ & $\begin{array}{l}0.431^{* *} \\
(0.033)\end{array}$ \\
\hline$\rho=\sigma_{\zeta}^{2} /\left(\sigma_{\zeta}^{2}+\sigma_{\varepsilon}^{2}\right)$ & $\begin{array}{l}0.059^{* *} \\
(0.009)\end{array}$ & $\begin{array}{l}0.149^{* *} \\
(0.020)\end{array}$ & $\begin{array}{l}0.118^{* *} \\
(0.014)\end{array}$ & $\begin{array}{l}0.169^{* *} \\
(0.020)\end{array}$ \\
\hline Average Partial Effect & 0.743 & 0.711 & 0.672 & 0.678 \\
\hline
\end{tabular}

Notes: The table presents the results from estimating equation (3) in the main text with a simulated maximum likelihood estimator using the GHK algorithm with $M A(1)$ errors. We find similar levels of state dependence across the two different panels, suggesting that entry costs have not declined significantly. The coefficient on "Exported last year" is an increasing function of the costs of entering foreign markets anew, $F_{0}$. The dependent variable is a $0 / 1$ indicator for a given plant's export status in the current year. Year effects are included in each specification. The average partial effect refers to the effect of exporting last year on the probability of exporting this year. The earlier period considers 1987-1997 and the later period considers 1995-2006, where both are balanced panels of plants. All estimations include 54,300 observations in the first panel and 43,100 observations in the second (both of these figures are rounded to the nearest 100 observations for the purposes of disclosure). Antithetic sampling is used in all estimations. Standard errors are in parentheses. The results with ${ }^{* *}$ denote significance at the 5 percent level. 
Table 10: Four Digit Subindustries for Structural Estimations

\begin{tabular}{ll}
\hline \hline 3 Digit SIC Industry & 4 Digit SIC Subindustry \\
\hline Preserved Fruits and & Canned specialties (2032) \\
Vegetables (203) & Canned fruits and vegetables (2033) \\
& Dehydrated fruits, vegetables, and soups (2034) \\
& Pickles, sauces, and salad dressings (2035) \\
& Frozen fruits and vegetables (2037) \\
& Frozen specialties, N.E.C. (2038) \\
& Aircraft (3721) \\
Aircraft and Parts (372) & Aircraft Engines and Engine Parts (3724) \\
& Aircraft Parts and Equipment, N.E.C. (3728) \\
& Laboratory Apparatus and Furniture (3821) \\
Measuring and Controlling & Environmental Controls (3822) \\
Devices (382) & Process Control Instruments (3823) \\
& Fluid Meters and Counting Devices (3824) \\
& Instruments to Measure Electricity (3825) \\
& Analytical Instruments (3826) \\
& Optical Instruments and Lenses (3827) \\
& Measuring and Controlling Devices, N.E.C. (3829) \\
\hline
\end{tabular}

Notes: The table lists the four digit 1987 SIC industries that compose the three digit 1987 SIC industries that we consider for our Monte Carlo Markov Chain estimations. 
Table 11: Industry Exchange Rates

\begin{tabular}{lrr}
\hline \hline & \multicolumn{2}{c}{ Panel } \\
\cline { 2 - 3 } Parameters for Each Industry & 0.0022 & 0.0079 \\
\hline Preserved Fruits \& Vegetables (203) & 0.7870 & 0.8250 \\
$\lambda_{0}$ (constant) & 0.0032 & 0.0032 \\
$\lambda_{e}$ (persistence) & & \\
$\sigma_{w}$ (std. deviation of the error term) & \\
Aircraft \& Parts (372) & -0.0075 & 0.0021 \\
$\lambda_{0}$ (constant) & 0.7613 & 0.8164 \\
$\lambda_{e}$ (persistence) & 0.0035 & 0.0037 \\
$\sigma_{w}$ (std. deviation of the error term) & \\
& & \\
Measuring \& Controlling Devices (382) & -0.0066 & 0.00063 \\
$\lambda_{0}$ (constant) & 0.7833 & 0.8325 \\
$\lambda_{e}$ (persistence) & 0.0031 & 0.0028 \\
$\sigma_{w}$ (std. deviation of the error term) & & \\
\hline
\end{tabular}

Notes: The table presents the results from fitting an $A R(1)$ process on the industry exchange rates for the sectors considered in our Monte Carlo Markov Chain estimations. Estimates are for each industry's constant $\lambda_{0}$, persistence parameter $\lambda_{e}$, and the standard deviation of the error term of the $A R(1)$ process $\sigma_{w}$. We assume that the transition density for the exchange rate process is $f_{e}\left(e^{\prime} \mid e\right)=\phi\left(\sigma_{w}^{-1}\left(e^{\prime}-\lambda_{0}-\lambda_{e} e\right)\right) \sigma_{w}^{-1}$, where $\phi(\cdot)$ is the standard normal density function. Industry specific exchange rates were calculated using publicly available data from Peter Schott and the Federal Reserve Bank of New York's "Industry-Specific Exchange Rates" webpage. 
Table 12: Prior Distributions

\begin{tabular}{|c|c|}
\hline & Profits \\
\hline$\psi_{01}($ intercept $)$ & $\psi_{01} \sim N(0,10)$ \\
\hline$\psi_{02}($ dom. size dummy) & $\psi_{02} \sim N(0,10)$ \\
\hline$\psi_{1}($ exchange rate $)$ & $\psi_{1} \sim N(0,10)$ \\
\hline$\lambda_{x}^{1}($ root, first $\mathrm{AR})$ & $\lambda_{x}^{1} \sim U(-1,1)$ \\
\hline$\lambda_{x}^{2}($ root, second AR) & $\lambda_{x}^{\tilde{2}} \sim U(-1,1)$ \\
\hline$\sigma_{\omega 1}^{2}($ variance, first $\mathrm{AR})$ & $\ln \left(\sigma_{\omega 1}^{2}\right) \sim N(0,20)$ \\
\hline$\sigma_{\omega 2}^{2}($ variance, second $\mathrm{AR})$ & $\ln \left(\sigma_{\omega 2}^{2}\right) \sim N(0,20)$ \\
\hline$v$ (foreign elas. premium) & $v \sim U[-5,5]$ \\
\hline$\lambda_{\xi}($ root, measurement error) & $\lambda_{\xi} \sim U(-1,1)$ \\
\hline$\sigma_{\xi}$ (std. dev., measurement error) & $\ln \left(\sigma_{\xi}\right) \sim N(0,2)$ \\
\hline$\eta_{i}($ demand elasticity) & $\begin{array}{l}\text { Elasticities of Demand } \\
\ln \left(\eta_{i}-1\right) \sim N(2,1)\end{array}$ \\
\hline & Exporting Decision \\
\hline$\gamma_{s 1}($ sunk cost, small plants $)$ & $\gamma_{s 1} \sim N(0,20)$ \\
\hline$\gamma_{s 2}($ sunk cost, large plants) & $\gamma_{s 2} \sim N(0,20)$ \\
\hline$\kappa\left(\right.$ mean, $\left.\varepsilon_{1} \& \varepsilon_{2}\right)$ & $\kappa \sim N(0,20)$ \\
\hline$\sigma_{\varepsilon 1}$ (st. dev., $\left.\varepsilon_{1}\right)$ & $\ln \left(\sigma_{\varepsilon 1}\right) \sim N(0,2)$ \\
\hline$\sigma_{\varepsilon 2}\left(\right.$ st. dev., $\left.\varepsilon_{2}\right)$ & $\ln \left(\sigma_{\varepsilon 2}\right) \sim N(0,2)$ \\
\hline & Initial Conditions \\
\hline$\alpha_{0}($ intercept $)$ & $\alpha_{0} \sim N(0,50)$ \\
\hline$\alpha_{1}$ (dom. size dummy) & $\alpha_{1} \sim N(0,50)$ \\
\hline$\alpha_{2}\left(x_{1}\right)$ & $\alpha_{2} \sim N(0,50)$ \\
\hline$\alpha_{3}\left(x_{2}\right)$ & $\alpha_{3} \sim N(0,50)$ \\
\hline
\end{tabular}

Notes: The table presents the priors used for our Monte Carlo Markov Chain estimations. The same distributions are used for each panel and industry. We generally choose diffuse priors to allow the data to speak for themselves. Variance parameters have log normal distributions to impose non-negativity. The root of each $A R(1)$ process is bounded on $(-1,1)$ in order to ensure stationarity. The notation here is the same as in the paper by Das, Roberts, and Tybout (2007) and the reader is referred to this work for additional details about the estimation methodology. 
Table 13: SIC 203 Posterior Parameter Distributions

\begin{tabular}{|c|c|c|}
\hline & \multicolumn{2}{|c|}{ Preserved Fruits \& Vegetables } \\
\hline & 1987-1997 & 1995-2006 \\
\hline & \multicolumn{2}{|c|}{ Profits } \\
\hline$\psi_{01}$ (intercept) & $-2.07(0.21)$ & $-2.08(0.29)$ \\
\hline$\psi_{02}$ (dom. size dummy) & $1.04(0.28)$ & $1.46(0.38)$ \\
\hline$\psi_{1}$ (exchange rate) & $0.85(1.49)$ & $-0.70(0.74)$ \\
\hline$\lambda_{x}^{1}($ root, first $\mathrm{AR})$ & $0.57(0.08)$ & $0.66(0.10)$ \\
\hline$\lambda_{x}^{2}($ root, second AR) & $0.64(0.04)$ & $0.91(0.02)$ \\
\hline$\sigma_{\omega 1}^{2}($ variance, first AR) & $0.68(0.07)$ & $0.27(0.07)$ \\
\hline$\sigma_{\omega, 2}^{2}($ variance, second $\mathrm{AR})$ & $0.73(0.07)$ & $0.43(0.07)$ \\
\hline$v$ (foreign elas. premium) & $0.03(0.04)$ & $-0.13(0.04)$ \\
\hline$\lambda_{\xi}$ (root, measurement error) & $0.89(0.01)$ & $0.84(0.02)$ \\
\hline \multirow[t]{2}{*}{$\sigma_{\xi}$ (std. error, measurement error) } & $0.23(0.03)$ & $0.18(0.02)$ \\
\hline & \multicolumn{2}{|c|}{ Elasticities of Demand } \\
\hline$\eta_{\mu}$ (demand elas., $\mu$ across plants) & $13.71(8.81)$ & $12.93(6.16)$ \\
\hline \multirow[t]{2}{*}{$\eta_{\sigma}$ (demand elas., $\sigma$ across plants) } & $11.61(7.35)$ & $12.59(6.67)$ \\
\hline & \multicolumn{2}{|c|}{ Exporting Decision } \\
\hline$\gamma_{s 1}($ sunk cost, small plants) & $2.85(0.80)$ & $2.49(0.41)$ \\
\hline$\gamma_{s 2}$ (sunk cost, large plants) & $2.62(0.74)$ & $2.26(0.36)$ \\
\hline$\kappa\left(\right.$ mean, $\left.\varepsilon_{1} \& \varepsilon_{2}\right)$ & $-0.14(0.04)$ & $-0.17(0.03)$ \\
\hline$\sigma_{\varepsilon 1}\left(\right.$ std. error, $\left.\varepsilon_{1}\right)$ & $1.55(0.48)$ & $1.17(0.32)$ \\
\hline \multirow[t]{2}{*}{$\sigma_{\varepsilon 2}\left(\right.$ std. error, $\left.\varepsilon_{2}\right)$} & $0.90(0.38)$ & $0.62(0.38)$ \\
\hline & \multicolumn{2}{|c|}{ Initial Conditions } \\
\hline$\alpha_{0}$ (intercept) & $8.68(8.58)$ & $-35.38(16.49)$ \\
\hline$\alpha_{1}$ (dom. size dummy) & $18.23(20.73)$ & $43.42(20.58)$ \\
\hline$\alpha_{2}\left(x_{1}\right)$ & $-23.95(48.44)$ & $17.41(45.75)$ \\
\hline$\alpha_{3}\left(x_{2}\right)$ & $9.33(78.54)$ & $-8.26(61.25)$ \\
\hline Observations & $N=1200, T=11$ & $N=1100, T=12$ \\
\hline
\end{tabular}

Notes: The table presents the results from estimating the structural model presented in Section 3.2 of the main text for the Preserved Fruits and Vegetables industry (SIC 203) over the time periods 1987-1997 and 1995-2006. All estimations are based on 100,000 draws from a post-burn in period from three separate chains, for 300,000 total draws. Means are presented along with standard deviations of the posterior distribution for each parameter in parentheses. Figures in dollars are in 1987 dollars. The number of observations in each panel has been rounded to the nearest 100 observations for the purposes of disclosure. Median values and estimates based on thinning each chain give similar results. 
Table 14: SIC 372 Posterior Parameter Distributions

\begin{tabular}{|c|c|c|}
\hline & \multicolumn{2}{|c|}{ Aircraft \& Parts } \\
\hline & 1987-1997 & $1995-2006$ \\
\hline & \multicolumn{2}{|c|}{ Profits } \\
\hline$\psi_{01}$ (intercept) & $-0.36(0.34)$ & $-0.21(0.31)$ \\
\hline$\psi_{02}($ dom. size dummy $)$ & $2.62(0.45)$ & $2.81(0.42)$ \\
\hline$\psi_{1}($ exchange rate $)$ & $-0.25(0.97)$ & $0.60(0.57)$ \\
\hline$\lambda_{x}^{1}($ root, first $\mathrm{AR})$ & $0.31(0.06)$ & $0.80(0.09)$ \\
\hline$\lambda_{x}^{2}($ root, second AR $)$ & $0.98(0.01)$ & $0.96(0.02)$ \\
\hline$\sigma_{\omega 1}^{2}($ variance, first $A R)$ & $0.65(0.06)$ & $0.46(0.10)$ \\
\hline$\sigma_{\omega 2}^{2}($ variance, second $\mathrm{AR})$ & $0.09(0.04)$ & $0.15(0.10)$ \\
\hline$v$ (foreign elas. premium) & $2.03(0.40)$ & $1.42(0.24)$ \\
\hline$\lambda_{\xi}$ (root, measurement error) & $0.98(0.01)$ & $0.95(0.01)$ \\
\hline \multirow[t]{2}{*}{$\sigma_{\xi}$ (std. error, measurement error) } & $1.29(0.29)$ & $0.74(0.15)$ \\
\hline & \multicolumn{2}{|c|}{ Elasticities of Demand } \\
\hline$\eta_{\mu}$ (demand elas., $\mu$ across plants) & $12.20(4.82)$ & $11.86(4.17)$ \\
\hline \multirow[t]{2}{*}{$\eta_{\sigma}$ (demand elas., $\sigma$ across plants) } & $12.80(5.56)$ & $12.16(4.55)$ \\
\hline & \multicolumn{2}{|c|}{ Exporting Decision } \\
\hline$\gamma_{s 1}($ sunk cost, small plants) & $2.39(0.62)$ & $2.90(0.65)$ \\
\hline$\gamma_{s 2}($ sunk cost, large plants) & $2.45(0.65)$ & $2.54(0.59)$ \\
\hline$\kappa\left(\right.$ mean, $\left.\varepsilon_{1} \& \varepsilon_{2}\right)$ & $-0.24(0.07)$ & $-0.26(0.07)$ \\
\hline$\sigma_{\varepsilon 1}\left(\right.$ std. error, $\left.\varepsilon_{1}\right)$ & $1.09(0.40)$ & $1.11(0.29)$ \\
\hline \multirow[t]{2}{*}{$\sigma_{\varepsilon 2}\left(\right.$ std. error, $\left.\varepsilon_{2}\right)$} & $0.85(0.38)$ & $1.06(0.40)$ \\
\hline & \multicolumn{2}{|c|}{ Initial Conditions } \\
\hline$\alpha_{0}$ (intercept) & $45.99(21.15)$ & $24.97(16.50)$ \\
\hline$\alpha_{1}$ (dom. size dummy) & $8.04(25.54)$ & $35.75(23.54)$ \\
\hline$\alpha_{2}\left(x_{1}\right)$ & $-3.26(25.49)$ & $-8.34(52.19)$ \\
\hline$\alpha_{3}\left(x_{2}\right)$ & $38.58(66.70)$ & $56.54(34.56)$ \\
\hline Observations & $N=900, T=11$ & $N=1000, T=12$ \\
\hline
\end{tabular}

Notes: The table presents the full results from estimating the structural model presented in Section 3.2 of the main text for the Aircraft and Parts industry (SIC 372) over the time periods 1987-1997 and 1995-2006. All estimations are based on 100,000 draws from a postburn in period from three separate chains, for 300,000 total draws. Means are presented along with standard deviations of the posterior distribution for each parameter in parentheses. Figures in dollars are in 1987 dollars. The number of observations in each panel has been rounded to the nearest 100 observations for the purposes of disclosure. Median values and estimates based on thinning each chain give similar results. 
Table 15: SIC 382 Posterior Parameter Distributions

\begin{tabular}{|c|c|c|}
\hline & \multicolumn{2}{|c|}{ Measuring \& Controlling Devices } \\
\hline & 1987-1997 & $1995-2006$ \\
\hline & \multicolumn{2}{|c|}{ Profits } \\
\hline$\psi_{01}$ (intercept) & $-0.18(0.17)$ & $0.26(0.22)$ \\
\hline$\psi_{02}($ dom. size dummy $)$ & $0.96(0.24)$ & $1.53(0.31)$ \\
\hline$\psi_{1}$ (exchange rate) & $-0.95(0.63)$ & $0.09(0.49)$ \\
\hline$\lambda_{x}^{1}($ root, first $\mathrm{AR})$ & $0.12(0.26)$ & $0.80(0.20)$ \\
\hline$\lambda_{x}^{2}($ root, second AR) & $0.91(0.07)$ & $0.92(0.03)$ \\
\hline$\sigma_{\omega 1}^{2}($ variance, first $\mathrm{AR})$ & $0.19(0.07)$ & $0.16(0.06)$ \\
\hline$\sigma_{\omega 2}^{2}($ variance, second $\mathrm{AR})$ & $0.16(0.06)$ & $0.09(0.06)$ \\
\hline$v$ (foreign elas. premium) & $1.23(0.16)$ & $0.89(0.26)$ \\
\hline$\lambda_{\xi}$ (root, measurement error) & $0.97(0.01)$ & $0.95(0.02)$ \\
\hline \multirow[t]{2}{*}{$\sigma_{\xi}$ (std. error, measurement error) } & $0.67(0.11)$ & $0.58(0.18)$ \\
\hline & \multicolumn{2}{|c|}{ Elasticities of Demand } \\
\hline$\eta_{\mu}$ (demand elas., $\mu$ across plants) & $10.95(6.39)$ & $10.58(5.49)$ \\
\hline \multirow[t]{2}{*}{$\eta_{\sigma}$ (demand elas., $\sigma$ across plants) } & $7.76(4.81)$ & $7.85(4.46)$ \\
\hline & \multicolumn{2}{|c|}{ Exporting Decision } \\
\hline$\gamma_{s 1}($ sunk cost, small plants) & $2.89(0.98)$ & $2.62(0.93)$ \\
\hline$\gamma_{s 2}$ (sunk cost, large plants) & $2.66(0.89)$ & $3.29(1.21)$ \\
\hline$\kappa\left(\right.$ mean, $\left.\varepsilon_{1} \& \varepsilon_{2}\right)$ & $-0.56(0.32)$ & $-0.95(0.74)$ \\
\hline$\sigma_{\varepsilon 1}\left(\right.$ std. error, $\left.\varepsilon_{1}\right)$ & $1.60(0.55)$ & $1.35(0.64)$ \\
\hline \multirow[t]{2}{*}{$\sigma_{\varepsilon 2}\left(\right.$ std. error, $\left.\varepsilon_{2}\right)$} & $1.12(0.84)$ & $2.75(2.17)$ \\
\hline & \multicolumn{2}{|c|}{ Initial Conditions } \\
\hline$\alpha_{0}$ (intercept) & $43.81(19.79)$ & $41.79(24.86)$ \\
\hline$\alpha_{1}$ (dom. size dummy) & $33.54(23.61)$ & $7.84(21.88)$ \\
\hline$\alpha_{2}\left(x_{1}\right)$ & $58.63(26.13)$ & $1.57(56.36)$ \\
\hline$\alpha_{3}\left(x_{2}\right)$ & $-13.26(43.48)$ & $41.30(51.51)$ \\
\hline Observations & $N=1100, T=11$ & $N=800, T=12$ \\
\hline
\end{tabular}

Notes: The table presents the results from estimating the structural model presented in Section 3.2 of the main text for the Measuring and Controlling Devices industry (SIC 382) over the time periods 1987-1997 and 1995-2006. All estimations are based on 100,000 draws from a post-burn in period from three separate chains, for 300,000 total draws. Means are presented along with standard deviations of the posterior distribution for each parameter in parentheses. Figures in dollars are in 1987 dollars. The number of observations in each panel has been rounded to the nearest 100 observations for the purposes of disclosure. Median values and estimates based on thinning each chain give similar results. 


\section{Appendix Fig. 1: Shipper's Export Declaration Form}

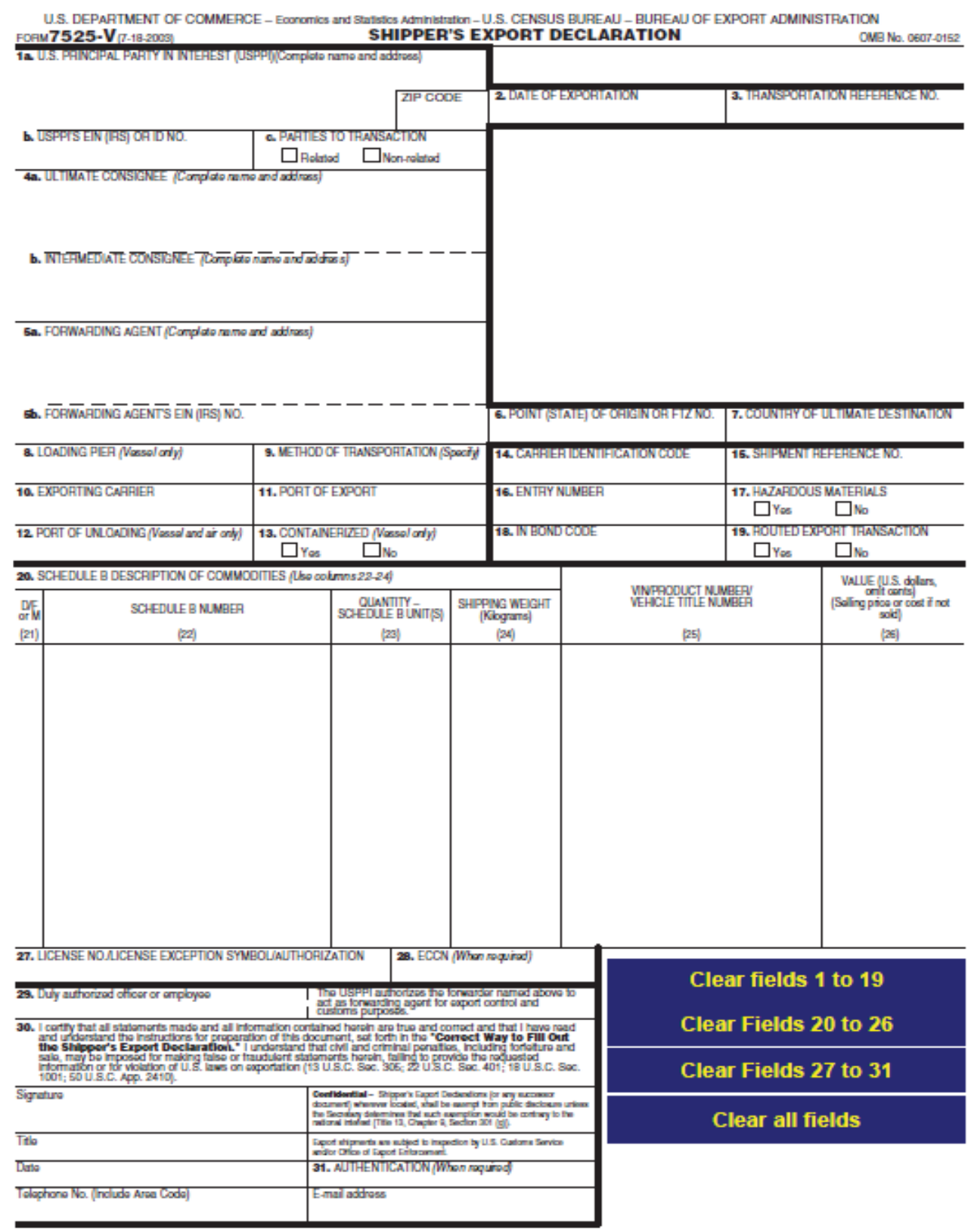

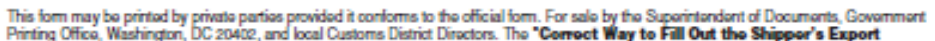
Doclaration" is avilublo from tho U.S. Consus Buroul, Washington, DC 20033 . 


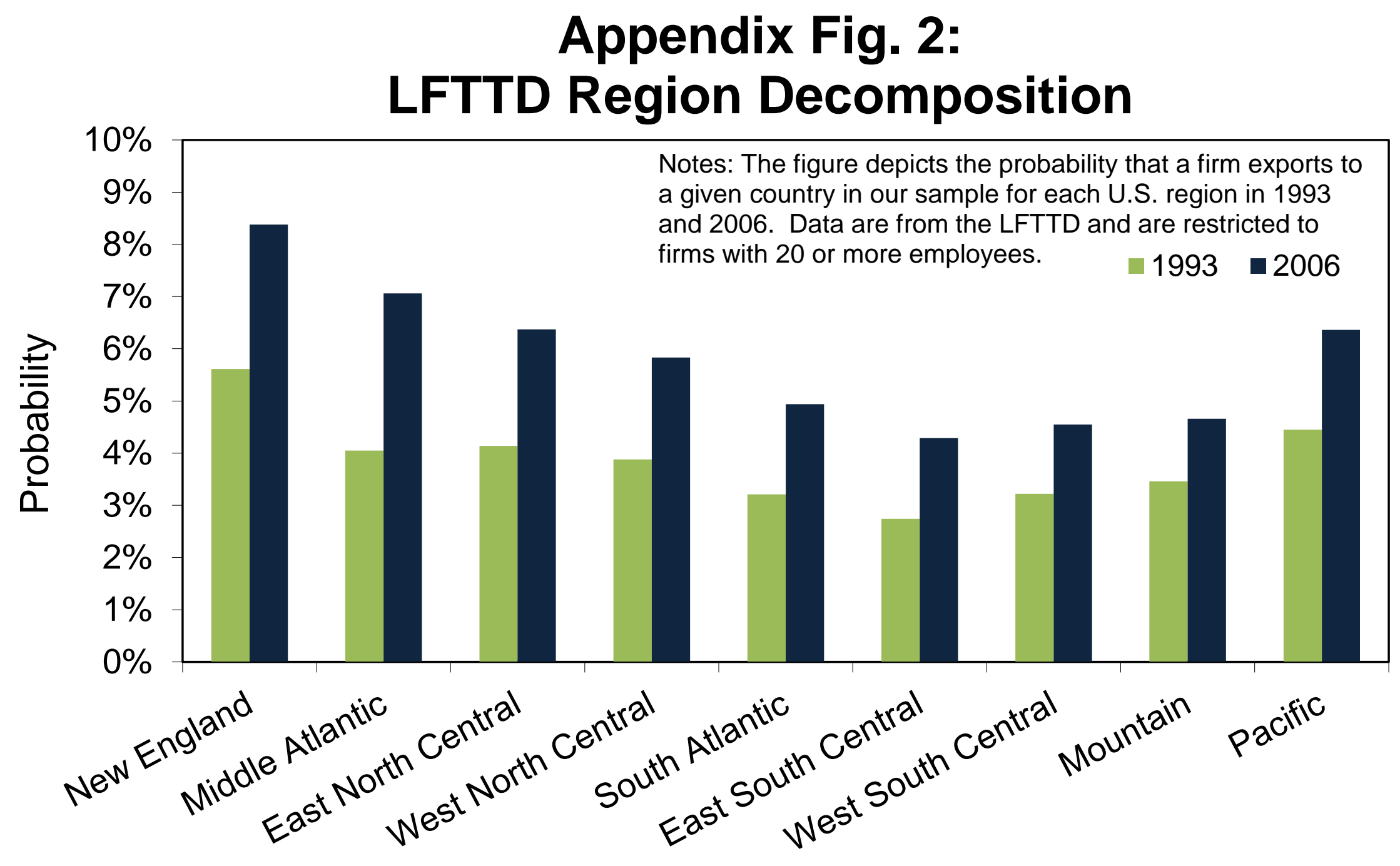

Region 


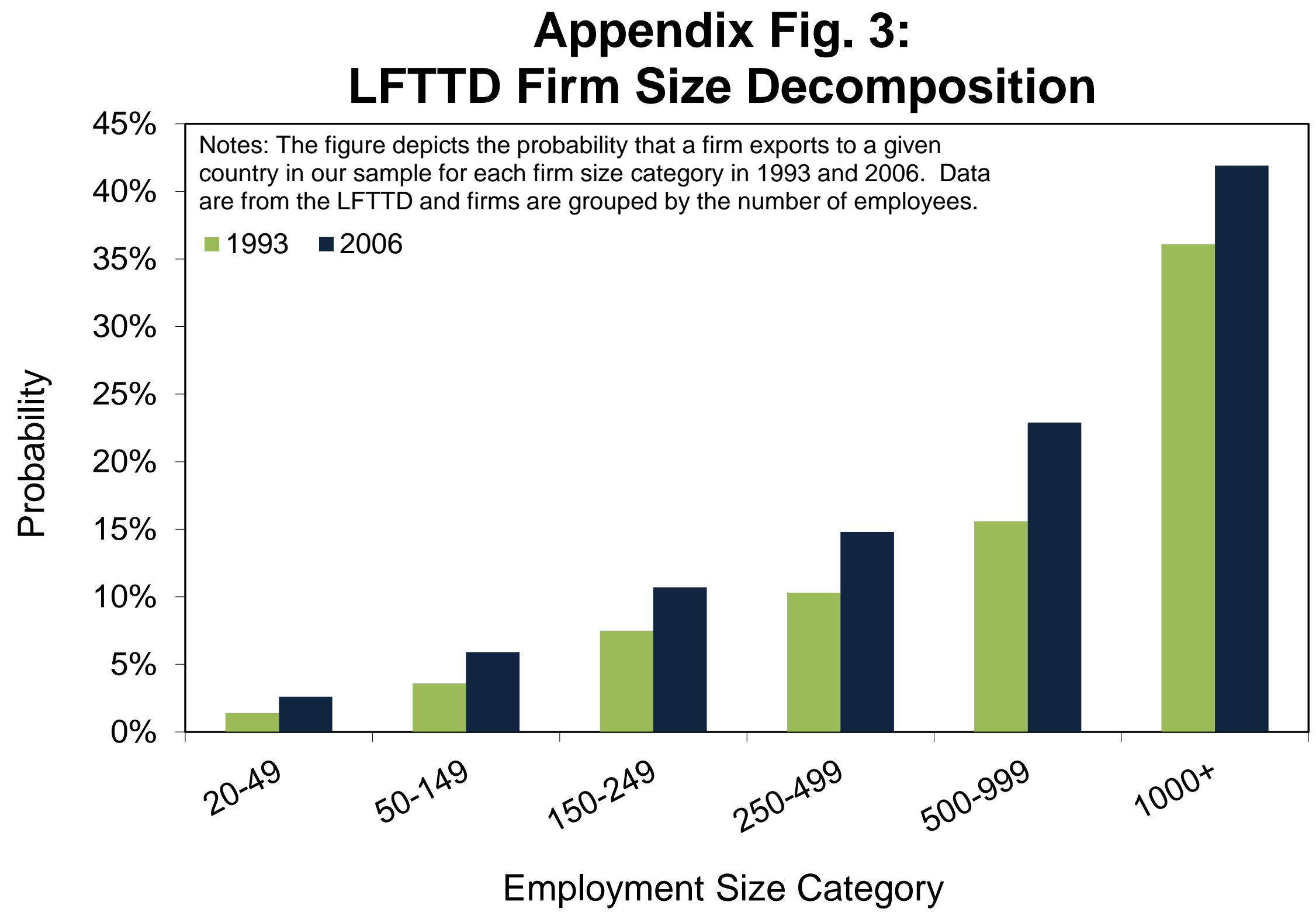




\section{Appendix Fig. 4: ASM Industry Decomposition}

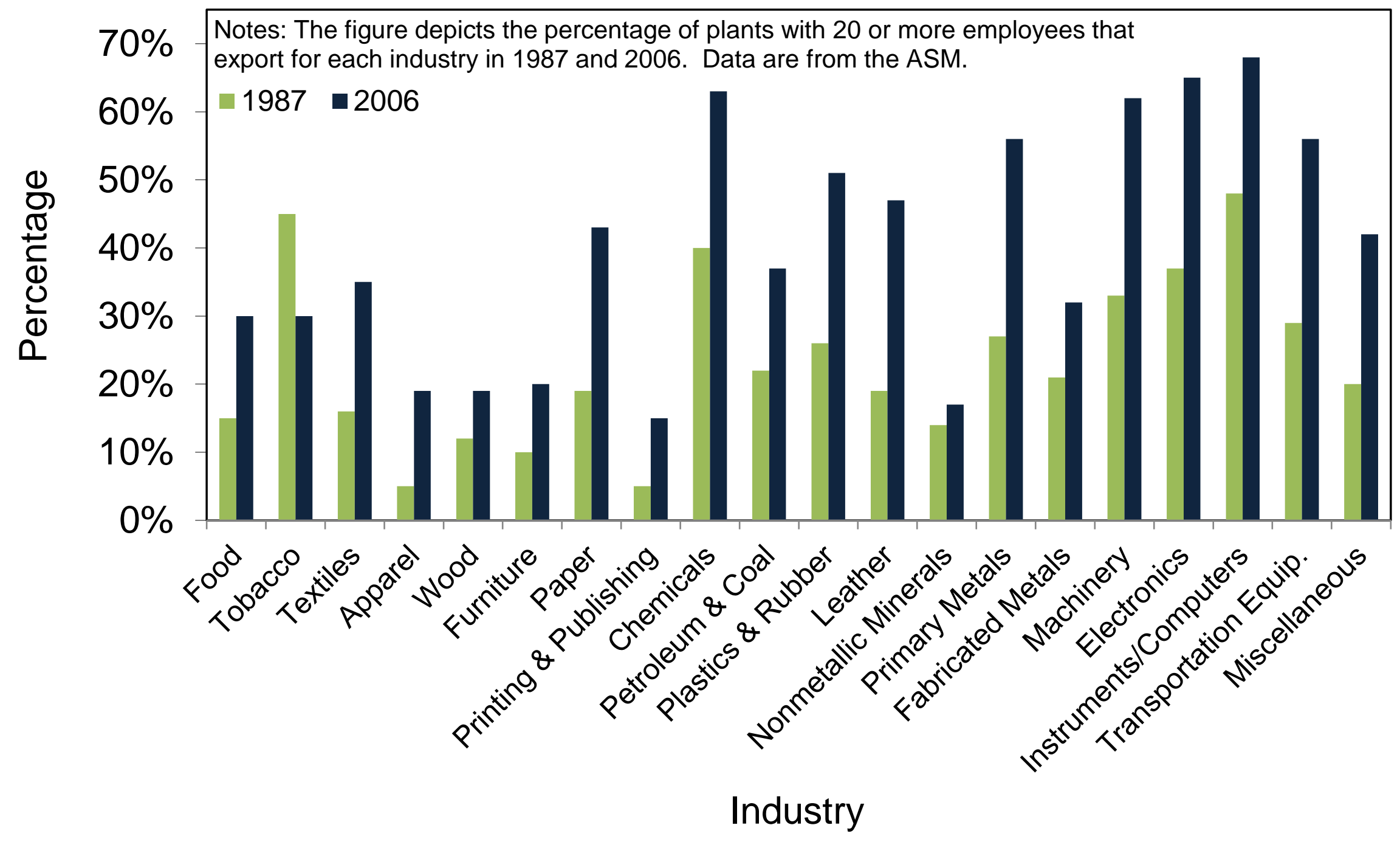




\section{Appendix Fig. 5: ASM Region Decomposition}

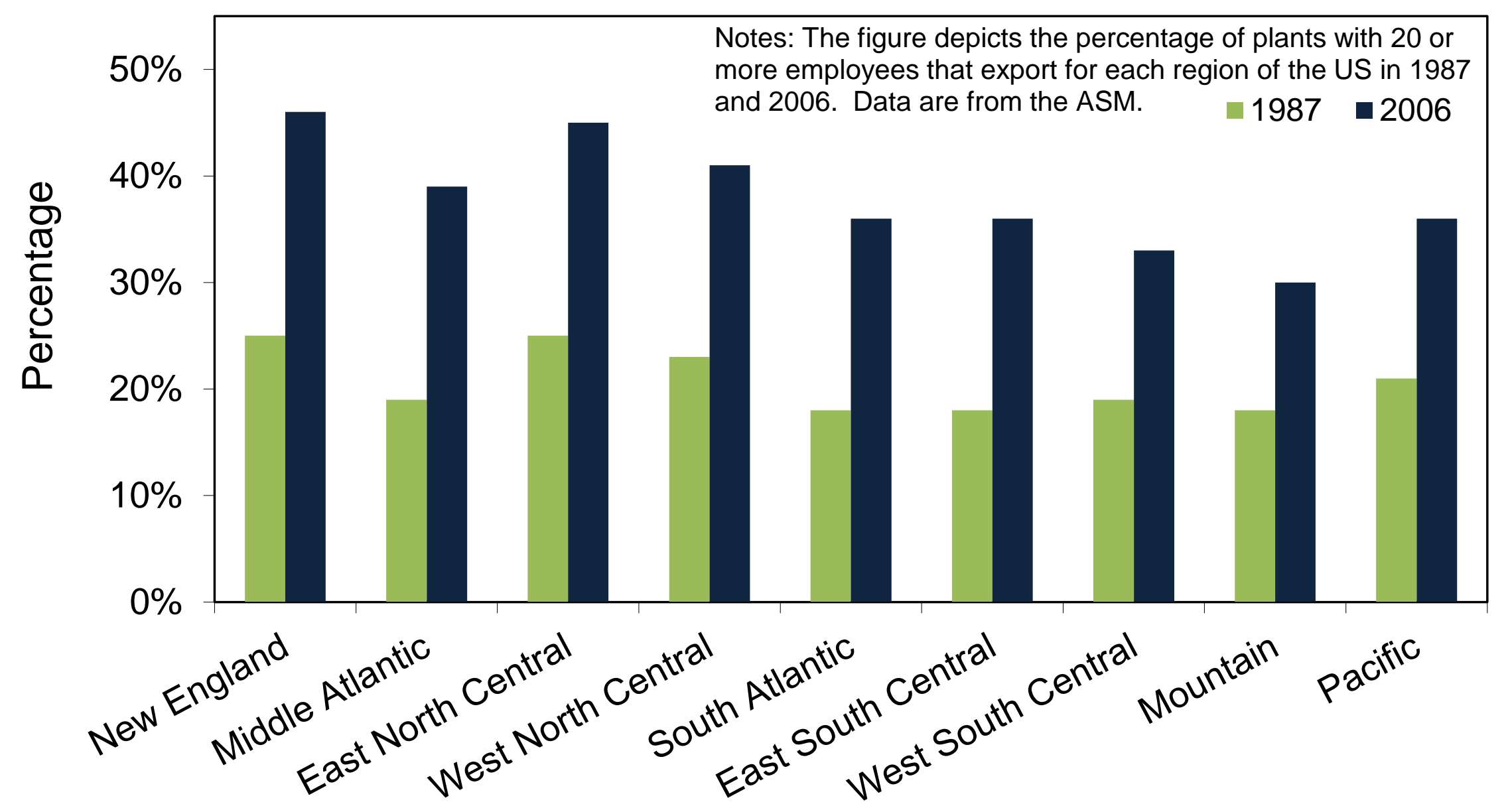

Region 


\section{Appendix Fig. 6:}

\section{ASM Firm Size Decomposition}

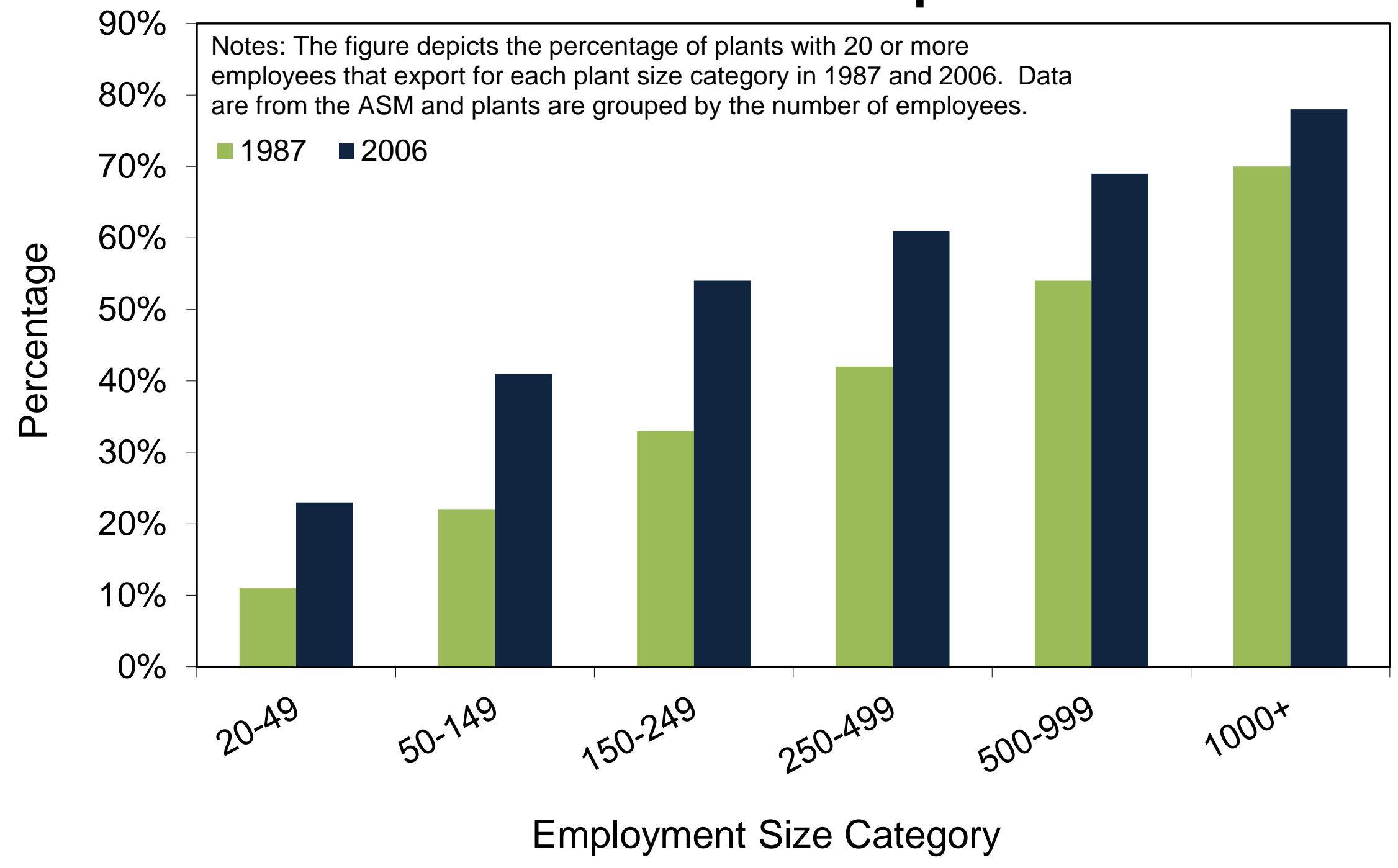

